\title{
Chemical yields from low- and intermediate-mass stars: Model predictions and basic observational constraints
}

\author{
P. Marigo \\ Dipartimento di Astronomia, Università di Padova, Vicolo dell'Osservatorio 2, 35122 Padova, Italia \\ Received 14 September 2000 / Accepted 5 December 2000

\begin{abstract}
In this work we analyse the role of low- and intermediate-mass stars in contributing to the chemical enrichment of the interstellar medium. First we present new sets of stellar yields basing on the results of updated evolutionary calculations, which extend from the ZAMS up to the end of the AGB phase (Girardi et al. 2000; those of other available sets (Renzini \& Voli 1981; van de Hoek \& Groenewegen 1997). The resulting differences are explained in terms of different model assumptions - i.e. treatment of convective boundaries, mass loss, dredgeup, hot-bottom burning - and further discussed on the basis of important empirical constraints which should be reproduced by theory - i.e. the initial-final mass relation, white dwarf mass distribution, carbon star luminosity function, and chemical abundances of planetary nebulae. We show that present models are able to reproduce such constraints in a satisfactory way.
\end{abstract} \\ Marigo et al. 1999). These new yields, that present a significant dependence on metallicity, are then compared to
}

Key words. stars: evolution - stars: AGB and post-AGB - stars: mass-loss - planetary nebulae: general - ISM: abundances - galaxies: abundances

\section{Introduction}

Low- and intermediate-mass stars (with masses $0.8 M_{\odot} \lesssim$ $M \lesssim 5-8 M_{\odot}$, depending on model details) play an important role in galactic chemical evolution, thanks to the ejection into the interstellar medium (ISM) of material containing newly synthesized nuclear products, mainly ${ }^{4} \mathrm{He},{ }^{12} \mathrm{C}$, and ${ }^{14} \mathrm{~N}$, and possibly ${ }^{16} \mathrm{O}$.

The interest in the nucleosynthetic history of ${ }^{12} \mathrm{C}$ and ${ }^{14} \mathrm{~N}$, in particular, has recently increased thanks to the observations of high red-shift systems. For instance, it is possible to measure the nitrogen abundance and the $\mathrm{N} / \mathrm{O}$ ratio in the damped Ly- $\alpha$ systems (e.g. Pettini et al. 1995; $\mathrm{Lu}$ et al. 1998), whereas carbon is detected in the Ly- $\alpha$ forest clouds (e.g. Lu 1991; Crotts et al. 1994; Tytler \& Fan 1994).

The chemical history of both these elements in a galaxy is quite complex, as it depends, besides other factors, on the relative contributions of stars with different masses, hence releasing their yields at different timescales. In the case of ${ }^{12} \mathrm{C}$ the relative role of low- and intermediate-mass stars, or rather of metal-rich, mass-losing massive stars, in the carbon enrichment at late galactic epochs is still a matter of debate (Prantzos et al. 1994). In the case of ${ }^{14} \mathrm{~N}$, large uncertainties affect the theoretical predictions on both the secondary and primary nucleosynthesis of

Send offprint requests to: P. Marigo,

e-mail: marigo@pd.astro.it nitrogen in low- and intermediate-mass stars, and the possible contribution of primary nitrogen from massive stars (Woosley \& Weaver 1982; Maeder 1983; see also the review by Maeder \& Meynet 2000).

It follows that, in order to trace the history of chemical evolution and of star formation in the Universe - which the observations of high red-shift systems are intended to infer - it is quite important to analyse in detail the nucleosynthesis of these elements taking place in low- and intermediate-mass stars. The contribution of these stars to the chemical enrichment of the ISM essentially occurs during the RGB and AGB phases, both characterized by the occurrence of mass loss and events of surface chemical pollution (dredge-up episodes).

Whereas modelling the evolution of a star on the RGB is rather easy by means of modern stellar evolutionary codes, dealing with the most advanced stages - characterised by the occurrence of thermal pulses (the TP-AGB phase) - is quite a difficult task, due to both the high complexity of the physics involved, and the remarkable requirement of computing time. Then, an alternative theoretical approach is offered by synthetic models, which summarise the results of complete stellar calculations through simple and practical analytical relations. This allows quick computing of the models and ready analysis of the results.

Historically, the first most significant AGB synthetic models were those developed by Iben \& Truran (1978) and Renzini \& Voli (1981). These pioneer works focused 
on the contribution of low- and intermediate-mass stars to the element enrichment of the ISM. In particular, the sets of stellar yields presented by Renzini \& Voli (1981) have been extensively used in chemical evolution models of galaxies, providing almost the only available data source up to recent years.

It is important to remark that in Renzini \& Voli (1981) synthetic AGB model the fundamental parameters (essentially mass-loss and dredge-up) were specified according to the indications from the current knowledge of the involved physical processes and available complete stellar calculations. In this sense the model was uncalibrated. That approach had the merit of supplying a testing tool for complete stellar models, as it pointed out at some fundamental inadequacies in the predictions (e.g. too low efficiency of the third dredge-up), and assumed prescriptions (e.g. too low mass-loss rates), which led to clear discrepancies between theory and observations (see, for instance, Iben 1981; Iben \& Renzini 1983; Bragaglia et al. 1995).

With awareness of that, the later synthetic AGB models (e.g. Groenewegen \& de Jong 1993; Marigo et al. 1996, 1999) have made the next step ahead, that is update the input prescriptions and calibrate the model parameters in order to reproduce fundamental observables (e.g. the carbon star luminosity functions, the initial-final mass relation). Basing on the results of these model calibrations, various sets of stellar yields from low- and intermediatemass stars have been presented in recent years as an alternative to Renzini \& Voli (1981), namely: Marigo et al. (1996, 1998), van de Hoek \& Groenewegen (1997); see also Forestini \& Charbonnel (1997), and Boothroyd \& Sackmann (1999).

To the above reference list we will now add the new homogeneous sets of stellar yields presented in this work. With respect to our previous calculations (Marigo et al. 1996, 1998), the present yields are derived from stellar models with updated input prescriptions and improved treatment of the relevant processes involved (i.e. the third dredge-up, see Marigo et al. 1999 for all details).

Specifically, we follow the evolution of low- and intermediate-mass stars, coupling the results of complete stellar models (Girardi et al. 2000) - that cover the evolution from the zero age main sequence (ZAMS) up to the onset of the thermally pulsing asymptotic giant branch (TP-AGB) - with synthetic TP-AGB models (Marigo 1998,b; Marigo et al. 1999) that extend the calculations up to the end of this phase. Relevant model prescriptions are briefly recalled in Sect. 2 .

With the aid of these evolutionary calculations, we then derive the stellar yields $(\mathrm{H}, \mathrm{He}$, and main $\mathrm{CNO}$ elements; refer to Sects. 3 and 4 ) for a dense grid of initial stellar masses (in the range $0.8 M_{\odot}-5 M_{\odot}$ ) and various metallicities $(Z=0.004,0.008,0.019)$. For the most massive stars, experiencing hot-bottom burning (hereinafter HBB, or envelope burning) during the TP-AGB phase, the corresponding yields are given for three values of the mixing-length parameter, i.e. $\alpha=1.68, \alpha=2.00$, and $\alpha=2.50$. This parameter mainly affects the predicted production of ${ }^{14} \mathrm{~N}$ and ${ }^{4} \mathrm{He}$ due to HBB (See Sect. 4.1).

The final part of this work (Sect. 5) is dedicated to compare our results with the yields calculated by other authors, i.e. Renzini \& Voli (1981), and van de Hoek \& Groenewegen (1997). In the attempt to single out the causes of the main differences, we analyse the effect of different model prescriptions (e.g. mass-loss, dredge-up, $\mathrm{HBB}$ ) on the predicted yields, testing at the same time the capability of a model to satisfy basic observational constraints (e.g. initial-final mass relations, white dwarf mass distribution, carbon star luminosity functions, chemical abundances of planetary nebulae).

\section{Evolutionary models}

\subsection{Some definitions}

Let us first define some quantities which will be often used throughout this paper to indicate critical masses for the occurrence of particular physical processes. These quantities are: $M_{\mathrm{HeF}}, M_{\mathrm{up}}, M_{\mathrm{HBB}}^{\mathrm{min}}, M_{\mathrm{dred}}^{\mathrm{min}}$, and $M_{\mathrm{c}}^{\mathrm{min}}$.

The first one, $M_{\mathrm{HeF}}$, denotes the maximum initial mass for a star to develop a degenerate He-core, hence experience the He-flash at the tip of the Red Gian Branch (RGB), and is comprised between 1.7-2.5 $M_{\odot}$ depending on metallicity and model details.

The second one, $M_{\text {up }}$, is defined as the critical stellar mass over which carbon ignition occurs in non-degenerate conditions, marking the boundary between intermediatemass and massive stars. It is worth recalling that this mass limit is usually comprised within $5-8 M_{\odot}$, being significantly affected by the adopted treatment of convective boundaries, as discussed in Sect. 5 .

The third one, $M_{\mathrm{HBB}}^{\mathrm{min}}$, corresponds to the minimum initial mass for a star to undergo HBB during the TPAGB phase. Stellar evolution calculations indicate that $M_{\mathrm{i}} \gtrsim M_{\mathrm{HBB}}^{\min } \sim 3.5-4.5 M_{\odot}$, depending on metallicity (see, for instance, Marigo 1998).

The fourth one, $M_{\mathrm{dred}}^{\min }$, denotes the minimum initial mass for a star to experience the third dredge-up during the TP-AGB phase. Observations of carbon stars suggest that $M_{\text {dred }}^{\min } \sim 1.1-1.5 M_{\odot}$, decreasing with the metallicity (see, for instance, Marigo et al. 1999).

Finally, we recall the basic parameters of the third dredge-up: $\lambda$ and $M_{\mathrm{c}}^{\mathrm{min}}$. The parameter $\lambda$ is intended to measure the efficiency the third dredge-up, being defined as the fraction of the increment of core mass over an interpulse period which is dredged-up to the surface at the subsequent thermal pulse. The actual values for $\lambda$ are still a matter of debate among theoreticians, and can range from $\lambda \sim 0$ to $\lambda \gtrsim 1$, depending both on stellar properties (e.g. mass and metallicity) and model details (e.g. treatment of convective boundaries).

The parameter $M_{\mathrm{c}}^{\text {min }}$ refers to the minimum core mass for the occurrence of the third dredge-up, and is affected by several factors as well. In general, theoretical models would predict that $M_{\mathrm{c}}^{\mathrm{min}}$ decreases - so that the third 
dredge-up is favoured - at increasing mass and mixinglength parameter, and decreasing metallicity (see, for instance, Wood 1981; Marigo et al. 1999).

\subsection{Input physics}

In this work we consider low- and intermediate-mass stars, i.e. those with initial masses in the range from about $0.8 M_{\odot}$ to $M_{\text {up }} \sim 5.0 M_{\odot}$ and and three choices of the original compositions (i.e. $[Y=0.273, Z=0.019]$, $[Y=0.250, Z=0.008],[Y=0.240, Z=0.004])$.

Their evolution from the ZAMS up to the beginning of the TP-AGB phase is taken from the Padua stellar models (Girardi et al. 2000), that include moderate overshoot from core and external convection (Chiosi et al. 1992; Alongi et al. 1993). The reader should refer to Girardi et al. (2000) for more details of the adopted input physics.

The models by Girardi et al. (2000) provide the expected changes in the surface abundance of several chemical elements $\left(\mathrm{H},{ }^{3} \mathrm{He},{ }^{4} \mathrm{He},{ }^{12} \mathrm{C},{ }^{13} \mathrm{C},{ }^{14} \mathrm{~N},{ }^{15} \mathrm{~N},{ }^{16} \mathrm{O}\right.$, $\left.{ }^{17} \mathrm{O},{ }^{18} \mathrm{O},{ }^{20} \mathrm{Ne},{ }^{22} \mathrm{Ne},{ }^{25} \mathrm{Mg}\right)$ caused by the first and second dredge-up episodes, i.e. prior to the onset of the TP-AGB phase. It should be also remarked that these models do not assume any ad-hoc "extra-mixing mechanism", e.g. the so-called cool-bottom process (Wasserburg et al. 1995; see also Charbonnel 1995; Boothroyd \& Sackmann 1999; Weiss et al. 2000), which is invoked to reconcile discrepant predictions of surface abundances with those measured in field Population II stars, galactic globular clusters, and Magellanic Clouds clusters (see, for instance, the results by Gratton et al. 2000 in their chemical analysis of field metal-poor stars).

Mass loss by stellar winds suffered by low-mass stars (with $M_{\mathrm{i}} \leq M_{\mathrm{HeF}} \sim 1.7-2.2 M_{\odot}$ ) on the ascent of RGB, is analytically included applying the classical Reimers (1975) formula to the evolutionary tracks calculated at constant mass by Girardi et al. (2000). An efficiency parameter $\eta=0.45$ is adopted to fulfil the classical observational constraint provided by the morphology of horizontal branches in Galactic Globular Clusters.

Finally, once the the first significant thermal pulse is singled out in each evolutionary sequence calculated by Girardi et al. (2000), that point is assumed to define the starting conditions for synthetic calculations of the TPAGB phase (following the model prescriptions described in Marigo 1998,b; Marigo et al. 1999), which are carried on up to the complete ejection of the envelope by stellar winds. Mass loss is included according to the semiempirical formalism developed by Vassiliadis \& Wood (1993). Nucleosynthesis occurring in the innermost envelope layers of TP-AGB stars with HBB is followed adopting the Caughlan \& Fowler (1988) compilation of reaction rates for $\mathrm{CNO}$ and p-p reactions. The electron-screening factors are those of Graboske et al. (1973).

\section{Derivation of the wind contributions}

Following the classical definition by Tinsley (1980), the stellar yield, $p_{k}\left(M_{\mathrm{i}}\right)$, of a given chemical element $k$, is the mass fraction of a star with initial mass $M_{\mathrm{i}}$ that is converted into the element $k$ and returned to the ISM during its entire lifetime, $\tau\left(M_{\mathrm{i}}\right)$. Tables A1-A12 give the quantities:

$M_{\mathrm{y}}(k)=M_{\mathrm{i}} p_{k}\left(M_{\mathrm{i}}\right)$

expressed in solar masses, for all the chemical elements considered, as function of the initial stellar mass $M_{\mathrm{i}}$, metallicity $Z$, and mixing-length parameter $\alpha$.

According to the definition of stellar yield we can write:

$M_{\mathrm{y}}(k)=\int_{0}^{\tau\left(M_{\mathrm{i}}\right)}\left[X(k)-X^{0}(k)\right] \frac{\mathrm{d} M}{\mathrm{~d} t} \mathrm{~d} t$

where $\mathrm{d} M / \mathrm{dt}$ is the current mass-loss rate; $X(k)$ and $X^{0}(k)$ refer to the current and initial surface abundance of the element $k$, respectively.

Thanks to the fact that the surface chemical composition of stars not suffering HBB during the TP-AGB phase (i.e. with initial masses $M_{\mathrm{i}} \lesssim M_{\mathrm{HBB}}^{\min }$ ), is altered by the occurrence of discrete and quasi-instantaneous episodes of convective dredge-up, that alternate with periods of continuous mass-loss, the evaluation of stellar yields can be simplified as follows.

Denoting by $X^{1}(k), X^{2}(k), X^{j}(k)$, the abundance of the species $k$ after the first dredge-up, the second dredgeup, and the $j$ th dredge-up event during the TP-AGB phase, respectively, we get:

$M_{\mathrm{y}}(k)=M_{\mathrm{y}}(k)_{\mathrm{RGB}}+M_{\mathrm{y}}(k)_{\mathrm{E}-\mathrm{AGB}}+M_{\mathrm{y}}(k)_{\mathrm{TP}-\mathrm{AGB}}$

where

$M_{\mathrm{y}}(k)_{\mathrm{RGB}}=\left[X^{1}(k)-X^{0}(k)\right] \Delta M_{\mathrm{RGB}}^{\mathrm{ej}}$

$M_{\mathrm{y}}(k)_{\mathrm{E}-\mathrm{AGB}}=\left[X^{2}(k)-X^{0}(k)\right] \Delta M_{\mathrm{E}-\mathrm{AGB}}^{\mathrm{ej}}$

$M_{\mathrm{y}}(k)_{\mathrm{TP}-\mathrm{AGB}}=\sum_{j}\left[X^{j}(k)-X^{0}(k)\right] \Delta M_{\mathrm{TP}-\mathrm{AGB}}^{j, \mathrm{ej}}$.

In Eq. (4) $\Delta M_{\mathrm{RGB}}^{\mathrm{ej}}$ is the mass of the envelope ejected during the entire RGB phase (defined only for low-mass stars). It is worth noticing that most of $\Delta M_{\mathrm{RGB}}^{\mathrm{ej}}$ is lost close to the tip of the RGB, that is after the occurrence of the first dredge-up, so that Eq. (4) is a good approximation of Eq. (2).

As far as mass loss on the AGB is concerned, we remark that, with the adopted prescription for $\dot{M}$ (Vassiliadis \& Wood 1993), the amount mass lost during the E-AGB phase is indeed negligible so that we can assume $\Delta M_{\mathrm{E}-\mathrm{AGB}}^{\mathrm{ej}}=0$ in Eq. (5).

The contribution of the TP-AGB phase is evaluated with Eq. (6), that sums all the partial contributions of the pulse cycles, the generic $j$ th one consisting of a thermal pulse - when the $j$ th dredge-up possibly occurs - followed by the inter-pulse period, during which the mass $\Delta M_{\mathrm{TP}-\mathrm{AGB}}^{j, \mathrm{ej}}$ is ejected. 
It should be noticed that this approximation holds for TP-AGB stars which experience only the third dredge-up. For more massive TP-AGB stars (with $M_{\mathrm{i}}>M_{\mathrm{HBB}}^{\min }$ ) also suffering $\mathrm{HBB}$, the changes in the surface chemical composition and mass loss are concomitant processes, so that the calculation of stellar yields requires the adoption of integration time steps shorter than the inter-pulse periods.

In general, negative $M_{\mathrm{y}}(k)$ correspond to those elemental species which are prevalently destroyed and diluted in the envelope, so that their abundances in the ejected material are lower with respect to the main sequence values. On the contrary, positive $M_{\mathrm{y}}(k)$ correspond to those elements which are prevalently produced so that a net enrichment of their abundances in the ejecta is predicted.

Figures 1 and 2 show the quantities $M_{\mathrm{y}}(k)$ for all the chemical elements considered, as a function of $M_{\mathrm{i}}$ and $Z$. For stars experiencing HBB results are given for three values of the mixing-length parameter.

Finally, for the sake of clarity, we remind that the CNO cycle does not change the total number of CNO nuclei involved as catalysts in the conversion of $\mathrm{H}$ into ${ }^{4} \mathrm{He}$, i.e. $Y_{\mathrm{CNO}}=\sum_{k} X_{k}^{\mathrm{CNO}} / A_{k}=$ constant. It follows that the first and second dredge-up, though affecting the surface abundances of the CNO isotopes, do not alter their total abundance by number. In fact, the material injected into the envelope has experienced the CNO cycle involving only isotopes already present in the original composition. On the contrary, the constancy of $Y_{\mathrm{CNO}}$ breaks down as soon as the dredge-up of primary carbon and oxygen, produced by $\alpha$-capture reactions at thermal pulses, occurs.

However, in all cases the total abundance by mass of the CNO isotopes is somewhat changed because of the conversion of these elements mainly into ${ }^{14} \mathrm{~N}$, so that a small positive CNO yield (in mass fraction), is expected, for example, from the RGB phase (see Tables A1-A3). The quantity, $M_{\mathrm{y}}(\mathrm{CNO})$, referring to the total net yield of all CNO isotopes, is shown in Fig. 3.

\section{Stellar yields as a function of $M_{\mathrm{i}}, Z$, and $\alpha$}

Model predictions can be understood more easily considering that the stellar yield of a given element is essentially determined by the efficiency and duration/frequency of:

- the nucleosynthesis/mixing processes (e.g. dredge-up events, HBB) which alter its abundance in the surface layers;

- the mass-loss process which ejects the surface layers into the ISM.

According to the physical prescriptions adopted in this work for the TP-AGB phase (see also Sect. 5.1) we can summarise the following points:

- The third dredge-up determines the surface enrichment mainly of ${ }^{4} \mathrm{He},{ }^{12} \mathrm{C}$, and ${ }^{16} \mathrm{O}$. The adopted intershell abundances are $\left[\mathrm{X}\left({ }^{4} \mathrm{He}\right)=0.76 ; \mathrm{X}\left({ }^{12} \mathrm{C}\right)=0.22\right.$; $\left.\mathrm{X}\left({ }^{4} \mathrm{He}\right)=0.02\right]$ according to Boothroyd \& Sackmann (1988). The process is more efficient (i.e. higher $\lambda$ ) at lower $Z$;
- HBB operates via the CNO-cycle, hence essentially increasing the surface abundances of ${ }^{4} \mathrm{He}$, and ${ }^{14} \mathrm{~N}$. The process is more efficient at higher $M$ (provided that $M>M_{\mathrm{HBB}}^{\min }$ ), lower $Z$, and larger $\alpha$;

- mass loss is, in general, less efficient (i.e. lower $\dot{M}$ ) at decreasing $Z$ and increasing $\alpha$. In fact, both factors tend to produce hotter tracks, and generally $\dot{M}$ anticorrelates with $T_{\text {eff }}$. As a consequence, lower mass-loss rates correspond to longer TP-AGB lifetimes, hence greater number of third dredge-up events and a longer duration of HBB.

The expected trend of $M_{\mathrm{y}}(k)$ for the elements under consideration as a function of the stellar initial mass, metallicity, and mixing-length parameter is shown in Figs. 1-3. We can notice the following:

\section{- $\mathbf{H}$ and ${ }^{4} \mathbf{H e}$}

The net yields of these elements have mirror-like trends, being negative for $\mathrm{H}$, and positive for ${ }^{4} \mathrm{He}$. The maximum of ${ }^{4} \mathrm{He}$ production at around $2-3 M_{\odot}$ (depending on metallicity) is explained considering the effect of the increase of the number of thermal pulses (hence dredge-up episodes) with stellar mass for $0.8 M_{\odot}<M_{\mathrm{i}} \lesssim 2-3 M_{\odot}$ (see Fig. 5). This peak is more pronounced at lower metallicities due to longer TP-AGB duration (Fig. 5) and larger number of thermal pulses (Fig. 6) for given stellar mass. The subsequent increase of ${ }^{4} \mathrm{He}$ production towards higher masses, $4 M_{\odot} \lesssim M_{\mathrm{i}} \leq 5 M_{\odot}$, is caused by the occurrence of $\mathrm{HBB}$ in addition to the third dredge-up. The yield of ${ }^{4} \mathrm{He}$ is larger for lower metallicities and higher values of the mixing-length parameter, reflecting the greater efficiency of both the third dredge-up and HBB.

\section{$-{ }^{3} \mathbf{H e}$}

The net yield of this element presents a pronounced peak at very low masses, say at $M_{\mathrm{i}} \sim 1 M_{\odot}$, and decreases at higher masses. This trend is explained considering that the main contribution to the yield is due to the first dredge-up, and that both the related surface enrichment of ${ }^{3} \mathrm{He}$ and the amount of mass lost during the RGB phase are inversely proportional to the stellar mass in the low-mass domain. At higher masses, $\left(M_{\mathrm{i}} \gtrsim 3 M_{\odot}\right)$, the net yield becomes even slightly negative because of HBB.

$-{ }^{12} \mathbf{C}$

The net positive yield increases with the initial mass, up to a maximum located at about $2-3 M_{\odot}$, corresponding to largest number of dredge-up episodes suffered during the TP-AGB phase, provided that HBB has not operated.

The subsequent decline towards higher masses is initially due to fewer dredge-up events, and then to the prevailing effect of HBB. It follows that no substantial enrichment of ${ }^{12} \mathrm{C}$ is provided from the most massive AGB stars. 


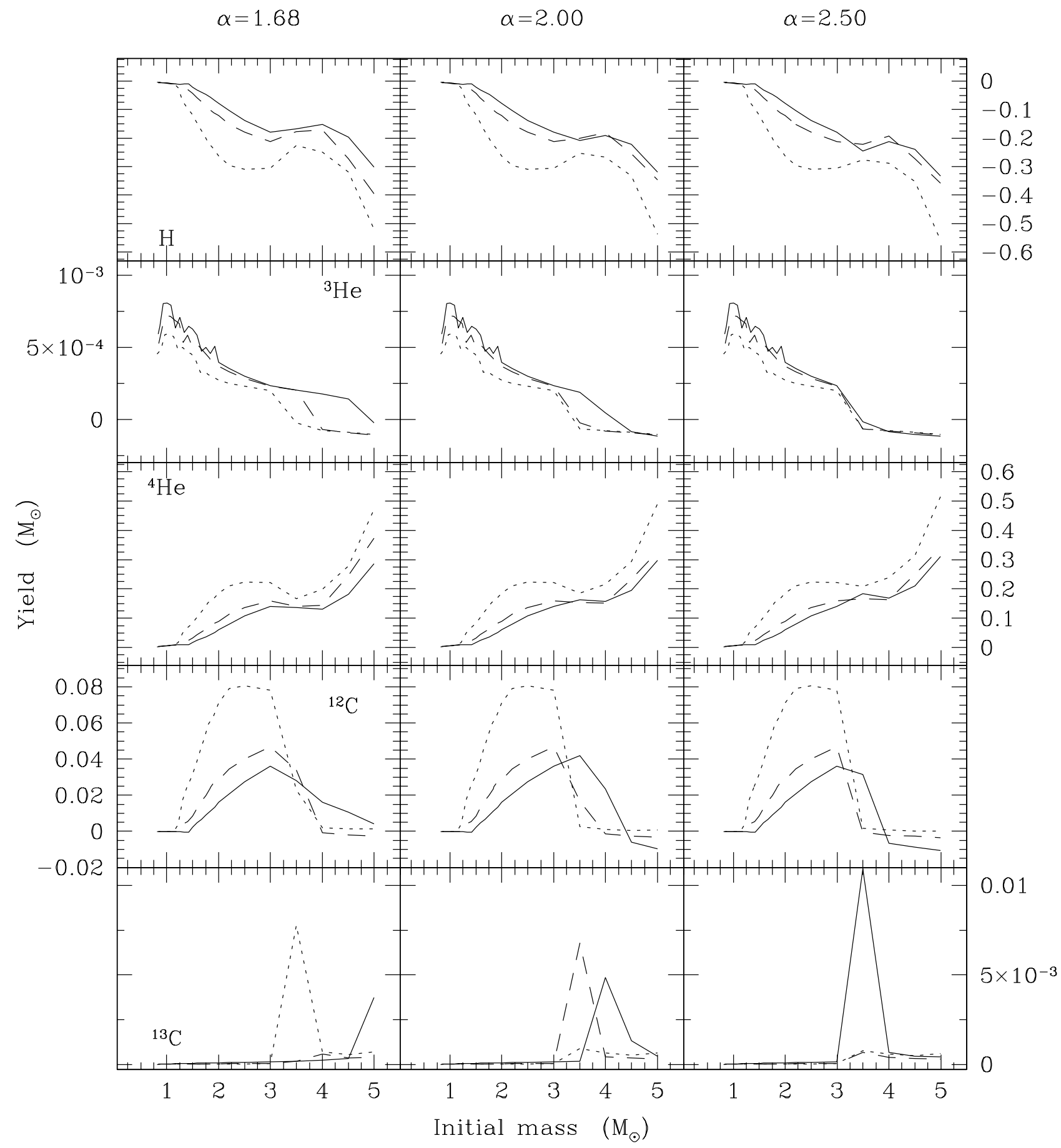

Fig. 1. Net yields $M_{\mathrm{y}}(k)$ (in $\left.M_{\odot}\right)$ for each indicated chemical element $\left(\mathrm{H},{ }^{3} \mathrm{He},{ }^{4} \mathrm{He},{ }^{12} \mathrm{C}\right.$, and $\left.{ }^{13} \mathrm{C}\right)$ as a function of the initial mass (in $M_{\odot}$ ) of the star. The solid, dashed, and dotted lines correspond to the metallicity sets $Z=0.019, Z=0.008$, and $Z=0.004$, respectively. Panels along each column refer to the same value of the mixing-length parameter

This general trend is more marked at lower metallicities, because of the longer TP-AGB phases, and the greater efficiency of the third dredge-up and HBB.

$-{ }^{13} \mathbf{C}$

The first dredge-up causes an increase of the ${ }^{13} \mathrm{C}$ surface abundance in stars of all masses, and the resulting yields are positive. A further contribution is provided by mild $\mathrm{HBB}$, as long as creation of ${ }^{13} \mathrm{C}$ via the reaction ${ }^{12} \mathrm{C}(p, \gamma){ }^{13} \mathrm{C}$ prevails over destruction via the reaction ${ }^{13} \mathrm{C}(p, \gamma){ }^{14} \mathrm{~N}$. The results also depend on the interplay between the strength of HBB and mass loss. The most favourable cases correspond to the models [e.g. $\left(4 M_{\odot}, Z=0.019, \alpha=2.00\right),\left(3.5 M_{\odot}, Z=\right.$ $0.004, \alpha=1.68)$ ], in which the efficiency of reactions allows the synthesis of ${ }^{13} \mathrm{C}$ for a long time before the drastic reduction of the envelope causes the extinction of nuclear burning. The spikes of ${ }^{13} \mathrm{C}$ production for these models would suggest that a proper tuning of 


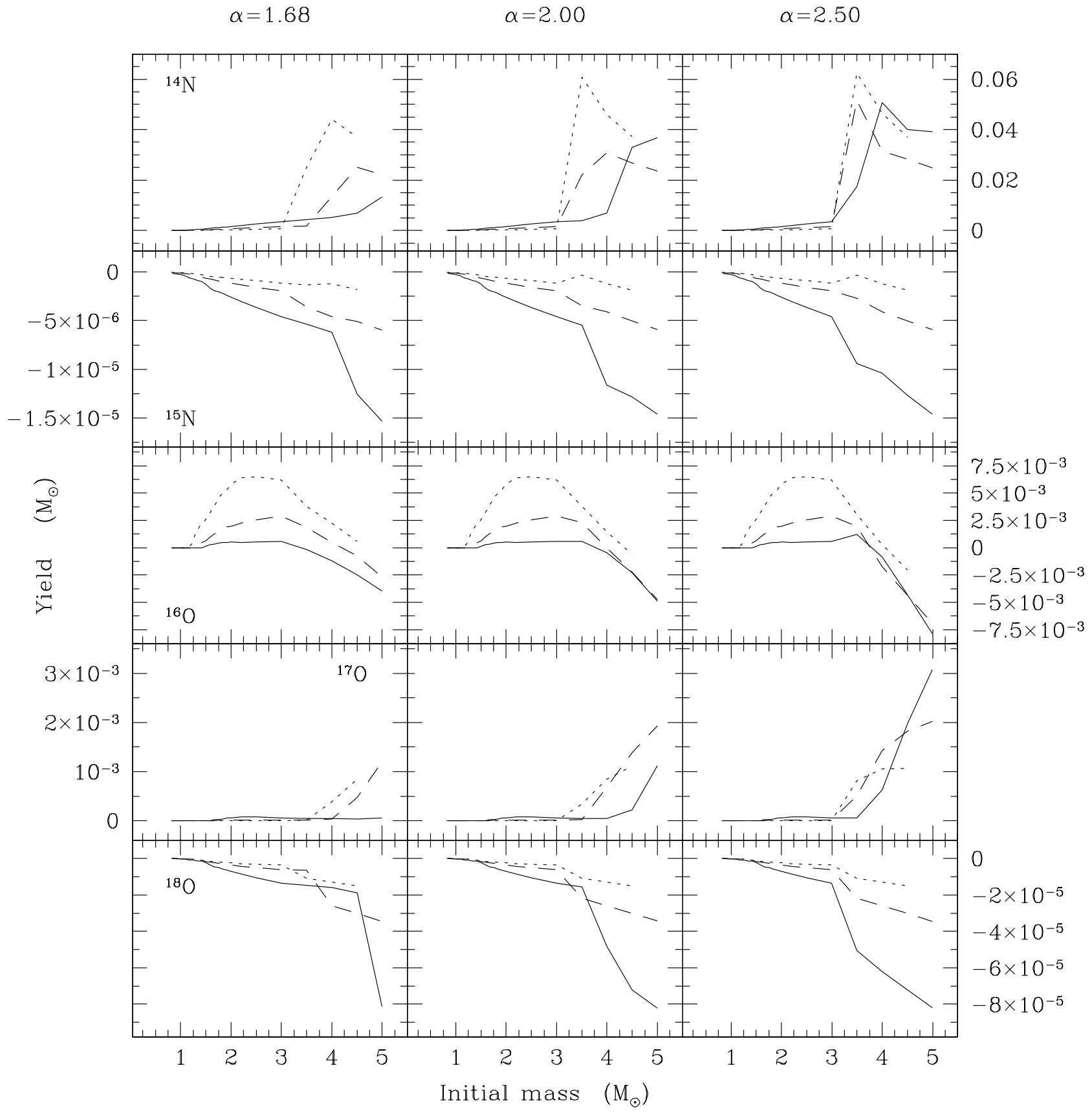

Fig. 2. Net stellar yields $M_{\mathrm{y}}(k)$ (in $M_{\odot}$ ) for each indicated chemical element $\left({ }^{14} \mathrm{~N},{ }^{15} \mathrm{~N},{ }^{16} \mathrm{O},{ }^{17} \mathrm{O}\right.$, and $\left.{ }^{18} \mathrm{O}\right)$ as a function of the initial stellar mass (in $M_{\odot}$ ). The notation is the same as in Fig. 1

HBB is required: if nuclear reactions are somewhat too weak ${ }^{13} \mathrm{C}$ is not significantly created, else if somewhat too strong ${ }^{13} \mathrm{C}$ is quickly destroyed in favour of ${ }^{14} \mathrm{~N}$.

$$
-{ }^{14} \mathrm{~N}
$$

It turns out that HBB plays the dominant role for the synthesis of ${ }^{14} \mathrm{~N}$. The positive yield as a function of the stellar mass depends on both the efficiency and duration of nuclear burning. It follows that lower metallicities and higher values of the mixing-length parameter concur to favour nitrogen production. The contribution from low- and intermediate-mass stars to the galactic enrichment of nitrogen may result important, as suggested by chemical evolutionary models of galaxies (e.g. Portinari et al. 1998).

$-{ }^{15} \mathrm{~N}$

The net yield of this element is mostly negative. For stars with initial masses in the range, $0.8 M_{\odot} \lesssim M_{\mathrm{i}} \lesssim$ $3.5 M_{\odot}$, the depletion of ${ }^{15} \mathrm{~N}$ is due to the effect of the first and second dredge-up. For higher mass stars, the results are affected by $\mathrm{HBB}$, depending on the degree of $\mathrm{CNO}$ cycling attained in the burning regions. This element has the shortest nuclear lifetime, after that of ${ }^{18} \mathrm{O}$, so that it quickly attains nuclear equilibrium with ${ }^{14} \mathrm{~N}$. We note that the depletion of 


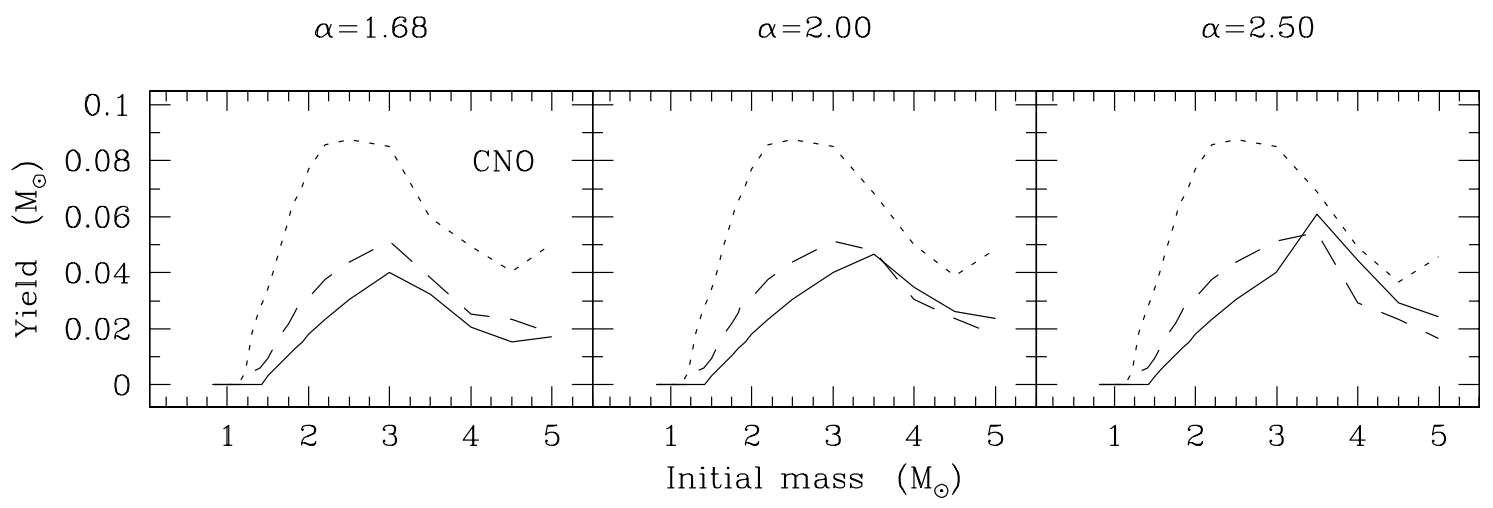

Fig. 3. Net stellar yields of all CNO elements as a function of the initial stellar mass. The notation is the same as in Fig. 1

${ }^{15} \mathrm{~N}$ is much more efficient at higher metallicities due to the increase of the CNO-cycling, which implies a more efficient destruction of this element. The predicted trend of the ${ }^{15} \mathrm{~N}$ yield mirrors, to some extent, that of the secondary component of ${ }^{14} \mathrm{~N}$ (cf. Sect. 4.1). $-{ }^{16} \mathbf{O}$

The net yield of this element is positive for stars with $0.8 M_{\odot} \lesssim M_{\mathrm{i}} \lesssim 3.5 M_{\odot}$ thanks to the dredge-up events during the TP-AGB phase, whereas it becomes negative at higher masses because of HBB.

The synthesis of fresh ${ }^{16} \mathrm{O}$ occurs via the reaction ${ }^{12} \mathrm{C}(\alpha, \gamma){ }^{16} \mathrm{O}$ during thermal pulses, so that the yield of this element depends, among other factors, on its abundance in the dredged-up material. According to recent TP-AGB calculations - which include deep overshooting from all convective boundaries - Herwig et al. (1997) find that the ${ }^{16} \mathrm{O}$ abundance in the convective intershell is roughly ten times higher, $X\left({ }^{16} \mathrm{O}\right) \sim 0.25$, than previously predicted, i.e. $X\left({ }^{12} \mathrm{C}\right) \sim 0.02$ by Boothroyd \& Sackmann (1988) (standard case). Then, adopting Herwig et al. indications, oxygen production by low- and intermediatemass stars may be favoured with respect to the standard case, but it is worth recalling that, in general, the final yields are crucially affected by various other factors (e.g. number and efficiency of dredge-up episodes; see also Sect. 6).

Anyhow, regardless of its abundance in the dredgedup material, the trend of ${ }^{16} \mathrm{O}$, as a function of $M$ and $Z$, is expected to be qualitatively similar to that of ${ }^{12} \mathrm{C}$. Moreover, according to the present calculations, a notable dependence on metallicity comes out. The increasing positive trend with decreasing metallicities essentially reflects the longer duration of the TP-AGB phase, and hence the greater number of dredge-up episodes, in combination with their larger efficiency. $-{ }^{17} \mathbf{O}$

A certain production of this element is provided by TP-AGB stars with $\mathrm{HBB}$, as long as the chain of reactions ${ }^{16} \mathrm{O}(p, \gamma){ }^{17} \mathrm{~F}\left(\beta^{+} \nu\right){ }^{17} \mathrm{O}$ prevails over nuclear destruction via the reactions ${ }^{17} \mathrm{O}(p, \gamma){ }^{18} \mathrm{~F}$ and
${ }^{17} \mathrm{O}(p, \alpha){ }^{14} \mathrm{~N}$. The behaviour resembles that of ${ }^{13} \mathrm{C}$, in the sense that under some fine-tuned conditions - for particular combinations of the stellar mass and metallicity - a production spike of ${ }^{17} \mathrm{O}$ can result.

$-{ }^{18} \mathbf{O}$

This element has the shortest nuclear lifetime against proton captures, so that it easily burns even at mild temperatures, quickly attaining the nuclear equilibrium with ${ }^{17} \mathrm{O}$. The net yield of ${ }^{18} \mathrm{O}$ is negative for all masses, with a trend mirroring that of ${ }^{17} \mathrm{O}$. Moreover, as in the case of ${ }^{15} \mathrm{~N}$, the depletion of ${ }^{18} \mathrm{O}$ is more pronounced at higher metallicities due to the more efficient CNO cycling.

\subsection{Secondary and primary components}

As far as the CNO nuclei are concerned, we can distinguish for each element $k$ the secondary, $M_{\mathrm{y}}^{\mathrm{S}}(k)$, and primary, $M_{\mathrm{y}}^{\mathrm{P}}(k)$, components of the stellar yield

$M_{\mathrm{y}}(k)=M_{\mathrm{y}}^{\mathrm{S}}(k)+M_{\mathrm{y}}^{\mathrm{P}}(k)$

calculated with (see Eq. (2))

$M_{\mathrm{y}}^{\mathrm{S}}(k)=\int_{0}^{\tau\left(M_{\mathrm{i}}\right)}\left[X^{\mathrm{S}}(k)-X^{\mathrm{S}, 0}(k)\right] \frac{\mathrm{d} M}{\mathrm{~d} t} \mathrm{~d} t$

and

$M_{\mathrm{y}}^{\mathrm{P}}(k)=\int_{0}^{\tau\left(M_{\mathrm{i}}\right)}\left[X^{\mathrm{P}}(k)-X^{\mathrm{P}, 0}(k)\right] \frac{\mathrm{d} M}{\mathrm{~d} t} \mathrm{~d} t$

where $X^{\mathrm{S}}(k)$ and $X^{\mathrm{P}}(k)$ denote the secondary and primary current surface abundances, respectively. Moreover, we have $X^{\mathrm{S}, 0}(k)=X^{0}(k)$ and $X^{\mathrm{P}, 0}(k)=0$, as follows from the definitions of secondary and primary abundances.

We notice that $M_{\mathrm{y}}^{\mathrm{P}}(k)$ can be only $\geq 0$, whereas $M_{\mathrm{y}}^{\mathrm{S}}(k)$ can be either $\geq 0$ or $<0$, in the respective cases that the mass-averaged secondary abundance of the element in the ejecta is greater, equal or smaller than its original value. 
A few basic remarks should be made at this point. Both the first and second dredge-up affect (by increasing or decreasing) only the secondary components of the CNO surface abundances. In fact, in these episodes the envelope is polluted by material which has undergone CNOcycling, with a net change in the relative abundances of the CNO isotopes synthesized from metal seeds originally present in the star. On the contrary, the third dredge-up enriches the chemical composition of the envelope with ${ }^{12} \mathrm{C}$ and ${ }^{16} \mathrm{O}$ of primary origin (synthesized by $\alpha$-capture reactions). Finally, HBB affects the abundance distribution of the CNO isotopes of both secondary and primary synthesis.

Keeping in mind these concepts, it turns out that:

- stars with initial masses $M_{\mathrm{i}}<M_{\mathrm{dred}}^{\min }$ can produce $\mathrm{CNO}$ yields of secondary origin only;

- for stars with initial masses $M_{\text {dred }}^{\min } \lesssim M_{\mathrm{i}} \lesssim M_{\mathrm{HBB}}^{\min }$ the yields of ${ }^{12} \mathrm{C}$ and ${ }^{16} \mathrm{O}$ should include a primary component, as a consequence of the third dredge-up during the TP-AGB phase; and

- for stars with initial masses $M_{\mathrm{i}} \gtrsim M_{\mathrm{HBB}}^{\min }$ undergoing HBB during the TP-AGB phase, the yields of the CNO isotopes should all display primary components, because of the injection of primary ${ }^{12} \mathrm{C}$ and ${ }^{16} \mathrm{O}$ nuclei (at each dredge-up event) into regions where the CNO cycle is operating.

Comparing the secondary and primary components of the CNO yields four cases can be met (Tables A1-A12; see also Marigo 1998):

1. $M_{\mathrm{y}}^{\mathrm{S}} \neq 0$ and $M_{\mathrm{y}}^{\mathrm{P}}=0$ so that $M_{\mathrm{y}}=M_{\mathrm{y}}^{\mathrm{S}}$

2. $M_{\mathrm{y}}^{\mathrm{S}}>0$ and $M_{\mathrm{y}}^{\mathrm{P}}>0$ so that $M_{\mathrm{y}}>0$

3. $M_{\mathrm{y}}^{\mathrm{S}}<0$ and $M_{\mathrm{y}}^{\mathrm{P}}>0$ so that $M_{\mathrm{y}}>0$

4. $M_{\mathrm{y}}^{\mathrm{S}}<0$ and $M_{\mathrm{y}}^{\mathrm{P}}>0$ so that $M_{\mathrm{y}}<0$.

The first (1.) case applies to low-mass stars with $M_{\mathrm{i}}<$ $M_{\text {dred }}^{\min }$, i.e. never experiencing the third dredge-up during the TP-AGB phase. No primary component of stellar yields is expected.

The second (2.) case corresponds to both primary and secondary production. In stars with $M_{\mathrm{i}}>M_{\mathrm{HBB}}^{\min }$ it applies, for instance, to ${ }^{13} \mathrm{C},{ }^{17} \mathrm{O}$, and ${ }^{14} \mathrm{~N}$. In general, for these elements a positive secondary contribution may be provided by the first (and possibly second) dredge-up and HBB, the latter process being also responsible for the primary synthesis of these elements (starting from primary ${ }^{12} \mathrm{C}$ and ${ }^{16} \mathrm{O}$ injected by the third dredge-up).

As far as ${ }^{13} \mathrm{C}$ is concerned (see also Sect. 4) we notice that a suitable interplay between the strength of HBB and mass loss can occasionally result in very favourable conditions for the production of ${ }^{13} \mathrm{C}$, giving a peak of the related yields (for instance, at the model $4 M_{\odot}$ in the case $Z=0.019, \alpha=2.0)$.

Concerning the yields of ${ }^{14} \mathrm{~N}$, it should be remarked that the contribution from intermediate-mass stars may be relevant in view of interpreting, with the aid of chemical evolutionary models of galaxies, the observed trend in the $\log (\mathrm{N} / \mathrm{O})$ vs. $\log (\mathrm{O} / \mathrm{H})$ diagram (see, for instance, Vila-Costas \& Edmunds 1993; Henry et al. 2000), where the large scatter of data points towards lower metallicities would imply the existence of a significant primary component in the measured nitrogen abundances.

The third (3.) possibility corresponds to a dominant primary production. In stars with initial masses $M_{\text {dred }}^{\min } \lesssim$ $M_{\mathrm{i}} \lesssim M_{\mathrm{HBB}}^{\min }$, this case applies to ${ }^{12} \mathrm{C}$ surface abundance, which is first decreased by the negative secondary contribution from the first and second dredge-up, and subsequently increased by the third dredge-up injecting primary nuclei into the envelope. A similar situation occurs for the yield ${ }^{16} \mathrm{O}$ in the same range of stellar masses, as the effect of the third dredge-up prevails over that of the previous mixing episodes (first and second).

Finally, the fourth (4.) case corresponds to a dominant secondary depletion. This refers to ${ }^{15} \mathrm{~N},{ }^{18} \mathrm{O}$ for stars of all masses, and to ${ }^{16} \mathrm{O}$ for stars with $M_{\mathrm{i}} \gtrsim M_{\mathrm{HBB}}^{\min }$ if the reduction of the original abundance caused by the first and second dredge-up dominates over the injection of primary oxygen via the third dredge-up (even possibly partially destroyed by HBB). Under these circumstances, no enrichment of the interstellar medium is expected for these elemental species.

Tables A10-A12 give the net yield for each element of the CNO group ( $\mathrm{T}$ entry), together with the secondary ( $\mathrm{S}$ entry) and primary (P entry) components, for stars with initial masses $3.5 M_{\odot} \leq M_{\mathrm{i}} \leq 5 M_{\odot}$, for various values of the original metallicity and mixing length parameter.

\section{Comparison with other calculations}

We will compare the stellar yields presented in this work (hereinafter also M2K) with those available in two widely used studies, namely the pioneer work by Renzini \& Voli (1981; RV81), and the more recent one by van de Hoek \& Groenewegen (1997; HG97). Before making a direct comparison between the yields of various elemental species, we consider it useful first to recall the relevant prescriptions adopted in the mentioned AGB models, and consequently analyse their effects by showing how the predictions of different models compare with basic observables.

\subsection{Model prescriptions}

Table 1 summarises the relevant assumptions adopted in the AGB calculations, which the three different sets of stellar yields under consideration are derived from. For further details the reader should refer to the original papers and references therein.

\subsubsection{The limiting mass $M_{\text {up }}$}

First of all, let us consider the quantity $M_{\text {up }}$ (see also Sect. 2.1), that corresponds to the maximum initial mass 
Table 1. Summary of the main prescriptions adopted in the synthetic TP-AGB models here considered for comparison

\begin{tabular}{|l|c|c|c|}
\hline PROCESS/QUANTITY & & MODEL PRESCRIPTION \\
\hline \hline & RV81 & HG97 & M2K (this work) \\
\hline$M_{\mathrm{up}}$ & $8 M_{\odot}$ & $7 M_{\odot}$ & $5 M_{\odot}$ \\
\hline$M_{\mathrm{c}}-L$ relation, $M_{\mathrm{c}}-T_{\mathrm{ip}}$ relation & no metallicity dependence & with metallicity dependence & with metallicity dependence \\
\hline |mass loss & Reimers $(1975) \eta=1 / 3-2 / 3$ & Reimers $(1975) \eta=5$ & Vassiliadis \& Wood (1993) \\
\hline 3 D.up: efficiency $\lambda$ & $\begin{array}{r}\sim 0.3-0.5 \\
\text { function of } M_{\mathrm{c}}, \text { any } Z\end{array}$ & $\begin{array}{c}0.75 \\
\text { for any } Z, M\end{array}$ & $\begin{array}{c}0.65 \text { for } Z=0.004, \text { any } M \\
0.55 \text { for } Z=0.008, \text { any } M\end{array}$ \\
\hline 3 D.up: minimum core mass $M_{\mathrm{c}}^{\text {min }}$ & $\begin{array}{c}0.60 ~ \\
\text { for } M_{\odot}\end{array}$ & $\begin{array}{c}0.58 M_{\odot} \\
\text { for any } Z, M\end{array}$ & $\begin{array}{r}\text { from envelope integrations } \\
\text { function of } M \text { and } Z\end{array}$ \\
\hline HBB: overluminosity & no & no & yes \\
\hline HBB: nucleosynthesis & nuclear network & parameterised approx. & nuclear network \\
\hline
\end{tabular}

of a star to develop a degenerate $\mathrm{C}-\mathrm{O}$ core, hence experience the AGB phase. This critical mass heavily depends on the previous evolutionary history, mainly the extension of the convective core during the H-burning phase. Evolutionary models (classical models) that adopt the Schwarzschild criterion to define the convective boundaries (e.g. Dominguez et al. 1999) predict higher values for $M_{\text {up }}$ than those models that assume some overshoot beyond the last formally stable layer against convection (e.g. Girardi et al. 2000).

Both RV81 and HG97 yields are based on classical models and have $M_{\text {up }} \sim 7-8 M_{\odot}$, whereas the pre-AGB evolutionary models used in this work (M2K) adopt a convective overshoot scheme so that $M_{\text {up }} \sim 5 M_{\odot}$. We remark that models with masses up to $M_{\text {up }}$ cover, by definition, the whole class of low- and intermediate-mass stars. In other words, models with $M_{\mathrm{i}}>M_{\mathrm{up}}$ (for whatever predicted $M_{\text {up }}$ ) would eventually meet the fate of supernova explosion.

Finally, a cautionary warning should be made in the context of practical application of chemical yields. When stellar yields from stars of different initial masses are to be included in galactic models of chemical evolution, attention should be paid to correctly match sets of yields of different mass intervals (i.e. low, intermediate, high). If the models do not belong to a homogeneous grid of stellar calculations, one should at least care to combine stellar yields of different origin (i.e. stellar code) but with the same predicted value for $M_{\text {up }}$. Otherwise, the relative weight of stars belonging to different classes (i.e. with different nucleosynthetic histories) to the integrated chemical enrichment may be substantially mistaken (for instance, by over- or under- estimating the role of supernovae).

\subsubsection{Analytical relations}

Fundamental relations in synthetic AGB models are the core mass - luminosity $\left(M_{\mathrm{c}}-L\right)$, and core mass interpulse period $\left(M_{\mathrm{c}}-T_{\mathrm{ip}}\right)$ relations. Predictions of stellar yields are significantly influenced by these input prescriptions, i.e. the luminosity affects the mass-loss rates on the TP-AGB, and interpulse-periods determine the temporal recurrence of the third dredge-up.

With respect to RV81 prescriptions (Iben \& Truran 1978 (IT78), see Fig. 4), M2K and HG97 models are based on more recent relations (Boothroyd \& Sackmann 1988; Wagenhuber \& Groenewegen 1998) in which a notable improvement is the inclusion of a composition dependence. For a given core mass, the quiescent luminosity/interpulse period of a TP-AGB star is found to increase/decrease at increasing metallicity. According to evolutionary calculations by Boothroyd \& Sackmann (1988), for instance, the quiescent TP-AGB luminosity for $Z=0.02$ is about $20 \%$ higher than for $Z=0.001$ (see Fig. 4).

\subsubsection{Mass loss on the $A G B$}

The adopted prescription for mass loss on the AGB crucially influences the predictions of stellar yields, as it affects the total number of thermal pulses (hence dredge-up episodes) suffered by a TP-AGB star, hence the growth of its core mass and AGB lifetime.

In this work we adopt the semi-empirical formalism presented by Vassiliadis \& Wood (1993) who couple results of pulsation theory with observations of variable AGB stars. In RV81 the classical Reimers' law (1975) is assumed with the efficiency parameter $\eta$ set equal to $1 / 3$ or $2 / 3$. HG97 as well use the Reimers' law, but with $\eta=5$, which they find as the best value to fulfil basic observational constraints (see Sects. 5.2.2 and 5.2.1).

To this regard the following remark should be made. As a matter of fact, the Reimers' prescription was originally designed to describe mass loss suffered by low-mass stars climbing up the RGB, and it is usually calibrated in view of reproducing observations of stars in the subsequent horizontal branch phase of quiescent core He-burning (see Sect. 2).

However, as already shown by RV81, the straightforward extension of the Reimers' formula to the AGB evolution does not suit important constraints. In fact, 


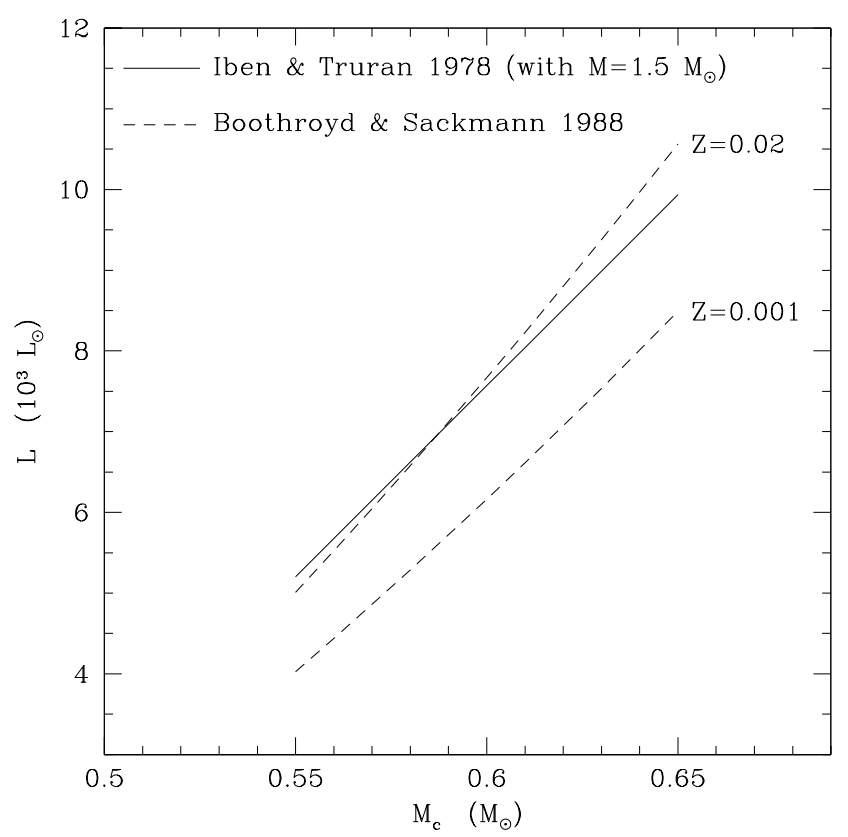

Fig. 4. Theoretical core mass-luminosity relations. The wellknown Iben \& Truran (1988) relation is extrapolated for small core masses and assuming a total mass of $1.5 M_{\odot}$. The predicted effect of the chemical composition of the envelope on the luminosity is shown according to Boothroyd \& Sackmann (1988a)

the Reimers' prescription with $\eta \lesssim 1$ cannot produce the "super-wind" mass-loss rates $\left(\dot{M} \sim 10^{-4}-\right.$ $\left.10^{-5} M_{\odot} \mathrm{yr}^{-1}\right)$ measured in stars close to the AGB-tip luminosities, and consequently it cannot account for the typical values of masses and radii of planetary nebulae at the observed luminosities.

These difficulties have been overcome by later massloss prescriptions - specifically designed for AGB stars (e.g. Bowen 1988; Fleisher et al. 1992; Vassiliadis \& Wood 1993; Blöcker 1995) - which are all characterised by a more rapid increase of mass-loss rates during the AGB evolution, then naturally leading to the development of the superwind regime.

The effect of different laws for mass loss is significant with respect to the expected number of thermal pulses experienced on the TP-AGB evolution. As an example (see Fig. 5), we can notice that for a $\left(5 M_{\odot}, Z=0.02\right)$ model our calculations yield $N_{\mathrm{p}}=117-153$ (depending on $\alpha$ ), whereas RV81 predict $N_{\mathrm{p}}=8941$ (1631) with the efficiency parameter $\eta=1 / 3(\eta=2 / 3)$. In general, it turns out that the largest differences in the number of thermal pulses show up for models with higher stellar masses (i.e. $\left.M_{\mathrm{i}} \gtrsim 2.5 M_{\odot}\right)$, that are expected to experience the superwind regime according to the the Vassiliadis \& Wood's prescription.

Moreover, significantly different results are obtained by RV81 and M2K as far as the TP-AGB duration is concerned (see Fig. 6). First of all, we can notice that our TPAGB lifetimes present a pronounced trend with the stellar

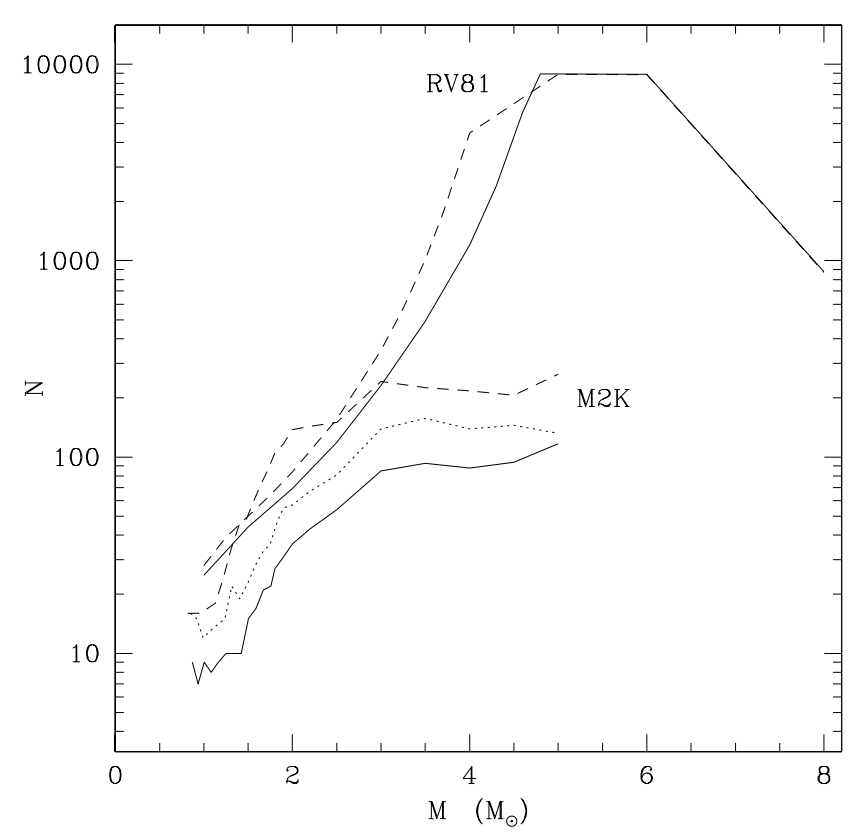

Fig. 5. Expected number of thermal pulses (and inter-pulse periods) as a function of the initial stellar mass for different values of the initial metallicity (see legenda in Fig. 6). Results of the present work (M2K) are compared with those of Renzini \& Voli (1981; RV81)

mass, showing a maximum at around 2-2.5 $M_{\odot}$ (depending on metallicity). In particular, a drastic drop of the TPAGB duration is expected in the highest mass domain, i.e. for stars with HBB. In RV81 the mass-dependence is much less marked, and such a strong reduction of the TP-AGB lifetimes of the most massive models is not predicted. This latter point is relevant for the interpretation of the highluminosity wing of the observed carbon star luminosity functions (see Sect. 5.2.3).

We also notice that with the Vassiliadis \& Wood's formalism both the total number of the thermal pulses and the TP-AGB lifetimes are notably sensitive to the metallicity, i.e. increase with decreasing $Z$. This feature reflects consequently on the predicted yields from stars with the same initial masses but different initial metallicities.

Finally, it is worth remarking that the efficiency of mass loss on the AGB crucially affects the masses of the bare $\mathrm{C}-\mathrm{O}$ cores left at the end of this phase. It follows that the empirical initial-final mass relation sets important constraints to the theoretical prescriptions for stellar winds (see Sect. 5.2.1). It is important also to recall that according to RV81 in stars with $M_{\mathrm{i}} \gtrsim(5-8) M_{\odot}$ the $\mathrm{C}-\mathrm{O}$ degenerate core grows up to the Chandrasekhar limit ( $1.4 M_{\odot}$; see Fig. 8), leading to explosive carbon ignition (type I-1/2 Supernova event; see Iben \& Renzini 1983). On the contrary, according to M2K and HG97 this circumstance is always prevented by the earlier removal of the whole stellar envelope. 


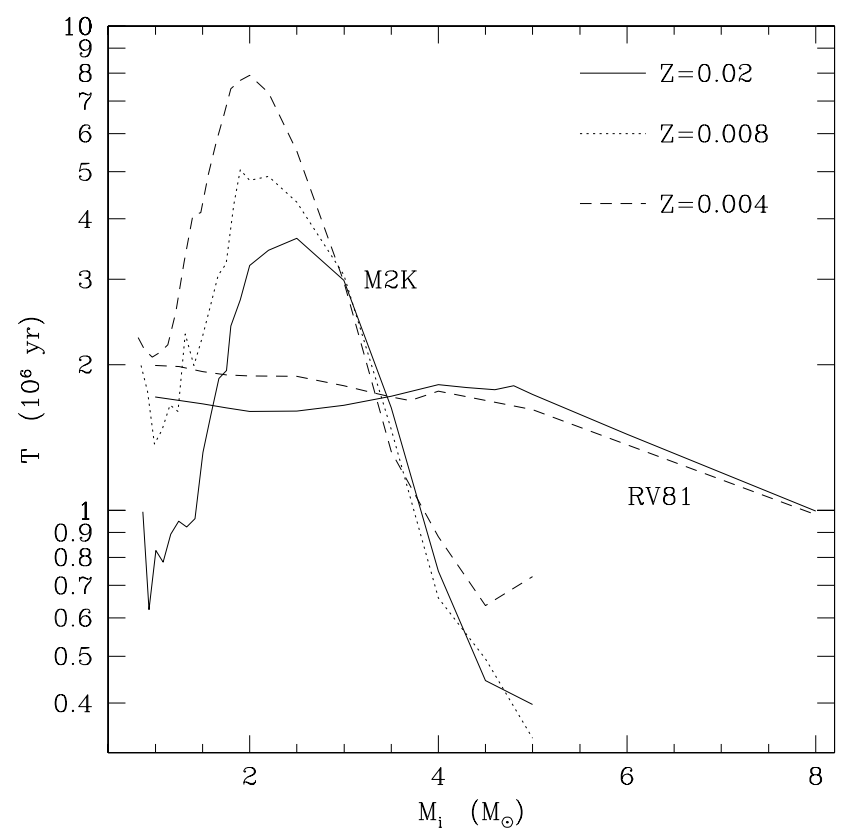

Fig. 6. Predicted TP-AGB lifetimes as a function of the initial stellar mass and metallicity according to the present work (M2K) and that of Renzini \& Voli (1981; RV81) with the massloss parameter $\eta=1 / 3$

\subsubsection{The treatment of the third dredge-up}

This process is expected to critically affect the actual yields of many elements, mainly ${ }^{4} \mathrm{He},{ }^{12} \mathrm{C}$, and ${ }^{16} \mathrm{O}$. Moreover, the reduction of the core mass caused by the third dredge-up concurs to determine the final mass of the remnant left at the end of the AGB.

The largest differences in the analytical treatment of this process, in the models here considered, can be summarised as follows. In RV81 model the onset of the third dredge-up in low-mass stars possibly occurs later (higher $M_{\mathrm{c}}^{\min }$ ) and with a lower efficiency (lower $\lambda$ ) than in the HG97 and M2K calculations, that are carried out with similar values of the parameters (see Table 1).

This can be explained considering the different usage of the quantities $M_{\mathrm{c}}^{\mathrm{min}}$, and $\lambda$ in the models. As already mentioned in Sect. 1, in RV81 these parameters were derived according to complete stellar models currently available at that epoch. The subsequent comparison between the predictions of synthetic models and observations pointed out at the so-called "carbon star mystery", as denominated by Iben (1981), i.e. too few faint and too many bright carbon stars expected than observed.

Differently, the later analyses carried out by HG97 and M2K move from another perspective, that is to consider $M_{\mathrm{c}}^{\min }$ and $\lambda$ as free parameters which should be calibrated in order to reproduce observations of carbon stars. The aim is to provide indications on the average characteristics of the third dredge-up, so as to remove the theoretical discrepancy related to the "carbon star mystery" (see Sect. 5.2.3).

\subsubsection{The treatment of hot bottom burning}

The most notable effect of this process on stellar yields involves ${ }^{14} \mathrm{~N}$ and ${ }^{4} \mathrm{He}$, which are newly synthesised at the expense of hydrogen and, in general, of the other CNO catalysts. It is important to stress that the occurrence of HBB in the most massive AGB stars $\left(M>3.5-4.5 M_{\odot}\right)$ has not only a direct effect on stellar yields - via changing the chemical abundances in the envelope - but also determines an indirect action, affecting the energetics of these stars, hence their evolutionary properties.

In fact, as a consequence of $\mathrm{HBB}$, the $M_{\mathrm{c}}-L$ relation breaks down, a feature clearly shown by complete AGB stellar calculations (e.g. Blöcker \& Scönberner 1991; see also Fig. 7). In these massive AGB models the luminosity evolution is characterised by a steeper increase with the core mass (above the $M_{\mathrm{c}}-L$ relation) up to a maximum, followed by a decline as soon as the envelope mass is significantly reduced by mass loss. Eventually the $M_{\mathrm{c}}-L$ relation is recovered (e.g. Vassiliadis \& Wood 1993; Marigo 1998). This behaviour is exemplified in Fig. 7 where we report the results of complete evolutionary calculations performed by Blöcker (1995) for a $7 M_{\odot}$ model with solar metallicity (triangles).

Actually, the effect of the predicted luminosity evolution on stellar yields is at least two-fold. In fact, the stellar luminosity is closely related to the temperature at the base of the envelope, which the nuclear reaction rates crucially depend on. Moreover, the overluminosity of AGB stars with HBB can trigger high mass-loss rates, thus favouring the onset of the super-wind regime with consequent reduction of the TP-AGB lifetimes.

Such overluminosity effect caused by HBB is included neither in RV81 nor in GdJ93, where the luminosity evolution is assumed to follow the $M_{\mathrm{c}}-L$ relation by IT78 (with some revision for the composition dependence in the GdJ93 work). In Fig. 7 we show the behaviour of the luminosity for the $7 M_{\odot}$ model (solid line) as it would result adopting the IT78 relation with the the same values for current $M_{\mathrm{c}}$ and $M$ as in the Blöcker (1995) model sequence. The discrepancy is notable. To overcome this limitation of synthetic models Marigo et al. (1998; see also Marigo 1998,b) developed a solution scheme based on envelope integrations, so that the overluminosity produced by HBB is taken into account and the results of complete stellar calculations are recovered (dashed line in Fig. 7).

\subsection{Observational constraints}

In the following we will examine the AGB synthetic models under consideration (RV81, HG97, M2K (this work)) in relation to their capability of reproducing important observational constraints, which are closely related to the stellar yields. 


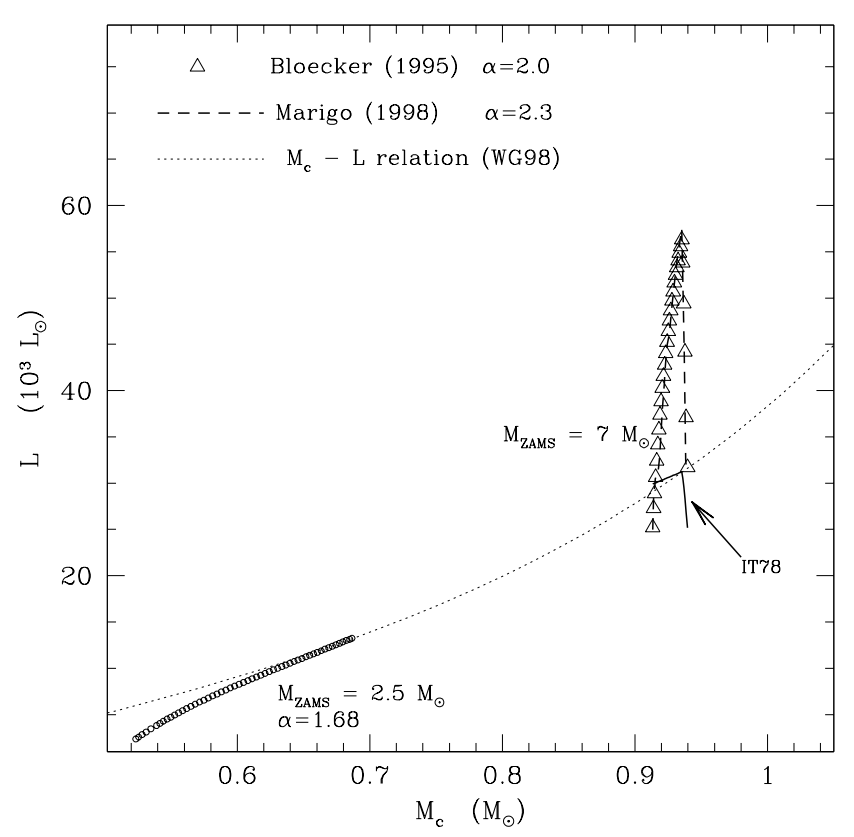

Fig. 7. Quiescent luminosity as a function of the core mass during the TP-AGB phase. The predictions for the $7 M_{\odot}, Z=$ 0.021 model with HBB according to full evolutionary calculations by Blöcker (1995) are compared to the those of synthetic calculations. The luminosity evolution for a $2.5 M_{\odot}$ model is also shown (Marigo et al. 1999a). The reference $M_{\mathrm{c}}-L$ relation is taken by Wagenhuber \& Groenewegen (1998). The adopted mass-loss prescription is that by Baud \& Habing (1983). See text for further explanation

\subsubsection{The initial-final mass relation}

The initial-final mass relation (IFMR) of low- and intermediate-mass stars is intimately linked to the chemical yields, as it determines the total amount of matter ejected by a star during its entire evolution. In a complementary way, it gives information on the reservoir of stellar remnants, irreversibly lost by the star-forming gas. Moreover, assessing the upper mass limit for WD progenitors $\left(M_{\mathrm{WD}}\right)$ is an important point, since it affects the expected rate of type II supernovae. All these aspects are fundamental issues for chemical evolutionary models.

Figure 8 shows a few empirical calibrations of the IFMR for the solar neighbourhood. The first striking point is that the more recent determinations significantly differ from the earlier work by Weidemann (1987). For instance, the revised relation by Herwig (1996) presents a flatter slope up to Hyades location $\left(M_{\mathrm{i}} \sim 3 M_{\odot}, M_{\mathrm{f}} \sim 0.7 M_{\odot}\right)$, followed by a steeper rise, and a final flattening towards higher initial masses $\left(M_{\mathrm{i}}>4 M_{\odot}\right)$. The presence of an inflection point at the Hyades mean location seems to be confirmed also by Reid (1996), as discussed by Weidemann (1997).

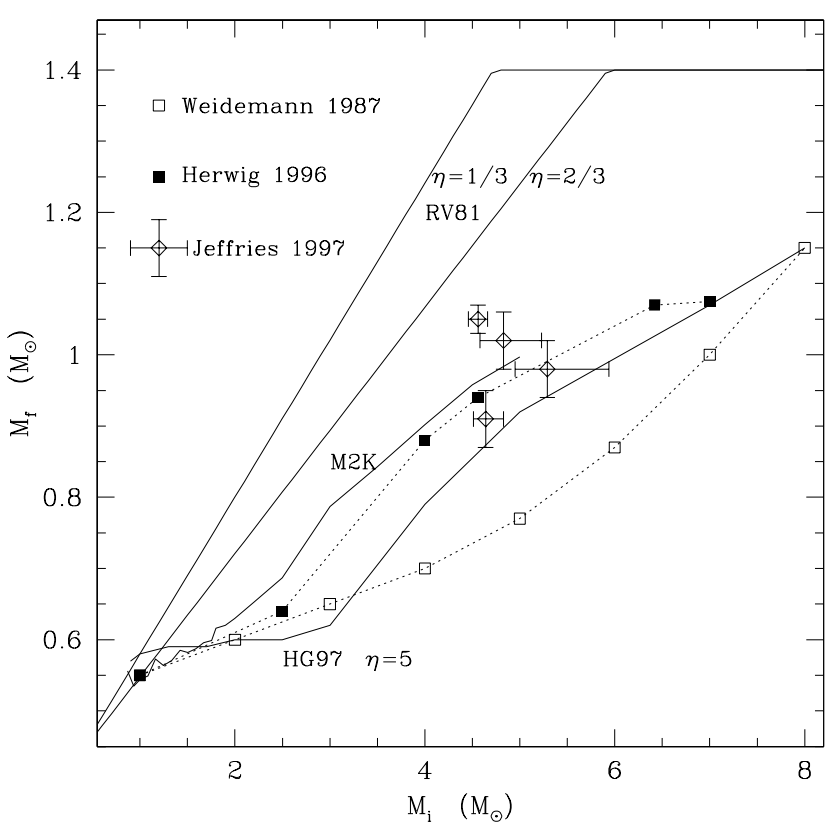

Fig. 8. Initial-final mass relation for low- and intermediatemass stars with solar metallicity. Semi-empirical calibrations for the solar neighbourhood are taken from Weidemann (1987), Herwig (1996), and Jeffries (1997). Solid lines refer to theoretical predictions. When the Reimers' prescription for mass-loss is adopted, the corresponding efficiency parameter $\eta$ is indicated. See text for more details

The second point to be made deals with the critical mass $M_{\mathrm{WD}}{ }^{1}$, that is the maximum initial mass of $\mathrm{WD}$ progenitors. At present, this limiting value is still rather uncertain (most likely in the range 5-8 $M_{\odot}$ ), since it heavily depends on model details. In particular, as already discussed by Weidemann (1987), the definition of convective boundaries - via either the Schwarzschild criterion or an overshooting scheme - plays a crucial role. It turns out that with the latter choice $M_{\mathrm{WD}}$ is lower than assuming the former classical assumption. However, other parameters may affect the predictions for $M_{\mathrm{WD}}$. For instance, the recent metallicity re-determination (i.e. half-solar) of the young open cluster NGC 2516 by Jeffries (1997; see Fig. 8) has lead to assign it a younger age. As a consequence, Jeffries (1997) derives $M_{\mathrm{WD}}$ around 5-6 $M_{\odot}$, that is considerably lower than $M_{\mathrm{WD}} \sim 7-8 M_{\odot}$ as estimated in previous studies (e.g. Weidemann 1987; Koester \& Reimers 1996). However, it should be noticed that in a more recent paper Jeffries et al. (1998) still do not exclude that the metallicity of NGC 2516 might be nearly solar.

Figure 8 displays the theoretical IMFRs as derived by RV81, HG97, and M2K for low- and intermediate massmodels with initial solar metallicity. We can notice that

${ }^{1}$ For the sake fo simplicity, we limit our discussion to $M_{\mathrm{WD}}$ for carbon/oxygen white dwarfs, i.e. not considering the neon/oxygen white dwarfs which would derive from "superAGB" stars according to Garcia-Berro et al. (1997) evolutionary calculations. 


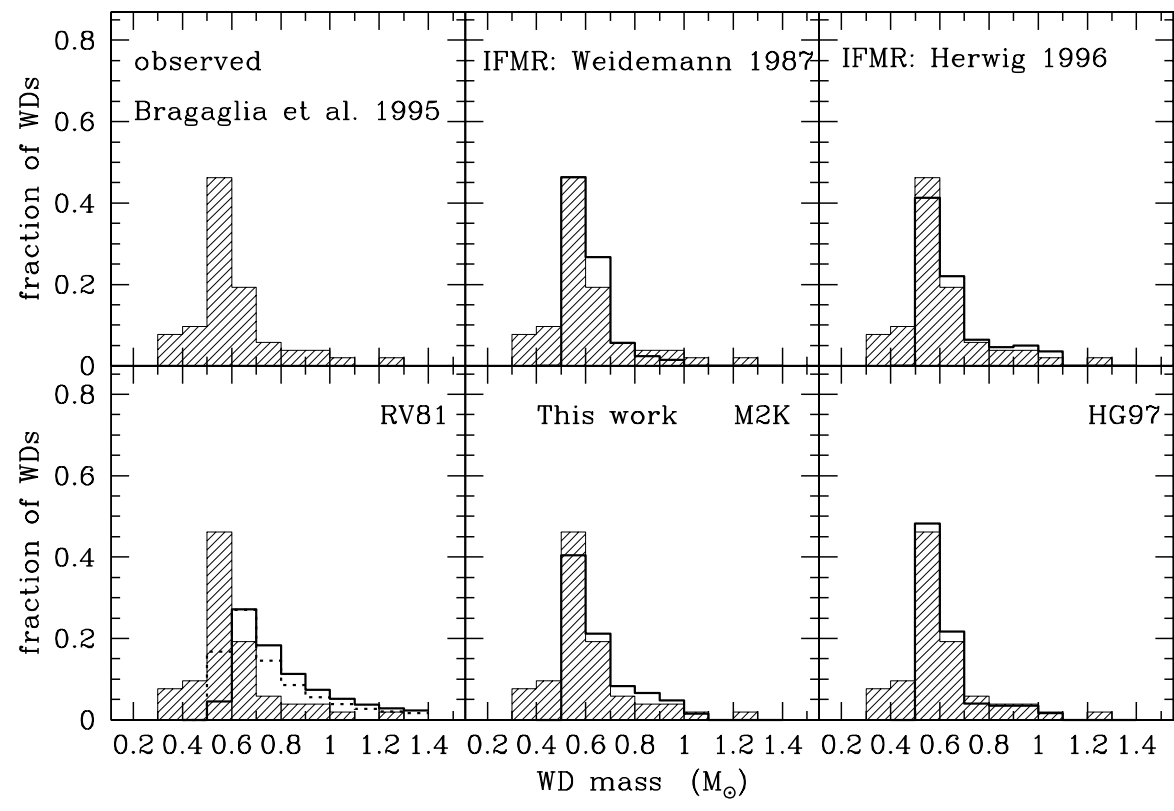

Fig. 9. WD mass distribution for solar metallicity. The observed data in the solar neighbourhood are taken from the sample of bright DA WDs by Bragaglia et al. (1995). The shaded area beneath the observed histogram is set equal to unity. The middle and right panels on the top show the WD mass distributions (solid line) derived by adopting the semi-empirical IFMRs by Weidemann (1987) and Herwig (1996), respectively. The bottom panels display the distributions obtained by assuming the theoretical IFMRs from the quoted works. All the solid line histograms are normalised to the fraction of observed WDs with masses larger than $0.5 M_{\odot}$. See text for more details the both HG97 and M2K are satisfactorily consistent with the trend of the most recent observational relations, whereas RV81 is far from reproducing the empirical data. In particular, the RV81 relation shows a quick divergency of the final mass at increasing initial mass, with the most massive stars being able to build $\mathrm{C}-\mathrm{O}$ cores up to the Chandrasekhar limit of $1.4 M_{\odot}$. The final fate of these stars would correspond to the occurrence of type I-1/2 supernova events, which seems not to be supported by the observations.

\subsubsection{The white dwarf mass distribution}

The white dwarf mass distribution (WDMD) is closely related to the IFMR from which it can be theoretically derived, provided that assumptions on the initial mass function (IMF) and star formation rate (SFR) are made to perform the integration over mass and time. The observed WDMD in the solar neighbourhood (Bergeron et al. 1992; see Fig. 9) is narrowly peaked in the mass range 0.5-0.6 $M_{\odot}$ (adopting a mass bin of $\left.0.1 M_{\odot}\right)$, which contains more than $45 \%$ of the observed objects.

We notice that, with a finer bin sampling (i.e. $\left.0.05 M_{\odot}\right)$, the location of observed peak would fall between 0.5 and $0.55 M_{\odot}$, which may be difficult to be theoretically reproduced. In fact, according to stellar evolutionary models, these values would be consistent with the minimum remnant mass produced by progenitor stars as old as the age of the Galaxy ( $\sim 15$ Gyr corresponding to initial masses $\sim 0.9 M_{\odot}$ ), provided that their $\mathrm{C}-\mathrm{O}$ cores do not grow in mass during the TP-AGB phase. In fact, these stars are predicted to enter the TP-AGB phase with a core mass of already $\sim 0.52 M_{\odot}$ (Girardi et al. 2000). Then, the location of the observed peak in the range $0.5-0.55 M_{\odot}$ might be explained by theory only if assuming i) that mass loss suffered by AGB low-mass stars is so strong that they leave this phase as soon as they enter it, or ii) very efficient dredge-up prevents the growth in mass of the core (Herwig et al. 1997). On the other hand, as suggested by Bragaglia et al. (1995), the origin of such discrepancy between theory and observations would be most likely due to a systematic underestimation of the surface gravities derived from WD models.

Given this point of uncertainty and considering that WDs with $M<0.4 M_{\odot}$ are probably helium WDs derived from binary evolution, in this work both theoretical and observed WDMDs (see Fig. 9) are derived adopting a mass bin of $0.1 M_{\odot}$, and normalising them to the observed fraction of WDs with $M \geq 0.5 M_{\odot}$.

The predicted fraction of WDs contained in the $k$ th mass bin (from $M_{\mathrm{f}}^{k}$ to $M_{\mathrm{f}}^{k+1}$ ) is calculated with:

$N^{k} \propto \frac{\left(M_{\mathrm{i}}^{k+1}-M_{\mathrm{i}}^{k}\right)}{\left(M_{\mathrm{f}}^{k+1}-M_{\mathrm{f}}^{k}\right)} \phi\left(M_{\mathrm{i}}^{k / 2}\right) \psi\left(T_{\mathrm{G}}-\tau_{k / 2}\right) \Delta T_{k / 2}$

where $\left(M_{\mathrm{i}}^{k}, M_{\mathrm{i}}^{k+1}\right)$ is the corresponding interval of initial stellar mass; $\phi\left(M_{\mathrm{i}}^{k / 2}\right)$ is the IMF (by number) evaluated at the mean initial mass $0.5\left(M_{\mathrm{i}}^{k+1}+M_{\mathrm{i}}^{k}\right) ; T_{\mathrm{G}}$ and $\tau_{k / 2}$ denote the age of the Galaxy, and the lifetime of a star with mass $M_{\mathrm{i}}^{k / 2}$, respectively; $\psi\left(T_{\mathrm{G}}-\tau_{k / 2}\right)$ is the SFR evaluated at the birth epoch of the star; and $\Delta T_{k / 2}$ is the time interval of detectability of the WD.

For the sake of simplicity, in our calculations we adopt a constant SFR, the IMF given by the Salpeter's law $\left(\phi(M) \propto M^{-2.5}\right)$, and suppose that any WD formed in the past is still detectable at the present time. This implies we assume that the WD fading time is always much longer than the WD's age. In this case $\Delta T_{k / 2}=T_{\mathrm{G}}-\tau_{k / 2}$, i.e. the WD has been detectable since the death of the progenitor.

Moreover, it is worth noticing the following points. Under the assumption of a constant SFR, the WDMD essentially depends on i) the slope, $\mathrm{d} M_{\mathrm{i}} / \mathrm{d} M_{\mathrm{f}}$, of the IFMR, 


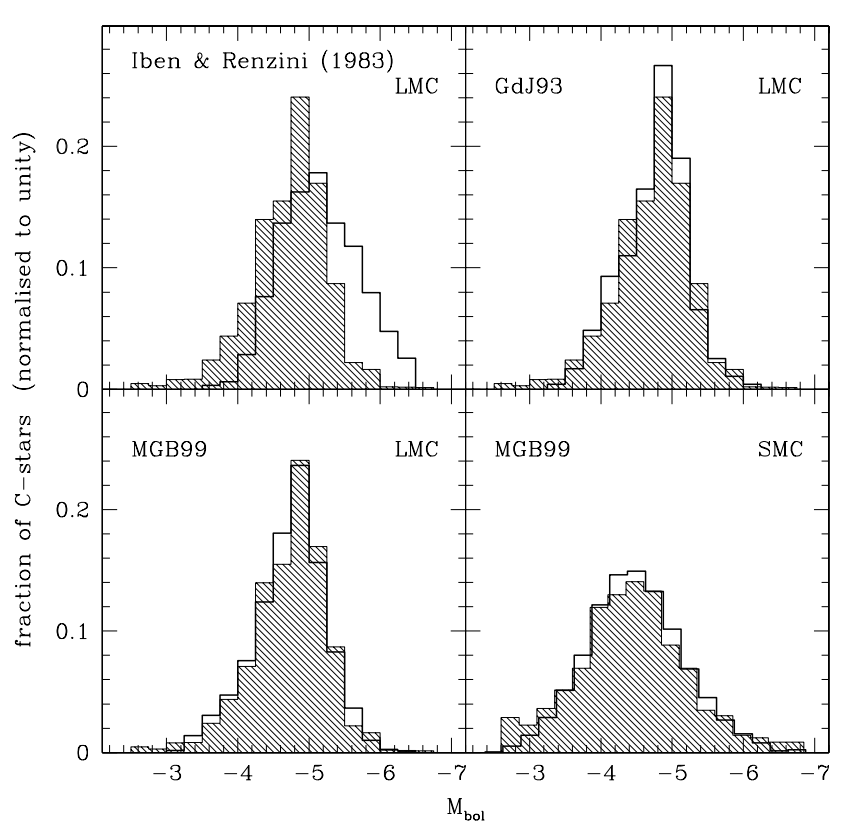

Fig. 10. Luminosity functions of field carbon stars in the Magellanic Clouds. The observed data (shaded histograms) are taken from Costa \& Frogel (1996) for the LMC, and Reiberot (1993) for the SMC. Theoretical distributions (thick solid line) are shown for comparison. Top left-hand side panel: Iben \& Renzini (1983) calculations for the LMC - based on a synthetic AGB model very similar to that of Renzini \& Voli (1981; RV81) - with the parameter set $(\eta=2 / 3, \alpha=2, \epsilon=0.1)$. Top righthand side panel: Groenewegen \& de Jong (1993; GdJ93) best fitting distribution for the LMC carbon stars. Bottom panels: Marigo et al. (1999a) best fits to the CSLFs in the LMC and SMC. See text for further explanation

ii) the IMF, and iii) the lifetimes of the stellar progenitors relative to the age of the Galaxy.

The first factor favours the population of those mass bins in which the slope of the IFMR is flatter, i.e. where stars with different initial masses build up WDs with similar masses. This should be one of the dominant effects which gives rise to the observed narrow peak of the WDMD at around $0.5-0.6 M_{\odot}$, just where the IFMR is rather flat (see Fig. 8).

The second and third factors tend to produce opposite effects. The IMF preferentially weighs the formation of WDs with lower masses, hence evolved from originally less massive stars if the IFMR is a monotonic function. On the contrary, the accumulation factor $\left(T_{\mathrm{G}}-\tau\right)$ favours the contribution of WDs of higher masses, evolved from more massive stars, hence with shorter lifetimes.

In Fig. 9 the observed WDMD in the solar neighbourhood is compared with the distributions derived according to Eq. (10) assuming different IFMRs, both empirical and theoretical ones. The relations by Weidemann (1987) and Herwig (1996), though being quite different, yields WDMDs both acceptably consistent with the observed one. This can be explained considering that the major differences between the two IFMRs show up for
$M_{\mathrm{i}}>2.5-3 M_{\odot}$, corresponding to WDs that do not contribute to the mass peak. For $M_{\mathrm{f}} \leq 0.55 M_{\odot}$ the relations are quite similar, showing a rather flat trend.

As far as the purely theoretical WDMDs are concerned (bottom panels), it turns out that a satisfactory reproduction of the observed data is attained by both HG97 and M2K (this work), whereas a notable discrepancy affects the predictions by RV81. As already anticipated in the discussion on the predicted IFMRs (Sect. 5.2.1), in RV81 there is a sizable overproduction of WDs more massive than $0.6 M_{\odot}$, a feature already pointed out by Bragaglia et al. (1995).

\subsubsection{The carbon star luminosity function}

The carbon star luminosity function (CSLF) is a fundamental observable as it gives indications on, at least, two basic processes occurring in TP-AGB stars with different masses, namely: the third dredge-up - that determines the increase of the surface carbon abundance -, and mass loss by stellar winds, that affects the duration, hence the luminosity excursion during this phase.

Iben (1981) first pointed out the so-called "carbon star mystery", corresponding to a long-standing discrepancy between theory and observations, i.e. current stellar models predicted a deficit of faint carbon stars, accompanied by an excess of bright carbon (in general AGB) stars. This situation is exemplified in Fig. 10, where we report the predicted CSLF for the LMC, according to the calculations performed by Iben \& Renzini (1983), with model prescriptions very similar to RV81. For this particular case, the authors adopt the following set of parameters: efficiency parameter $\eta=2 / 3$ in the Reimers (1975) mass-loss formula; mixing-length parameter, $\alpha=2$; minimum core for the third dredge-up to occur, $M_{\mathrm{c}}^{\text {min }}=0.5 M_{\odot}$; and efficiency of the third dredge-up, $\lambda$, as a function of the core mass.

The CSLF in the LMC is instead very well fitted (Fig. 10) by the other two AGB synthetic models here considered, namely: Groenewegen \& de Jong (1993, GdJ93; top right-hand side panel) and Marigo et al. (1999, MGB99; bottom left-hand side panel). We remind again that, differently from RV81, in these studies the third dredge-up is suitably calibrated in order to reproduce the CLSF in the LMC. Finally, it should be remarked that Marigo et al. (1999) have extended the analysis to the CSLF in the SMC (see bottom right-hand side panel of Fig. 11), so as to include a metallicity-dependent treatment of the third dredge-up in their synthetic AGB model.

\subsubsection{The chemical abundances of planetary nebulae}

The observed chemical composition of planetary nebulae represents another crucial constraint for stellar models, as it is the record of the nucleosynthetic and mixing processes occurred during the previous stellar evolution. 

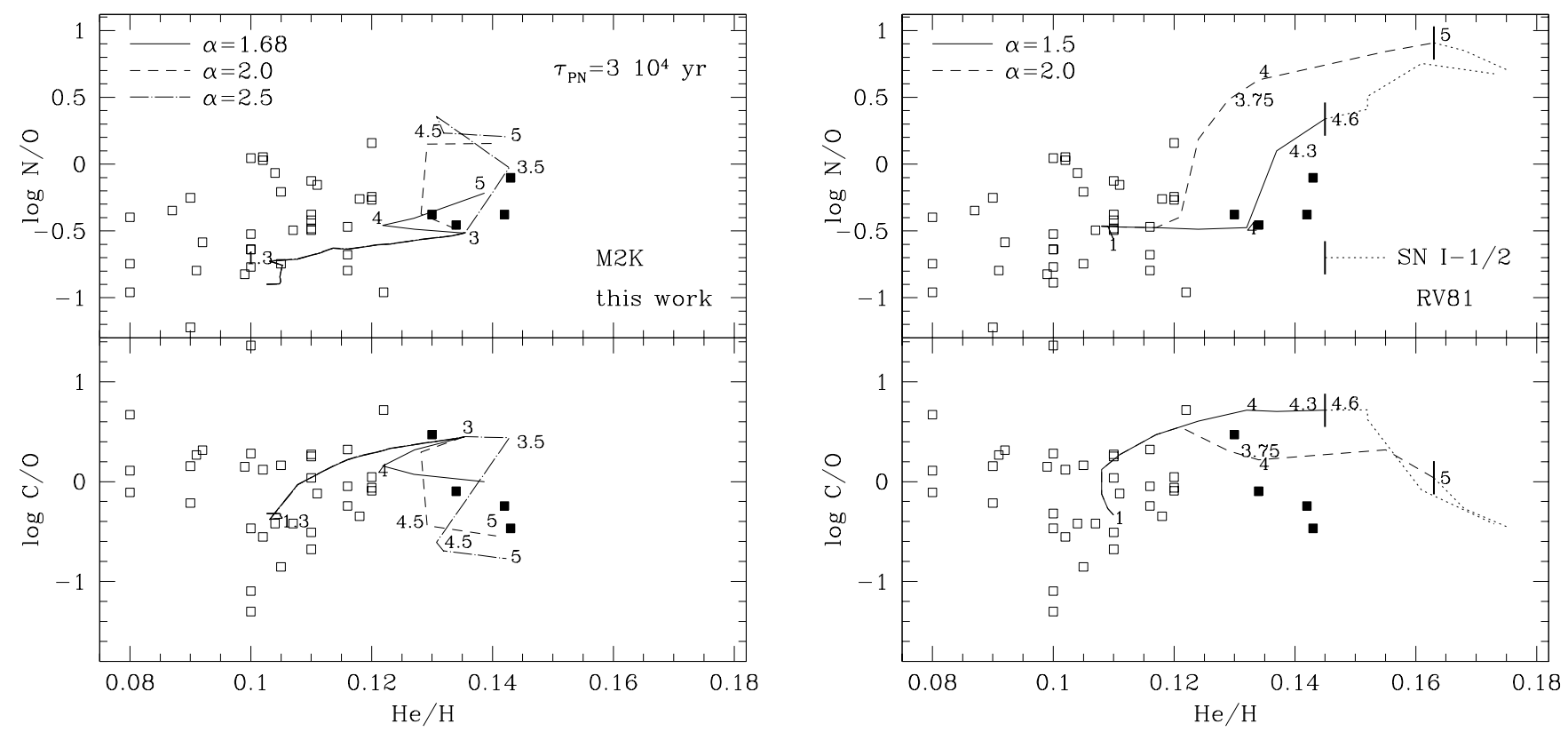

Fig. 11. Abundance ratios of galactic planetary nebulae. Observed data (squares) are taken from Kingsburgh \& Barlow (1994), and Henry et al. (2000a). Filled squares correspond to PNe with $\log (\mathrm{N} / \mathrm{O})>-0.5$ and $\mathrm{He} / \mathrm{H}>0.125$. Predicted PN abundances are shown as a function of the initial mass of solar-metallicity progenitor stars, as derived in this work (left-hand side panel), and in Renzini \& Voli (1981, right-hand side panel). Lines (solid and dashed) connect predicted abundances at increasing stellar mass (a few values are indicated nearby) for two values of the mixing length parameter. In the case of RV81 model, surface abundances just prior Chandrasekhar carbon explosion are also shown (dotted line)

As far as HG97 predictions are concerned, a detailed discussion is given in Groenewegen \& de Jong (1994) and it will not be repeated here. We restrict here to the results of RV81 and M2K which are compared in Fig. 11 with the measured abundances of $\mathrm{He}, \mathrm{C}$, and $\mathrm{O}$ in galactic planetary nebulae. Predicted PN abundances can be found in Tables A13-A15. Since a full analysis is beyond the purpose of this work, we simply consider the most relevant aspects.

Both RV81 and M2K results shown here are derived from calculations of stellar models with initial solar composition. Therefore, they cannot reproduce the data points with $\mathrm{He} / \mathrm{H} \lesssim 0.10-0.11$, since these latter most likely correspond to progenitor stars with initial subsolar metallicity.

The expected paths of PN abundances as a function of the initial mass of the progenitor star reflect the efficiency and duration of the involved processes. For instance, in both models the $\mathrm{C} / \mathrm{O}$ ratio first increases at increasing mass due to the third dredge-up, and then (for $\left.M>3-4 M_{\odot}\right)$ it starts to decline because of HBB.

An interesting point is the anticorrelation between the $\mathrm{N} / \mathrm{O}$ ratio and the $\mathrm{C} / \mathrm{O}$ ratio exhibited by observed $\mathrm{PNe}$ with the highest helium content $(\mathrm{He} / \mathrm{H}>0.125$; the socalled type I PNe according to the classification introduced by Peimbert 1978). This trend is reproduced by M2K synthetic calculations, tracing the signature of HBB in the most massive AGB stars $\left(M \gtrsim 3.5 M_{\odot}\right)$, where carbon in the envelope is quickly converted into nitrogen.
Note that theoretical results are notably sensitive to the adopted value for the mixing-length parameter, i.e. the larger $\alpha$ is, the more efficiently HBB operates, yielding higher $\mathrm{N} / \mathrm{O}$ and lower $\mathrm{C} / \mathrm{O}$ ratios. Limiting to the observed sample of PNe, we might deduce that HBB has operated in the most massive progenitors of solar metallicity, but with a rather mild efficiency, in agreement with the conclusion already mentioned by Henry et al. (2000a). In fact, as we can see from Fig. 11, predictions for the case $(\alpha=2.5)$ - which correspond to strong HBB - lead to $\mathrm{N} / \mathrm{O}$ ratios quite higher than observed.

Hower, these indications should be considered with some caution, as the considered sample of PNe might not cover the whole relevant mass range of the progenitors (see Henry et al. 2000a), and predictions of PNe abundances are derived under very simple assumptions (see Appendix A). A much better approach will be adopted with the aid of a detailed synthetic model of PN evolution, which is being developed (Marigo et al. 2001, in preparation; see Marigo et al. 1999 for a preliminary presentation).

Finally, we would remark that RV81 results for the most massive stellar models - shown in Fig. 11 with dotted lines - do not correspond to PN abundances, but rather to surface abundances just prior the progenitor stars explode as SNe I-1/2. Therefore, attention must be paid not to use these data for a comparison with observed PN abundances. 


\subsection{Yields from simple stellar generations}

We will compare here the stellar yields presented in this work with those calculated by RV81 and HG97. Possible differences are then discussed on the basis of different model prescriptions and observational constraints, already mentioned in the previous sections.

We choose not to make a direct comparison between yields produced by models with the same initial mass, because different sets of yields cover different mass-ranges in the domain of low- and intermediate-mass stars (see Sect. 5.1.1). For this reason, it is more meaningful to compare the whole chemical contribution provided by low- and intermediate-mass stars belonging to a given simple (i.e. coeval) stellar population. To this aim, we recall that according to the standard definition (Tinsley 1980), the yield from a stellar generation, $y_{k}$, is the mass converted into the chemical element $k$ and ejected by all stars per unit mass locked into stars:

$y_{k}=(1-R) \frac{\int_{M_{\mathrm{u}}}^{M_{\mathrm{u}}} M_{\mathrm{i}} p_{k}\left(M_{\mathrm{i}}\right) \phi\left(M_{\mathrm{i}}\right) \mathrm{d} M_{\mathrm{i}}}{\int_{M_{\mathrm{l}}}^{M_{\mathrm{u}}} M_{\mathrm{i}} \phi\left(M_{\mathrm{i}}\right) \mathrm{d} M_{\mathrm{i}}}$.

In the above equation $p_{k}(m)$ is the stellar yield of the $k$ th element (see Sect. 3), and $R$ is the returned fraction, expressing the fraction of mass that has formed stars and then been ejected:

$R=\frac{\int_{M_{\mathrm{l}}}^{M_{\mathrm{u}}}\left[M_{\mathrm{i}}-W\left(M_{\mathrm{i}}\right)\right] \phi\left(M_{\mathrm{i}}\right) \mathrm{d} M_{\mathrm{i}}}{\int_{M_{\mathrm{u}}}^{M_{\mathrm{u}}} M_{\mathrm{i}} \phi\left(M_{\mathrm{i}}\right) \mathrm{d} M_{\mathrm{i}}}$

where $\phi(M)=\mathrm{d} N / \mathrm{d} M_{\mathrm{i}}$ is the IMF (by number) defined between the lower $\left(M_{\mathrm{l}}\right)$ and upper $\left(M_{\mathrm{u}}\right)$ mass limits; $W\left(M_{\mathrm{i}}\right)$ is the remnant mass.

In order to weigh the sole contribution from the generation of low- and intermediate-mass stars, let us consider the quantity:

$y_{k}^{\operatorname{lims}}=\frac{\int_{M_{\mathrm{l}}}^{M_{\mathrm{up}}} M p_{k}\left(M_{\mathrm{i}}\right) \phi\left(M_{\mathrm{i}}\right) \mathrm{d} M_{\mathrm{i}}}{\int_{M_{\mathrm{l}}}^{M_{\mathrm{u}}} M_{\mathrm{i}} \phi\left(M_{\mathrm{i}}\right) \mathrm{d} M_{\mathrm{i}}}$

that is similar to Eq. (11) with $M_{\mathrm{u}}=M_{\mathrm{up}}$. The adopted integration extremes are $M_{\mathrm{l}}=0.9 M_{\odot}, M_{\mathrm{u}}=100 M_{\odot}$, and $M_{\mathrm{up}}$ according to the set of stellar yields under consideration (see Table 1 and Sect. 5.1.1). The IMF is expressed by the classical Salpeter's law, i.e. $\phi\left(M_{\mathrm{i}}\right)=\mathrm{d} N / \mathrm{d} M_{\mathrm{i}} \propto$ $M_{\mathrm{i}}^{-(1+x)}$ with $x=1.35$ (Salpeter 1955).

The quantities $y_{k}^{\text {lims }}$ express the relative chemical contribution (for a given elemental species $k$ ) from low- and intermediate-mass stars belonging to a given simple stellar population. They are shown in Fig. 12 as a function of the metallicity for the three sets here considered.

It should be remarked that the differences between our results (M2K) and those derived by RV81 and HG97 are not only due to the different mass-range covered by lowand intermediate- mass stars, but mainly reflect substantial differences in the adopted physical prescriptions as already illustrated in Sect. 5.1.
Differences essentially show up both in metallicity trends and absolute values of $y_{k}^{\text {lims }}$. Compared to previous calculations, M2K yields show a pronounced dependence on the metallicity, i.e. positive yields increase with decreasing $Z$. Conversely, the RV81 and HG97 sets present weak trends with $Z$.

The metallicity dependence can be explained as follows. On one side, AGB lifetimes of low-mass stars increase at decreasing metallicities, as mass-loss rates are expected to be lower. This fact leads to a larger number of dredge-up episodes. Moreover, both the onset and the efficiency of the third dredge-up are favoured at lower metallicities. These factors concur to produce a greater enrichment in carbon. On the other side, HBB in more massive AGB stars becomes more efficient at lower metallicities, leading to a greater enrichment in nitrogen. The combination of all factors favours higher positive yields of helium at lower $Z$.

As far as the single elemental species are concerned, we can notice:

- M2K yields of ${ }^{4} \mathrm{He}$ are larger than those by HG97 and RV81 towards lower $Z$, likely due to the earlier activation and larger efficiency of the third dredge-up in our models. With respect to RV81 and HG97 predictions, our yields of ${ }^{4} \mathrm{He}$ present a significant trend with $Z$;

- M2K yields of ${ }^{12} \mathrm{C}$ are systematically higher than those of RV81 and HG97 because of the earlier onset (and average greater efficiency than in RV81) of the third dredge-up;

- The dominant contribution to the yields of ${ }^{14} \mathrm{~N}$ comes from HBB in the most massive AGB stars. Differences in the results reflect different efficiencies of nuclear reactions and AGB lifetimes. In particular, according to $\mathrm{M} 2 \mathrm{~K}$ the production of ${ }^{14} \mathrm{~N}$, mainly of primary synthesis, is favoured at lower $Z$, and is sistematically lower than RV81 and HG97 results. This latter difference can be explained considering the drastic reduction of TP-AGB lifetimes for the most massive AGB models with HHB (see Fig. 6) in M2K models with respect to RV81.

In general, our expected dependence of chemical yields on metallicity is far for being linear, and much caution should be used when extrapolating these quantities with respect to $Z$ in chemical evolutionary models. We cannot verify whether such a non-linear relation with metallicity was displayed also in the RV81 models, since just two values of metallicities were considered there. However, the very high number of thermal pulses suffered by stars with HBB regardless of the metallicity, according to the RV81 models, might already explain the apparent lower sensitiveness of their yields to the metallicity.

\section{Final remarks}

We would like to outline briefly the aims and findings of the present work. 


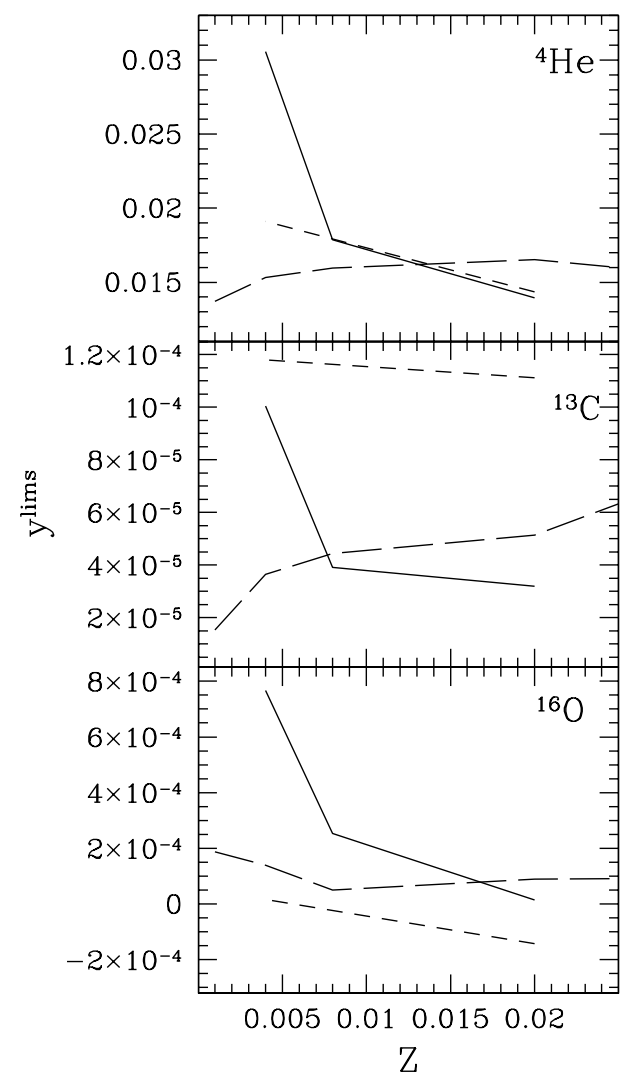

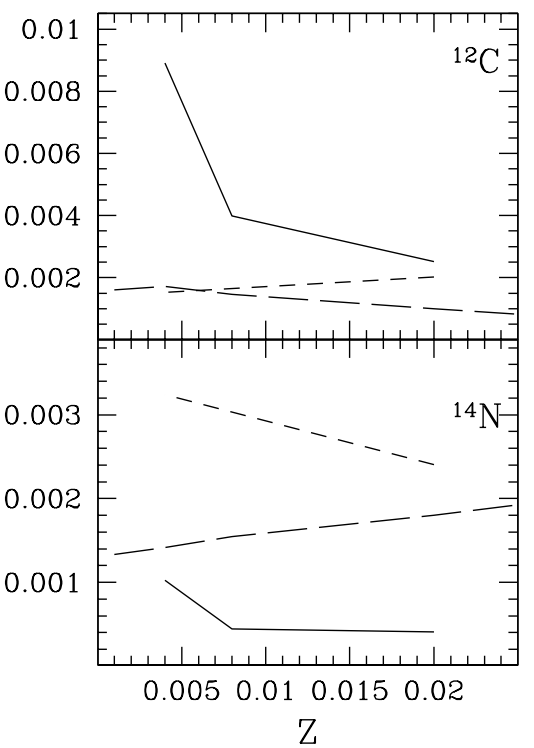

M2K $(\alpha=1.68)$

$---\cdot \operatorname{RV} 81(\alpha=1.5)$

- HG97 $(\alpha=2.0)$
Fig. 12. Integrated yield contributions from low- and intermediate-mass stars as a function of the metallicity, as defined by Eq. (12). The mixinglength parameters $(\alpha)$ adopted by the authors are indicated
In the first part we have presented new homogeneous sets of stellar yields ejected from low- and intermediatemass stars, in view of providing updated ingredients for modelling the chemical evolution of complex stellar systems. Thanks to the updated input physics employed in the calculations, and the improved treatment of both the third dredge-up and hot-bottom burning, the present estimation of the stellar yields from low- and intermediatemass stars has led to new results and developments.

In particular, a pronounced trend of the yields with the metallicity is expected. Specifically, at given stellar mass positive yields of ${ }^{4} \mathrm{He},{ }^{12} \mathrm{C},{ }^{14} \mathrm{~N}$, and ${ }^{16} \mathrm{O}$ are larger at decreasing metallicity. This feature is the result of concurring factors: at lower $Z$ both the third dredge-up and hot-bottom burning are more efficient, and TP-AGB lifetimes are, on average, longer because of lower mass-loss rates.

Moreover, it is interesting to notice that low-mass stars may produce positive yields of ${ }^{16} \mathrm{O}$, which is brought up to the surface by the third dredge-up. The entity of this contribution (as well as for that of ${ }^{12} \mathrm{C}$ ) depends crucially on the efficiency $\lambda$, number of dredge-up episodes, and chemical composition of the convective intershell (for this latter, see Boothroyd \& Sackmann 1988; Herwig 2000 for different model results).

The possible production and ejection of newly synthesised oxygen from low- and intermediate-mass stars may be an interesting prediction to be tested through its consequences in various possible applications, mostly in relation to the chemical composition of planetary nebulae (e.g. Péquignot et al. 2000), and galactic chemical evolutionary models.

The second part of the paper is meant to examine several aspects concerning the stellar models which the chemical yields are derived from. To this aim, we have analysed how the main model prescriptions (i.e. treatment of convective boundaries, mass loss, analytical relations, third dredge-up parameters, treatment of hot-bottom burning, etc.) may affect the predictions of stellar yields.

Finally, the third final part is dedicated to compare our new yields with other available data sets of large usage, in the attempt of explaining the existing differences as the result of particular assumptions. To do this, we have considered basic observational constraints which are closely related to the stellar yields - namely: i) the initialfinal mass relation; ii) the white dwarf mass distribution; iii) the carbon star luminosity function; and iv) the chemical composition of planetary nebulae - and tested the capability of different models in reproducing them through a direct comparison between predictions and observations.

In particular, it has been shown how much the choice of calibrating fundamental efficiency parameters (e.g. of the third dredge-up and mass loss) in recent works has 
changed the predictions of stellar yields compared to earlier studies.

To conclude, we wish this work has somehow contributed to clarify a few important general points on theoretical stellar yields, in view of stimulating an aware and critical usage of them.

Acknowledgements. I would like to thank Léo Girardi, Laura Portinari, and Cesare Chiosi for their important professional advice and support, and the referee, Dr. R. B. C. Henry, for his helpful remarks on this work. This study has been financially supported by the Italian Ministry of University, Scientific Research and Technology (MURST) under contract "Formation and evolution of Galaxies" No. 9802192401.

\section{References}

Alongi, M., Bertelli, G., Bressan, et al. 1993, A\&AS, 97, 851 Baud, B., \& Habing, H. J. 1983, A\&A, 127, 73

Bergeron, P., Saffer, R. A., \& Liebert, J. 1992, ApJ, 394, 228

Blöcker, T. 1995, A\&A, 297, 727 (B95)

Blöcker, T., \& Schönberner, D. 1991, A\&A, 244, L43

Boothroyd, A. I., \& Sackmann, I.-J. 1988a, ApJ, 328, 641

Boothroyd, A. I., \& Sackmann, I.-J. 1988b, ApJ, 328, 653

Boothroyd, A. I., \& Sackmann, I.-J. 1999, ApJ, 510, 232

Bowen, G. H. 1988, ApJ, 329, 844

Bragaglia, A., Renzini, A., \& Bergeron, P. 1995, ApJ, 443, 735

Caughlan, G. R., \& Fowler, W. A. 1988, Atomic Data Nucl. Data Tables, 40, 283

Charbonnel, C. 1995, ApJ, 453, L41

Chiosi, C., Bertelli, G., \& Bressan, A. 1992, ARA\&A, 30, 305

Costa, E., \& Frogel, J. A. 1996, AJ, 112, 2607

Crotts, A. P. S., Bechtold, J., Fang, Y., \& Duncan, R. C. 1994, Bull. Am. Astron. Soc., 185, 1807

Dominguez, I., Chieffi, A., Limongi, M., et al. 1999, ApJ, 524, 226

Fleischer, A. J., Gauger, A., \& Sedlmayr, E. 1992, A\&A, 266, 321

Forestini, M., \& Charbonnel, C. 1997, A\&AS, 123, 241

Garcia-Berro, E., Ritossa, C., \& Iben, I. 1997, ApJ, 485, 765

Girardi, L., Bressan, A., Bertelli, G., \& Chiosi, C. 2000, A\&AS, 141,371

Graboske, H. C., de Witt, H. E., Grossman, A. S., \& Cooper, M. S. 1973, AJ, 181, 457

Gratton, R. G., Sneden, C., Carretta, E., \& Bragaglia, A. 2000, A\&A, 354, 169

Groenewegen, M. A. T., \& de Jong, T. 1993, A\&A, 267, 410

Groenewegen, M. A. T., \& de Jong, T. 1994, A\&A, 282, 115

Henry, R. B. C., Kwitter, K. B., \& Bates, J. A. 2000a, ApJ, 531, 928

Henry, R. B. C., Edmunds, M. G., \& Köppen, J. 2000b, ApJ, 541,660

Herwig, F. 1996, in Stellar Evolution: What Should Be Done, 32nd Liège Int. Astrophys. Coll., ed. A. Noels et al., 441

Herwig, F., Blöcker, T., Schönberner, D., \& El Eid, M. 1997, A\&A, 324, L81

Herwig, F. 2000, A\&A, 360, 952

van den Hoek, L. B., \& Groenewegen, M. A. T. 1997, A\&AS, 123, 305 (HG97)

Iben, I. 1981, ApJ, 246, 278

Iben, I., \& Renzini, A. 1983, ARA\&A, 21, 27

Iben, I., \& Truran, J. W. 1978, ApJ, 220, 980 (IT78)

Jeffries, R. D. 1997, MNRAS, 288, 585
Jeffries, R. D., James, D. J., \& Thurston, M. R. 1998, MNRAS, 300,550

Kingsburgh, R. L., \& Barlow, M. J. 1994, MNRAS, 271, 257

Koester, D., \& Reimers, D. 1996, A\&A, 313, 810

Lu, L. 1991, ApJ, 379, 99

Lu, L., Sargent, W. L. W., \& Barlow, T. A. 1998, AJ, 115, 55

Maeder, A. 1983, A\&A, 120, 113

Maeder, A., \& Meynet, G. 2000, ARA\&A, 38, in press

Marigo, P. 1998a, Ph.D. Thesis, University of Padova

Marigo, P. 1998b, A\&A, 340, 463

Marigo, P., Bressan, A., \& Chiosi, C. 1996, A\&A, 313, 545

Marigo, P., Bressan, A., \& Chiosi, C. 1998, A\&A, 331, 564

Marigo, P., Girardi, L., \& Bressan, A. 1999a, A\&A, 344, 123

Marigo, P., Weiss, A., Groenewegen, M. A. T., \& Girardi, L. 1999b, in From extrasolar planets to Cosmology: The VLT Opening Symposium, Proceedings ESO/MPA Parallel Workshop 2: Star-Way to the Universe, held in Antofagasta (Chile), March 1999, ed. J. Bergeron, \& A. Renzini, 248

Peimbert, M. 1978, in IAU Symposium 76, Planetary Nebulae, ed. Y. Terzian (Dordrecht: Reidel), 215

Pèquignot, D., Walsh, J. R., Zijlstra, A. A., \& Dudziak, G. 2000, A\&A, 361, L1

Pettini, M., Lipman, K., \& Hunstead, R. W. 1995, ApJ, 451, 100

Portinari, L., Chiosi, C., \& Bressan, A. 1998, A\&A, 334, 505

Prantzos, N., Vangioni-Flam, E., \& Casse, M. 1994, RAS Canada J., 88, 356

Rebeirot, E., Azzopardi, M., \& Westerlund, B. E. 1993, A\&AS, 97,603

Reid, N. 1996, AJ, 111 (5), 2000

Reimers, D. 1975, Mem. Soc. R. Sci. Liège, Ser. 6, 8, 369

Renzini, A., \& Voli, M. 1981, A\&A, 94, 175 (RV81)

Salpeter, E. E. 1955, ApJ, 121, 161

Tinsley, B. M. 1980, Fund. Cosmic Phys., 5, 287

Tytler, D., \& Fan, X.-M. 1994, ApJ, 424, L87

Vassiliadis, E., \& Wood, P. R. 1993, ApJ, 413, 641

Vila-Costas, M. B., \& Edmunds, M. G. 1993, MNRAS, 265, 199

Wagenhuber, J., \& Groenewegen, M. A. T. 1998, A\&A, 340, 183

Wasserburg, G. J, Boothroyd, A. I., \& Sackmann, I.-J. 1995, ApJ, 447, L37

Weidemann, V. 1987, A\&A, 188, 74

Weidemann, V. 1997, in Advances in Stellar Evolution, Proceedings of the Workshop Stellar Ecology (Cambridge University Press), 169

Weiss, A., Denissenkov, P. A., \& Charbonnel, A. 2000, A\&A, 355,299

Woosley, S. E., Weaver, T. A. 1982, in Supernovae: a Survey of Current Research, ed. M. J. Rees, \& R. J. Stoneham (Reidel, Dordrecht), 79

Wood, P. R. 1981, in Physical processes in red giants, Proc. of the Second Workshop, Erice, Italy (September 3-13, 1980) (Dordrecht, D. Reidel Publishing Co.), 135

\section{Appendix A: Tables of stellar yields and planetary nebulae chemical abundances}

Tables A1-A12 contain the yields from low- and intermediate-mass stars, in the form $M_{\mathrm{y}}$ (see Eq. (1)), as a function of the initial mass $M_{\mathrm{i}}$ and metallicity $Z$. All specified masses are expressed in solar units. 
Concerning low-mass stars (with $M_{\mathrm{i}} \lesssim M_{\mathrm{HeF}}$ ), we give separately the yields ejected during the RGB (Tables A1-A3) and AGB phases (Tables A4-A6). The quantity, $M_{\mathrm{TP}, 0}$, corresponds to the mass at the onset of the TP-AGB phase, which is smaller than $M_{\mathrm{i}}$ by the amount of mass lost during the previous RGB phase, $\Delta M_{\mathrm{ej}}(\mathrm{RGB})$. The mass lost during the AGB is denoted with $\Delta M_{\mathrm{ej}}$ (AGB).

Total yields produced by stars in the whole mass range $\left(0.8 M_{\odot} \lesssim M_{\mathrm{i}} \lesssim 5 M_{\odot}\right)$ are presented in Tables A7-A12. The total amount of ejected mass is denoted with $\Delta M_{\mathrm{ej}}$.

Total yields from stars with $M_{\mathrm{i}} \geq 3.5 M_{\odot}$ are given in Tables A10-A12 for three values of the mixing-length parameter $\alpha$, and distinguishing between the secondary ( $\mathrm{S}$ entry) and primary (P entry) components in the case of the $\mathrm{CNO}$ elements.

Tables A13-A14 present the predicted abundances ratios $(\mathrm{He} / \mathrm{H}, \mathrm{C} / \mathrm{H}, \mathrm{N} / \mathrm{H}, \mathrm{O} / \mathrm{H})$ in planetary nebulae, as a function of the initial stellar mass $\left(M_{\mathrm{i}}\right)$, metallicity $Z$, and mixing-length parameter. The PNe chemical abundances (by number, in mole $\mathrm{gr}^{-1}$ ) are calculated by averaging the abundances in the wind ejecta over the last stages (i.e. a time period $\tau_{\mathrm{PN}}=310^{4} \mathrm{yr}$ ) on the AGB, weighted by the masses of the ejecta.

For the sake of simplicity, we do not consider the question on the actual observability of $\mathrm{PNe}$ (which depends on both dynamical and ionisation properties), and the fact that evolutionary timescales of PNe (hence the time $\tau_{\mathrm{PN}}$ ) may largely vary according to the mass of the progenitor star. These points deserve a more complex study, which is currently in progress and presented in a preliminary form by Marigo et al. (1999b).

All data are available in electronic format at the web site address: http://pleiadi.pd.astro.it

Table A1. STELLAR YIELDS EJECTED DURING THE RGB PHASE - INITIAL METALLICITY $Z=0.019$

\begin{tabular}{|c|c|c|c|c|c|c|c|c|c|c|c|c|}
\hline$M_{\mathrm{i}}$ & $\Delta M_{\mathrm{ej}}(\mathrm{RGB})$ & $M_{\mathrm{y}}(\mathrm{H})$ & $M_{\mathrm{y}}\left({ }^{3} \mathrm{He}\right)$ & $M_{\mathrm{y}}\left({ }^{4} \mathrm{He}\right)$ & $M_{\mathrm{y}}\left({ }^{12} \mathrm{C}\right)$ & $M_{\mathrm{y}}\left({ }^{13} \mathrm{C}\right)$ & $M_{\mathrm{y}}\left({ }^{14} \mathrm{~N}\right)$ & $M_{\mathrm{y}}\left({ }^{15} \mathrm{~N}\right)$ & $M_{\mathrm{y}}\left({ }^{16} \mathrm{O}\right)$ & $M_{\mathrm{y}}\left({ }^{17} \mathrm{O}\right)$ & $M_{\mathrm{y}}\left({ }^{18} \mathrm{O}\right)$ & $M_{\mathrm{y}}(\mathrm{CNO})$ \\
\hline 0.837 & $2.870 \mathrm{E}-01$ & $-4.793 \mathrm{E}-03$ & $5.564 \mathrm{E}-04$ & 4.219E-03 & $-3.230 \mathrm{E}-05$ & $1.193 \mathrm{E}-05$ & $2.479 \mathrm{E}-05$ & $-1.507 \mathrm{E}-07$ & $-2.296 \mathrm{E}-08$ & $1.435 \mathrm{E}-09$ & $-3.300 \mathrm{E}-08$ & $4.209 \mathrm{E}-06$ \\
\hline 0.868 & $2.680 \mathrm{E}-01$ & $-4.449 \mathrm{E}-03$ & $4.837 \mathrm{E}-04$ & $3.966 \mathrm{E}-03$ & $-3.767 \mathrm{E}-05$ & $1.159 \mathrm{E}-05$ & $3.118 \mathrm{E}-05$ & $-1.525 \mathrm{E}-07$ & $-2.144 \mathrm{E}-08$ & $1.876 \mathrm{E}-09$ & $-4.422 \mathrm{E}-08$ & $4.892 \mathrm{E}-06$ \\
\hline 0.934 & $2.340 \mathrm{E}-01$ & $-3.884 \mathrm{E}-03$ & $3.629 \mathrm{E}-04$ & $3.533 \mathrm{E}-03$ & $-4.833 \mathrm{E}-05$ & $1.117 \mathrm{E}-05$ & $4.408 \mathrm{E}-05$ & $-1.589 \mathrm{E}-07$ & $-1.872 \mathrm{E}-08$ & 4.914E-09 & $-8.307 \mathrm{E}-08$ & $6.654 \mathrm{E}-06$ \\
\hline 1.082 & $1.820 \mathrm{E}-01$ & $-3.058 \mathrm{E}-03$ & $2.043 \mathrm{E}-04$ & $2.839 \mathrm{E}-03$ & $-6.762 \mathrm{E}-05$ & $1.044 \mathrm{E}-05$ & $6.759 \mathrm{E}-05$ & $-1.694 \mathrm{E}-07$ & $-1.456 \mathrm{E}-08$ & $2.239 \mathrm{E}-08$ & $-1.775 \mathrm{E}-07$ & $1.007 \mathrm{E}-05$ \\
\hline 1.163 & $1.630 \mathrm{E}-01$ & $-2.510 \mathrm{E}-03$ & $1.584 \mathrm{E}-04$ & $2.331 \mathrm{E}-03$ & $-6.969 \mathrm{E}-05$ & $9.799 \mathrm{E}-06$ & $7.096 \mathrm{E}-05$ & $-1.677 \mathrm{E}-07$ & $-1.304 \mathrm{E}-08$ & $3.928 \mathrm{E}-08$ & $-2.046 \mathrm{E}-07$ & $1.073 \mathrm{E}-05$ \\
\hline 1.248 & $1.480 \mathrm{E}-01$ & $-2.013 \mathrm{E}-03$ & $1.266 \mathrm{E}-04$ & $1.865 \mathrm{E}-03$ & $-6.890 \mathrm{E}-05$ & $9.141 \mathrm{E}-06$ & $7.080 \mathrm{E}-05$ & $-1.632 \mathrm{E}-07$ & $-1.184 \mathrm{E}-08$ & $5.609 \mathrm{E}-08$ & $-2.183 \mathrm{E}-07$ & $1.070 \mathrm{E}-05$ \\
\hline 1.334 & $1.340 \mathrm{E}-01$ & $-1.662 \mathrm{E}-03$ & $1.023 \mathrm{E}-04$ & $1.541 \mathrm{E}-03$ & $-6.949 \mathrm{E}-05$ & $8.411 \mathrm{E}-06$ & $7.214 \mathrm{E}-05$ & $-1.592 \mathrm{E}-07$ & $-1.072 \mathrm{E}-08$ & $8.120 \mathrm{E}-08$ & $-2.392 \mathrm{E}-07$ & $1.074 \mathrm{E}-05$ \\
\hline 1.504 & $1.040 \mathrm{E}-01$ & $-1.373 \mathrm{E}-03$ & $6.238 \mathrm{E}-05$ & $1.300 \mathrm{E}-03$ & $-8.128 \mathrm{E}-05$ & 7.464E-06 & 8.719E-05 & $-1.597 \mathrm{E}-07$ & $-2.163 \mathrm{E}-07$ & $2.251 \mathrm{E}-07$ & $-3.094 \mathrm{E}-07$ & 1.291E-05 \\
\hline 1.588 & $8.800 \mathrm{E}-02$ & $-1.144 \mathrm{E}-03$ & $4.634 \mathrm{E}-05$ & $1.082 \mathrm{E}-03$ & $-7.494 \mathrm{E}-05$ & $6.245 \mathrm{E}-06$ & $8.152 \mathrm{E}-05$ & $-1.425 \mathrm{E}-07$ & $-1.415 \mathrm{E}-06$ & $8.338 \mathrm{E}-07$ & $-2.979 \mathrm{E}-07$ & 1.181E-05 \\
\hline 1.672 & $7.200 \mathrm{E}-02$ & $-9.432 \mathrm{E}-04$ & $3.375 \mathrm{E}-05$ & $9.000 \mathrm{E}-04$ & $-6.412 \mathrm{E}-05$ & $5.095 \mathrm{E}-06$ & 7.174E-05 & $-1.201 \mathrm{E}-07$ & $-3.822 \mathrm{E}-06$ & $1.441 \mathrm{E}-06$ & $-2.596 \mathrm{E}-07$ & $9.953 \mathrm{E}-06$ \\
\hline 1.756 & $5.600 \mathrm{E}-02$ & $-7.728 \mathrm{E}-04$ & $2.339 \mathrm{E}-05$ & $7.448 \mathrm{E}-04$ & $-5.138 \mathrm{E}-05$ & $3.924 \mathrm{E}-06$ & $5.960 \mathrm{E}-05$ & $-9.514 \mathrm{E}-08$ & $-5.716 \mathrm{E}-06$ & $1.663 \mathrm{E}-06$ & $-2.125 \mathrm{E}-07$ & $7.784 \mathrm{E}-06$ \\
\hline 1.839 & $3.900 \mathrm{E}-02$ & $-5.850 \mathrm{E}-04$ & $1.562 \mathrm{E}-05$ & $5.655 \mathrm{E}-04$ & $-3.664 \mathrm{E}-05$ & $2.713 \mathrm{E}-06$ & $4.428 \mathrm{E}-05$ & $-6.724 \mathrm{E}-08$ & $-6.243 \mathrm{E}-06$ & $1.465 \mathrm{E}-06$ & $-1.542 \mathrm{E}-07$ & $5.350 \mathrm{E}-06$ \\
\hline 1.923 & $2.300 \mathrm{E}-02$ & $-3.703 \mathrm{E}-04$ & $8.507 \mathrm{E}-06$ & $3.634 \mathrm{E}-04$ & $-2.200 \mathrm{E}-05$ & $1.607 \mathrm{E}-06$ & $2.761 \mathrm{E}-05$ & $-4.018 \mathrm{E}-08$ & $-5.039 \mathrm{E}-06$ & $1.038 \mathrm{E}-06$ & $-9.373 \mathrm{E}-08$ & $3.080 \mathrm{E}-06$ \\
\hline
\end{tabular}

Table A2. STELLAR YIELDS EJECTED DURING THE RGB PHASE - INITIAL METALLICITY $Z=0.008$

\begin{tabular}{|c|c|c|c|c|c|c|c|c|c|c|c|c|}
\hline$M_{\mathrm{i}}$ & $\Delta M_{\mathrm{ej}}(\mathrm{RGB})$ & $M_{\mathrm{y}}(\mathrm{H})$ & $M_{\mathrm{y}}\left({ }^{3} \mathrm{He}\right)$ & $M_{\mathrm{y}}\left({ }^{4} \mathrm{He}\right)$ & $M_{\mathrm{y}}\left({ }^{12} \mathrm{C}\right)$ & $M_{\mathrm{y}}\left({ }^{13} \mathrm{C}\right)$ & $M_{\mathrm{y}}\left({ }^{14} \mathrm{~N}\right)$ & $M_{\mathrm{y}}\left({ }^{15} \mathrm{~N}\right)$ & $M_{\mathrm{y}}\left({ }^{16} \mathrm{O}\right)$ & $M_{\mathrm{y}}\left({ }^{17} \mathrm{O}\right)$ & $M_{\mathrm{y}}\left({ }^{18} \mathrm{O}\right)$ & $M_{\mathrm{y}}(\mathrm{CNO})$ \\
\hline 0.817 & $2.670 \mathrm{E}-01$ & $-4.325 \mathrm{E}-03$ & $5.271 \mathrm{E}-04$ & 3.791E-03 & $-1.142 \mathrm{E}-05$ & $4.627 \mathrm{E}-06$ & $8.131 \mathrm{E}-06$ & $-5.794 \mathrm{E}-08$ & $-1.175 \mathrm{E}-09$ & $5.340 \mathrm{E}-10$ & $-1.121 \mathrm{E}-08$ & $1.268 \mathrm{E}-06$ \\
\hline 0.850 & $2.500 \mathrm{E}-01$ & $-4.075 \mathrm{E}-03$ & $4.566 \mathrm{E}-04$ & 3.625E-03 & $-1.444 \mathrm{E}-05$ & $4.553 \mathrm{E}-06$ & $1.176 \mathrm{E}-05$ & $-6.050 \mathrm{E}-08$ & $-1.100 \mathrm{E}-09$ & $7.500 \mathrm{E}-10$ & $-1.825 \mathrm{E}-08$ & $1.794 \mathrm{E}-06$ \\
\hline 0.918 & $2.180 \mathrm{E}-01$ & $-3.597 \mathrm{E}-03$ & $3.423 \mathrm{E}-04$ & $3.248 \mathrm{E}-03$ & $-1.891 \mathrm{E}-05$ & $4.382 \mathrm{E}-06$ & $1.739 \mathrm{E}-05$ & $-6.300 \mathrm{E}-08$ & $-9.592 \mathrm{E}-08$ & $1.744 \mathrm{E}-09$ & $-3.183 \mathrm{E}-08$ & $2.673 \mathrm{E}-06$ \\
\hline 0.992 & $1.920 \mathrm{E}-01$ & $-3.130 \mathrm{E}-03$ & $2.592 \mathrm{E}-04$ & $2.880 \mathrm{E}-03$ & $-2.242 \mathrm{E}-05$ & $4.314 \mathrm{E}-06$ & $2.148 \mathrm{E}-05$ & $-6.490 \mathrm{E}-08$ & $-8.448 \mathrm{E}-08$ & 3.840E-09 & $-4.896 \mathrm{E}-08$ & $3.180 \mathrm{E}-06$ \\
\hline 1.071 & $1.710 \mathrm{E}-01$ & $-2.753 \mathrm{E}-03$ & $1.981 \mathrm{E}-04$ & $2.548 \mathrm{E}-03$ & $-2.612 \mathrm{E}-05$ & $4.056 \mathrm{E}-06$ & $2.612 \mathrm{E}-05$ & $-6.703 \mathrm{E}-08$ & $-7.524 \mathrm{E}-08$ & $9.234 \mathrm{E}-09$ & $-6.857 \mathrm{E}-08$ & $3.854 \mathrm{E}-06$ \\
\hline 1.154 & $1.540 \mathrm{E}-01$ & $-2.387 \mathrm{E}-03$ & $1.542 \mathrm{E}-04$ & $2.233 \mathrm{E}-03$ & $-2.861 \mathrm{E}-05$ & $3.753 \mathrm{E}-06$ & $2.936 \mathrm{E}-05$ & $-6.730 \mathrm{E}-08$ & $-6.776 \mathrm{E}-08$ & $1.894 \mathrm{E}-08$ & $-8.686 \mathrm{E}-08$ & 4.302E-06 \\
\hline 1.239 & $1.390 \mathrm{E}-01$ & $-2.029 \mathrm{E}-03$ & $1.206 \mathrm{E}-04$ & $1.904 \mathrm{E}-03$ & $-2.971 \mathrm{E}-05$ & $3.550 \mathrm{E}-06$ & 3.093E-05 & $-6.686 \mathrm{E}-08$ & $-7.784 \mathrm{E}-08$ & $3.350 \mathrm{E}-08$ & $-9.966 \mathrm{E}-08$ & $4.561 \mathrm{E}-06$ \\
\hline 1.315 & $1.150 \mathrm{E}-01$ & $-1.576 \mathrm{E}-03$ & $8.802 \mathrm{E}-05$ & $1.484 \mathrm{E}-03$ & $-2.734 \mathrm{E}-05$ & $3.136 \mathrm{E}-06$ & $2.865 \mathrm{E}-05$ & $-6.015 \mathrm{E}-08$ & $-6.440 \mathrm{E}-08$ & $4.623 \mathrm{E}-08$ & $-9.648 \mathrm{E}-08$ & 4.271E-06 \\
\hline 1.407 & $1.070 \mathrm{E}-01$ & $-1.423 \mathrm{E}-03$ & 7.076E-05 & $1.338 \mathrm{E}-03$ & $-3.004 \mathrm{E}-05$ & 3.073E-06 & $3.175 \mathrm{E}-05$ & $-6.260 \mathrm{E}-08$ & $-5.992 \mathrm{E}-08$ & $8.068 \mathrm{E}-08$ & $-1.107 \mathrm{E}-07$ & 4.632E-06 \\
\hline 1.499 & $9.900 \mathrm{E}-02$ & $-1.534 \mathrm{E}-03$ & $5.908 \mathrm{E}-05$ & $1.465 \mathrm{E}-03$ & $-3.611 \mathrm{E}-05$ & $2.932 \mathrm{E}-06$ & $3.909 \mathrm{E}-05$ & $-6.762 \mathrm{E}-08$ & $-1.544 \mathrm{E}-07$ & $1.574 \mathrm{E}-07$ & $-1.459 \mathrm{E}-07$ & $5.701 \mathrm{E}-06$ \\
\hline 1.583 & $8.300 \mathrm{E}-02$ & $-1.262 \mathrm{E}-03$ & $4.398 \mathrm{E}-05$ & 1.203E-03 & $-3.203 \mathrm{E}-05$ & $2.448 \mathrm{E}-06$ & $3.540 \mathrm{E}-05$ & $-5.897 \mathrm{E}-08$ & $-1.042 \mathrm{E}-06$ & $4.274 \mathrm{E}-07$ & $-1.343 \mathrm{E}-07$ & $5.009 \mathrm{E}-06$ \\
\hline 1.667 & $6.700 \mathrm{E}-02$ & $-1.012 \mathrm{E}-03$ & $3.172 \mathrm{E}-05$ & $9.782 \mathrm{E}-04$ & $-2.692 \mathrm{E}-05$ & $1.986 \mathrm{E}-06$ & $3.087 \mathrm{E}-05$ & $-4.892 \mathrm{E}-08$ & $-2.249 \mathrm{E}-06$ & $5.956 \mathrm{E}-07$ & $-1.148 \mathrm{E}-07$ & $4.115 \mathrm{E}-06$ \\
\hline 1.750 & $5.000 \mathrm{E}-02$ & $-7.850 \mathrm{E}-04$ & $2.134 \mathrm{E}-05$ & $7.650 \mathrm{E}-04$ & $-2.059 \mathrm{E}-05$ & $1.473 \mathrm{E}-06$ & $2.494 \mathrm{E}-05$ & $-3.709 \mathrm{E}-08$ & $-3.278 \mathrm{E}-06$ & $5.330 \mathrm{E}-07$ & $-8.850 \mathrm{E}-08$ & $2.952 \mathrm{E}-06$ \\
\hline 1.832 & $3.200 \mathrm{E}-02$ & $-5.248 \mathrm{E}-04$ & $1.230 \mathrm{E}-05$ & $5.184 \mathrm{E}-04$ & $-1.349 \mathrm{E}-05$ & $9.312 \mathrm{E}-07$ & $1.715 \mathrm{E}-05$ & $-2.406 \mathrm{E}-08$ & $-3.058 \mathrm{E}-06$ & $4.115 \mathrm{E}-07$ & $-5.859 \mathrm{E}-08$ & $1.863 \mathrm{E}-06$ \\
\hline
\end{tabular}


Table A3. STELLAR YIELDS EJECTED DURING THE RGB PHASE - INITIAL METALLICITY $Z=0.004$

\begin{tabular}{|c|c|c|c|c|c|c|c|c|c|c|c|c|}
\hline$M_{\mathrm{i}}$ & $\Delta M_{\mathrm{ej}}(\mathrm{RGB})$ & $M_{\mathrm{y}}(\mathrm{H})$ & $M_{\mathrm{y}}\left({ }^{3} \mathrm{He}\right)$ & $M_{\mathrm{y}}\left({ }^{4} \mathrm{He}\right)$ & $M_{\mathrm{y}}\left({ }^{12} \mathrm{C}\right)$ & $M_{\mathrm{y}}\left({ }^{13} \mathrm{C}\right)$ & $M_{\mathrm{y}}\left({ }^{14} \mathrm{~N}\right)$ & $M_{\mathrm{y}}\left({ }^{15} \mathrm{~N}\right)$ & $M_{\mathrm{y}}\left({ }^{16} \mathrm{O}\right)$ & $M_{\mathrm{y}}\left({ }^{17} \mathrm{O}\right)$ & $M_{\mathrm{y}}\left({ }^{18} \mathrm{O}\right)$ & $M_{\mathrm{y}}(\mathrm{CNO})$ \\
\hline 0.817 & $2.170 \mathrm{E}-01$ & $-3.363 \mathrm{E}-03$ & 4.102E-04 & $2.973 \mathrm{E}-03$ & $-4.878 \mathrm{E}-06$ & $2.020 \mathrm{E}-06$ & $3.488 \mathrm{E}-06$ & $-2.487 \mathrm{E}-08$ & $-6.076 \mathrm{E}-08$ & $1.953 \mathrm{E}-10$ & $-4.774 \mathrm{E}-09$ & $5.404 \mathrm{E}-07$ \\
\hline 0.888 & $1.880 \mathrm{E}-01$ & $-2.989 \mathrm{E}-03$ & $3.009 \mathrm{E}-04$ & $2.688 \mathrm{E}-03$ & $-7.479 \mathrm{E}-06$ & $1.929 \mathrm{E}-06$ & $6.632 \mathrm{E}-06$ & $-2.662 \mathrm{E}-08$ & $-5.264 \mathrm{E}-08$ & $5.264 \mathrm{E}-10$ & $-1.109 \mathrm{E}-08$ & $9.923 \mathrm{E}-07$ \\
\hline 0.966 & $1.660 \mathrm{E}-01$ & $-2.822 \mathrm{E}-03$ & $2.227 \mathrm{E}-04$ & $2.606 \mathrm{E}-03$ & $-1.065 \mathrm{E}-05$ & $1.914 \mathrm{E}-06$ & $1.029 \mathrm{E}-05$ & $-2.946 \mathrm{E}-08$ & $-4.648 \mathrm{E}-08$ & $2.058 \mathrm{E}-09$ & $-2.357 \mathrm{E}-08$ & $1.451 \mathrm{E}-06$ \\
\hline 1.046 & $1.460 \mathrm{E}-01$ & $-2.526 \mathrm{E}-03$ & $1.652 \mathrm{E}-04$ & $2.351 \mathrm{E}-03$ & $-1.226 \mathrm{E}-05$ & $1.819 \mathrm{E}-06$ & $1.236 \mathrm{E}-05$ & $-3.019 \mathrm{E}-08$ & $-4.088 \mathrm{E}-08$ & $5.504 \mathrm{E}-09$ & $-3.402 \mathrm{E}-08$ & $1.821 \mathrm{E}-06$ \\
\hline 1.131 & $1.310 \mathrm{E}-01$ & $-2.161 \mathrm{E}-03$ & $1.272 \mathrm{E}-04$ & $2.044 \mathrm{E}-03$ & $-1.297 \mathrm{E}-05$ & $1.695 \mathrm{E}-06$ & $1.335 \mathrm{E}-05$ & $-3.006 \mathrm{E}-08$ & $-3.668 \mathrm{E}-08$ & $1.047 \mathrm{E}-08$ & $-4.087 \mathrm{E}-08$ & $1.977 \mathrm{E}-06$ \\
\hline 1.218 & $1.180 \mathrm{E}-01$ & $-1.817 \mathrm{E}-03$ & $1.006 \mathrm{E}-04$ & $1.711 \mathrm{E}-03$ & $-1.337 \mathrm{E}-05$ & $1.560 \mathrm{E}-06$ & $1.396 \mathrm{E}-05$ & $-2.957 \mathrm{E}-08$ & $-3.304 \mathrm{E}-08$ & $1.602 \mathrm{E}-08$ & $-4.449 \mathrm{E}-08$ & $2.058 \mathrm{E}-06$ \\
\hline 1.307 & $1.070 \mathrm{E}-01$ & $-1.562 \mathrm{E}-03$ & 8.102E-05 & $1.477 \mathrm{E}-03$ & $-1.380 \mathrm{E}-05$ & $1.450 \mathrm{E}-06$ & $1.459 \mathrm{E}-05$ & $-2.926 \mathrm{E}-08$ & $-2.996 \mathrm{E}-08$ & $2.273 \mathrm{E}-08$ & $-4.911 \mathrm{E}-08$ & $2.156 \mathrm{E}-06$ \\
\hline 1.396 & $9.600 \mathrm{E}-02$ & $-1.344 \mathrm{E}-03$ & $6.533 \mathrm{E}-05$ & $1.286 \mathrm{E}-03$ & $-1.378 \mathrm{E}-05$ & $1.409 \mathrm{E}-06$ & $1.462 \mathrm{E}-05$ & $-2.844 \mathrm{E}-08$ & $-2.688 \mathrm{E}-08$ & $3.782 \mathrm{E}-08$ & $-5.088 \mathrm{E}-08$ & $2.176 \mathrm{E}-06$ \\
\hline 1.481 & $8.100 \mathrm{E}-02$ & $-1.288 \mathrm{E}-03$ & $4.786 \mathrm{E}-05$ & $1.239 \mathrm{E}-03$ & $-1.476 \mathrm{E}-05$ & $1.192 \mathrm{E}-06$ & $1.592 \mathrm{E}-05$ & $-2.764 \mathrm{E}-08$ & $-1.037 \mathrm{E}-07$ & 7.347E-08 & $-6.018 \mathrm{E}-08$ & $2.240 \mathrm{E}-06$ \\
\hline 1.564 & $6.400 \mathrm{E}-02$ & $-9.984 \mathrm{E}-04$ & $3.355 \mathrm{E}-05$ & $9.600 \mathrm{E}-04$ & $-1.270 \mathrm{E}-05$ & $9.382 \mathrm{E}-07$ & $1.391 \mathrm{E}-05$ & $-2.309 \mathrm{E}-08$ & $-2.099 \mathrm{E}-07$ & $1.487 \mathrm{E}-07$ & $-5.376 \mathrm{E}-08$ & $2.016 \mathrm{E}-06$ \\
\hline 1.647 & $4.700 \mathrm{E}-02$ & $-7.191 \mathrm{E}-04$ & $2.200 \mathrm{E}-05$ & $6.956 \mathrm{E}-04$ & $-9.794 \mathrm{E}-06$ & $6.867 \mathrm{E}-07$ & $1.111 \mathrm{E}-05$ & $-1.752 \mathrm{E}-08$ & $-5.772 \mathrm{E}-07$ & $1.471 \mathrm{E}-07$ & $-4.221 \mathrm{E}-08$ & $1.517 \mathrm{E}-06$ \\
\hline 1.729 & $2.900 \mathrm{E}-02$ & $-4.495 \mathrm{E}-04$ & $1.214 \mathrm{E}-05$ & $4.379 \mathrm{E}-04$ & $-6.319 \mathrm{E}-06$ & $4.225 \mathrm{E}-07$ & $7.551 \mathrm{E}-06$ & $-1.113 \mathrm{E}-08$ & $-7.621 \mathrm{E}-07$ & $8.085 \mathrm{E}-08$ & $-2.749 \mathrm{E}-08$ & $9.350 \mathrm{E}-07$ \\
\hline
\end{tabular}

Table A4. STELLAR YIELDS EJECTED DURING THE AGB PHASE - INITIAL METALLICITY $Z=0.019$

\begin{tabular}{|c|c|c|c|c|c|c|c|c|c|c|c|c|c|}
\hline$M_{\mathrm{i}}$ & $M_{\mathrm{TP}, 0}$ & $\Delta M_{\mathrm{ej}}(\mathrm{AGB})$ & $M_{\mathrm{y}}(\mathrm{H})$ & $M_{\mathrm{y}}\left({ }^{3} \mathrm{He}\right)$ & $M_{\mathrm{y}}\left({ }^{4} \mathrm{He}\right)$ & $M_{\mathrm{y}}\left({ }^{12} \mathrm{C}\right)$ & $M_{\mathrm{y}}\left({ }^{13} \mathrm{C}\right)$ & $M_{\mathrm{y}}\left({ }^{14} \mathrm{~N}\right)$ & $M_{\mathrm{y}}\left({ }^{15} \mathrm{~N}\right)$ & $M_{\mathrm{y}}\left({ }^{16} \mathrm{O}\right)$ & $M_{\mathrm{y}}\left({ }^{17} \mathrm{O}\right)$ & $M_{\mathrm{y}}\left({ }^{18} \mathrm{O}\right)$ & $M_{\mathrm{y}}(\mathrm{CNO})$ \\
\hline 0.837 & 0.55 & $9.437 \mathrm{E}-03$ & $-1.274 \mathrm{E}-04$ & $3.410 \mathrm{E}-05$ & $9.343 \mathrm{E}-05$ & $-1.467 \mathrm{E}-08$ & $1.949 \mathrm{E}-08$ & $3.407 \mathrm{E}-09$ & $-4.813 \mathrm{E}-10$ & $-7.550 \mathrm{E}-10$ & $0.000 \mathrm{E}+00$ & $-4.719 \mathrm{E}-11$ & $7.031 \mathrm{E}-09$ \\
\hline 0.868 & 0.60 & $4.408 \mathrm{E}-02$ & $-5.951 \mathrm{E}-04$ & $1.607 \mathrm{E}-04$ & 4.364E-04 & $-6.854 \mathrm{E}-08$ & $9.323 \mathrm{E}-08$ & $1.591 \mathrm{E}-08$ & $-2.380 \mathrm{E}-09$ & $-3.526 \mathrm{E}-09$ & $2.647 \mathrm{E}-23$ & $-2.204 \mathrm{E}-10$ & $3.491 \mathrm{E}-08$ \\
\hline 0.934 & 0.70 & $1.647 \mathrm{E}-01$ & $-2.800 \mathrm{E}-03$ & 4.407E-04 & $2.355 \mathrm{E}-03$ & $-3.550 \mathrm{E}-06$ & $3.232 \mathrm{E}-06$ & $7.182 \mathrm{E}-07$ & $-5.155 \mathrm{E}-08$ & $-1.317 \mathrm{E}-08$ & $1.059 \mathrm{E}-22$ & $-8.234 \mathrm{E}-10$ & $3.348 \mathrm{E}-07$ \\
\hline 1.005 & 0.80 & $2.550 \mathrm{E}-01$ & $-4.284 \mathrm{E}-03$ & $5.339 \mathrm{E}-04$ & $3.799 \mathrm{E}-03$ & $-1.978 \mathrm{E}-05$ & $1.011 \mathrm{E}-05$ & $1.259 \mathrm{E}-05$ & $-1.214 \mathrm{E}-07$ & $-2.040 \mathrm{E}-08$ & $5.100 \mathrm{E}-10$ & $-1.402 \mathrm{E}-08$ & $2.770 \mathrm{E}-06$ \\
\hline 1.082 & 0.90 & $3.548 \mathrm{E}-01$ & $-5.854 \mathrm{E}-03$ & $5.881 \mathrm{E}-04$ & $5.286 \mathrm{E}-03$ & $-5.944 \mathrm{E}-05$ & $1.604 \mathrm{E}-05$ & $5.228 \mathrm{E}-05$ & $-2.214 \mathrm{E}-07$ & $-2.838 \mathrm{E}-08$ & 3.193E-09 & $-7.982 \mathrm{E}-08$ & $8.550 \mathrm{E}-06$ \\
\hline 1.163 & 1.00 & $4.428 \mathrm{E}-01$ & $-7.440 \mathrm{E}-03$ & $4.746 \mathrm{E}-04$ & $6.997 \mathrm{E}-03$ & $-1.734 \mathrm{E}-04$ & $2.594 \mathrm{E}-05$ & $1.751 \mathrm{E}-04$ & $-4.296 \mathrm{E}-07$ & $-3.543 \mathrm{E}-08$ & $6.244 \mathrm{E}-08$ & $-4.628 \mathrm{E}-07$ & $2.676 \mathrm{E}-05$ \\
\hline 1.248 & 1.10 & $5.395 \mathrm{E}-01$ & $-9.063 \mathrm{E}-03$ & $5.782 \mathrm{E}-04$ & $8.524 \mathrm{E}-03$ & $-2.112 \mathrm{E}-04$ & $3.163 \mathrm{E}-05$ & $2.133 \mathrm{E}-04$ & $-5.233 \mathrm{E}-07$ & $-4.316 \mathrm{E}-08$ & $7.607 \mathrm{E}-08$ & $-5.691 \mathrm{E}-07$ & $3.262 \mathrm{E}-05$ \\
\hline 1.334 & 1.20 & $6.320 \mathrm{E}-01$ & $-7.900 \mathrm{E}-03$ & $5.000 \mathrm{E}-04$ & $7.458 \mathrm{E}-03$ & $-3.062 \mathrm{E}-04$ & $3.967 \mathrm{E}-05$ & $3.162 \mathrm{E}-04$ & $-7.262 \mathrm{E}-07$ & $-5.056 \mathrm{E}-08$ & $2.939 \mathrm{E}-07$ & $-1.008 \mathrm{E}-06$ & $4.817 \mathrm{E}-05$ \\
\hline 1.420 & 1.30 & $7.152 \mathrm{E}-01$ & $-8.940 \mathrm{E}-03$ & $5.650 \mathrm{E}-04$ & $8.439 \mathrm{E}-03$ & $-3.465 \mathrm{E}-04$ & 4. $496 \mathrm{E}-05$ & $3.578 \mathrm{E}-04$ & $-8.246 \mathrm{E}-07$ & $-5.721 \mathrm{E}-08$ & $3.326 \mathrm{E}-07$ & $-1.141 \mathrm{E}-06$ & $5.457 \mathrm{E}-05$ \\
\hline 1.588 & 1.50 & $9.197 \mathrm{E}-01$ & $-2.946 \mathrm{E}-02$ & $5.368 \mathrm{E}-04$ & $2.343 \mathrm{E}-02$ & $4.718 \mathrm{E}-03$ & $6.350 \mathrm{E}-05$ & $7.216 \mathrm{E}-04$ & $-1.476 \mathrm{E}-06$ & $2.699 \mathrm{E}-04$ & $1.626 \mathrm{E}-06$ & $-3.157 \mathrm{E}-06$ & $5.770 \mathrm{E}-03$ \\
\hline 1.672 & 1.60 & $1.008 \mathrm{E}+00$ & $-3.768 \mathrm{E}-02$ & $4.369 \mathrm{E}-04$ & $2.935 \mathrm{E}-02$ & $6.700 \mathrm{E}-03$ & $6.754 \mathrm{E}-05$ & $9.547 \mathrm{E}-04$ & $-1.779 \mathrm{E}-06$ & $3.140 \mathrm{E}-04$ & $2.387 \mathrm{E}-05$ & $-4.288 \mathrm{E}-06$ & $8.054 \mathrm{E}-03$ \\
\hline 1.756 & 1.70 & $1.105 \mathrm{E}+00$ & $-4.660 \mathrm{E}-02$ & $4.761 \mathrm{E}-04$ & $3.601 \mathrm{E}-02$ & $9.064 \mathrm{E}-03$ & $7.316 \mathrm{E}-05$ & $1.031 \mathrm{E}-03$ & $-1.965 \mathrm{E}-06$ & $4.308 \mathrm{E}-04$ & $2.595 \mathrm{E}-05$ & $-4.838 \mathrm{E}-06$ & $1.062 \mathrm{E}-02$ \\
\hline 1.839 & 1.80 & $1.185 \mathrm{E}+00$ & $-5.631 \mathrm{E}-02$ & $4.414 \mathrm{E}-04$ & $4.329 \mathrm{E}-02$ & $1.126 \mathrm{E}-02$ & $7.619 \mathrm{E}-05$ & $1.184 \mathrm{E}-03$ & $-2.158 \mathrm{E}-06$ & $4.711 \mathrm{E}-04$ & $3.836 \mathrm{E}-05$ & $-5.570 \mathrm{E}-06$ & $1.302 \mathrm{E}-02$ \\
\hline 1.923 & 1.90 & $1.284 \mathrm{E}+00$ & $-6.698 \mathrm{E}-02$ & $4.996 \mathrm{E}-04$ & $5.187 \mathrm{E}-02$ & $1.345 \mathrm{E}-02$ & $8.183 \mathrm{E}-05$ & $1.377 \mathrm{E}-03$ & $-2.385 \mathrm{E}-06$ & $4.807 \mathrm{E}-04$ & $5.231 \mathrm{E}-05$ & $-6.316 \mathrm{E}-06$ & $1.543 \mathrm{E}-02$ \\
\hline
\end{tabular}

Table A5. STELLAR YIELDS EJECTED DURING THE AGB PHASE - INITIAL METALLICITY $Z=0.008$

\begin{tabular}{|c|c|c|c|c|c|c|c|c|c|c|c|c|c|}
\hline$M_{\mathrm{i}}$ & $M_{\mathrm{TP}, 0}$ & $\Delta M_{\mathrm{ej}}(\mathrm{AGB})$ & $M_{\mathrm{y}}(\mathrm{H})$ & $M_{\mathrm{y}}\left({ }^{3} \mathrm{He}\right)$ & $M_{\mathrm{y}}\left({ }^{4} \mathrm{He}\right)$ & $M_{\mathrm{y}}\left({ }^{12} \mathrm{C}\right)$ & $M_{\mathrm{y}}\left({ }^{13} \mathrm{C}\right)$ & $M_{\mathrm{y}}\left({ }^{14} \mathrm{~N}\right)$ & $M_{\mathrm{y}}\left({ }^{15} \mathrm{~N}\right)$ & $M_{\mathrm{y}}\left({ }^{16} \mathrm{O}\right)$ & $M_{\mathrm{y}}\left({ }^{17} \mathrm{O}\right)$ & $M_{\mathrm{y}}\left({ }^{18} \mathrm{O}\right)$ & $M_{\mathrm{y}}(\mathrm{CNO})$ \\
\hline 0.850 & 0.6 & $2.877 \mathrm{E}-02$ & $-4.575 \mathrm{E}-04$ & $6.851 \mathrm{E}-05$ & $3.913 \mathrm{E}-04$ & $-3.959 \mathrm{E}-07$ & $3.576 \mathrm{E}-07$ & $9.356 \mathrm{E}-08$ & $-6.099 \mathrm{E}-09$ & $-1.611 \mathrm{E}-08$ & $0.000 \mathrm{E}+00$ & $-2.302 \mathrm{E}-10$ & $3.286 \mathrm{E}-08$ \\
\hline 0.918 & 0 & & $.937 \mathrm{E}-03$ & $50 \mathrm{E}-04$ & $545 \mathrm{E}-03$ & $676 \mathrm{E}-06$ & $412 \mathrm{E}-06$ & $71 \mathrm{E}-07$ & $-2.229 \mathrm{E}-08$ & $822 \mathrm{E}-08$ & $2.647 \mathrm{E}-23$ & -10 & \\
\hline 0.992 & 0.8 & $2.343 \mathrm{E}-01$ & $-3.772 \mathrm{E}-03$ & $4.597 \mathrm{E}-04$ & $3.327 \mathrm{E}-03$ & $-8.846 \mathrm{E}-06$ & $4.561 \mathrm{E}-06$ & $5.564 \mathrm{E}-06$ & $-5.693 \mathrm{E}-08$ & $-1.312 \mathrm{E}-07$ & $2.343 \mathrm{E}-10$ & -09 & $1.085 \mathrm{E}-06$ \\
\hline 1.071 & 0.9 & $3.276 \mathrm{E}-01$ & $-5.438 \mathrm{E}-03$ & $5.167 \mathrm{E}-04$ & $4.914 \mathrm{E}-03$ & $-2.711 \mathrm{E}-05$ & $7.106 \mathrm{E}-06$ & $2.419 \mathrm{E}-05$ & $-9.992 \mathrm{E}-08$ & $-1.835 \mathrm{E}-07$ & $1.966 \mathrm{E}-09$ & & $3.866 \mathrm{E}-06$ \\
\hline 1.154 & 1.0 & & $-6.682 \mathrm{E}-03$ & $5.318 \mathrm{E}-04$ & $6.229 \mathrm{E}-03$ & $-5.064 \mathrm{E}-05$ & $1.015 \mathrm{E}-05$ & $4.849 \mathrm{E}-05$ & & $-2.310 \mathrm{E}-07$ & & & \\
\hline 1.239 & 1.1 & 01 & 03 & & & -8 & & & & -07 & & & \\
\hline 1.315 & 1.2 & $84 \mathrm{E}-01$ & $-2.264 \mathrm{E}-02$ & $4.456 \mathrm{E}-04$ & $1.763 \mathrm{E}-02$ & $4.168 \mathrm{E}-03$ & $1.603 \mathrm{E}-05$ & $328 \mathrm{E}-04$ & $-3.387 \mathrm{E}-07$ & $3.178 \mathrm{E}-04$ & $1.725 \mathrm{E}-07$ & -6.405 & $4.634 \mathrm{E}-03$ \\
\hline 1.407 & 1.3 & $6.901 \mathrm{E}-01$ & $-2.779 \mathrm{E}-02$ & $5.126 \mathrm{E}-04$ & $2.147 \mathrm{E}-02$ & $5.320 \mathrm{E}-03$ & $1.837 \mathrm{E}-05$ & $1.518 \mathrm{E}-04$ & $-3.932 \mathrm{E}-07$ & $4.042 \mathrm{E}-04$ & $1.941 \mathrm{E}-07$ & $-7.568 \mathrm{E}-07$ & $5.894 \mathrm{E}-03$ \\
\hline 1.499 & 1.4 & $7.905 \mathrm{E}-01$ & $-4.138 \mathrm{E}-02$ & $4.393 \mathrm{E}-04$ & $3.157 \mathrm{E}-02$ & $8.468 \mathrm{E}-03$ & $2.230 \mathrm{E}-05$ & $2.827 \mathrm{E}-04$ & $-5.898 \mathrm{E}-07$ & $6.445 \mathrm{E}-04$ & $1.141 \mathrm{E}-06$ & $-1.459 \mathrm{E}-06$ & $9.416 \mathrm{E}-03$ \\
\hline 1.667 & 1.6 & & & & & & & & & & & & \\
\hline 1.750 & 1.7 & & & & & & & & & & & & $2.168 \mathrm{E}-02$ \\
\hline 1.832 & 1.8 & $1.145 \mathrm{E}+00$ & $-9.844 \mathrm{E}-02$ & $4.119 \mathrm{E}-04$ & $7.249 \mathrm{E}-02$ & $2.363 \mathrm{E}-02$ & $2.842 \mathrm{E}-05$ & $4.948 \mathrm{E}-04$ & $-9.588 \mathrm{E}-07$ & $1.681 \mathrm{E}-03$ & $1.107 \mathrm{E}-05$ & $-2.816 \mathrm{E}-06$ & $2.584 \mathrm{E}-02$ \\
\hline
\end{tabular}

Table A6. STELLAR YIELDS EJECTED DURING THE AGB PHASE - INITIAL METALLICITY $Z=0.004$

\begin{tabular}{|c|c|c|c|c|c|c|c|c|c|c|c|c|c|}
\hline$M_{\mathrm{i}}$ & $M_{\mathrm{TP}, 0}$ & $\Delta M_{\mathrm{ej}}(\mathrm{AGB})$ & $M_{\mathrm{y}}(\mathrm{H})$ & $M_{\mathrm{y}}\left({ }^{3} \mathrm{He}\right)$ & $M_{\mathrm{y}}\left({ }^{4} \mathrm{He}\right)$ & $M_{\mathrm{y}}\left({ }^{12} \mathrm{C}\right)$ & $M_{\mathrm{y}}\left({ }^{13} \mathrm{C}\right)$ & $M_{\mathrm{y}}\left({ }^{14} \mathrm{~N}\right)$ & $M_{\mathrm{y}}\left({ }^{15} \mathrm{~N}\right)$ & $M_{\mathrm{y}}\left({ }^{16} \mathrm{O}\right)$ & $M_{\mathrm{y}}\left({ }^{17} \mathrm{O}\right)$ & $M_{\mathrm{y}}\left({ }^{18} \mathrm{O}\right)$ & $M_{\mathrm{y}}(\mathrm{CNO})$ \\
\hline 0.817 & 0.6 & $1.438 \mathrm{E}-02$ & $-1.496 \mathrm{E}-04$ & $4.183 \mathrm{E}-05$ & $1.079 \mathrm{E}-04$ & $-9.607 \mathrm{E}-08$ & $6.961 \mathrm{E}-08$ & $3.561 \mathrm{E}-08$ & $-1.050 \mathrm{E}-09$ & $-4.027 \mathrm{E}-09$ & $5.753 \mathrm{E}-12$ & $-7.191 \mathrm{E}-11$ & $4.004 \mathrm{E}-09$ \\
\hline 0.888 & 0 & & & $1.830 \mathrm{E}-04$ & $1.378 \mathrm{E}-03$ & $-2.211 \mathrm{E}-06$ & $1.147 \mathrm{E}-06$ & $1.356 \mathrm{E}-06$ & $-1.403 \mathrm{E}-08$ & $-2.817 \mathrm{E}-08$ & $5.030 \mathrm{E}-11$ & $-1.710 \mathrm{E}-09$ & $2.475 \mathrm{E}-07$ \\
\hline 0.966 & 0.8 & $1.967 \mathrm{E}-01$ & $.030 \mathrm{E}-03$ & $656 \mathrm{E}-04$ & $2.695 \mathrm{E}-03$ & $-4.344 \mathrm{E}-06$ & $180 \mathrm{E}-06$ & $749 \mathrm{E}-06$ & $-2.618 \mathrm{E}-08$ & $-5.508 \mathrm{E}-08$ & $377 \mathrm{E}-10$ & $-3.344 \mathrm{E}-09$ & $10 \mathrm{E}-07$ \\
\hline 1.046 & & & & & & $80 \mathrm{E}-05$ & & $9 \mathrm{E}-05$ & E-08 & & & & -06 \\
\hline 1.131 & 1.0 & $3.688 \mathrm{E}-$ & $-6.491 \mathrm{E}$ & & & $-2.868 \mathrm{E}-05$ & $4.890 \mathrm{E}$ & & & & -09 & & -06 \\
\hline 1.218 & 1.1 & $4.654 \mathrm{E}-01$ & $-2.084 \mathrm{E}-02$ & $3.784 \mathrm{E}-04$ & $1.619 \mathrm{E}-02$ & $3.982 \mathrm{E}-03$ & $6.172 \mathrm{E}-06$ & $4.877 \mathrm{E}-05$ & $-1.312 \mathrm{E}-07$ & & $4.046 \mathrm{E}-08$ & $-2.429 \mathrm{E}-07$ & $4.370 \mathrm{E}-03$ \\
\hline 1.307 & 1.2 & & & & & & & & & & & $-5.248 \mathrm{E}-07$ & $1.886 \mathrm{E}-02$ \\
\hline 1.396 & & & & & & & & & & & & & \\
\hline 1.481 & 1.4 & $552 \mathrm{E}-01$ & -01 & $69 \mathrm{E}-04$ & 7.940 & $2.993 \mathrm{E}-02$ & $26 \mathrm{E}-06$ & $20 \mathrm{E}-05$ & E-07 & 2.47 & $1.423 \mathrm{E}-07$ & $-9.264 \mathrm{E}-07$ & $3.248 \mathrm{E}-02$ \\
\hline 1.564 & 1.5 & $.394 \mathrm{E}-01$ & E-01 & & $9.839 \mathrm{E}-02$ & E-02 & -06 & E-04 & E-07 & & $7 \mathrm{E}-07$ & $264 \mathrm{E}-06$ & $4.010 \mathrm{E}-02$ \\
\hline 1.647 & 1.6 & $9.225 \mathrm{E}-01$ & $-1.663 \mathrm{E}-01$ & $3.029 \mathrm{E}-04$ & $1.176 \mathrm{E}-01$ & $4.490 \mathrm{E}-02$ & $9.075 \mathrm{E}-06$ & $1.376 \mathrm{E}-04$ & $-4.480 \mathrm{E}-07$ & $3.699 \mathrm{E}-03$ & $1.922 \mathrm{E}-06$ & $-1.560 \mathrm{E}-06$ & $4.875 \mathrm{E}-02$ \\
\hline 1.729 & 1.7 & $1.004 \mathrm{E}+00$ & $-1.925 \mathrm{E}-01$ & $3.226 \mathrm{E}-04$ & $1.357 \mathrm{E}-01$ & $5.226 \mathrm{E}-02$ & $9.522 \mathrm{E}-06$ & $1.426 \mathrm{E}-04$ & $-4.946 \mathrm{E}-07$ & $4.304 \mathrm{E}-03$ & $2.034 \mathrm{E}-06$ & $-1.749 \mathrm{E}-06$ & $5.672 \mathrm{E}-02$ \\
\hline
\end{tabular}


Table A7. TOTAL STELLAR YIELDS - MIXING-LENGTH PARAMETER $\alpha=1.68$ - INITIAL METALLICITY $Z=0.019$

\begin{tabular}{|c|c|c|c|c|c|c|c|c|c|c|c|c|}
\hline$M_{\mathrm{i}}$ & $\Delta M_{\mathrm{ej}}$ & $M_{\mathrm{y}}(\mathrm{H})$ & $M_{\mathrm{y}}\left({ }^{3} \mathrm{He}\right)$ & $M_{\mathrm{y}}\left({ }^{4} \mathrm{He}\right)$ & $M_{\mathrm{y}}\left({ }^{12} \mathrm{C}\right)$ & $M_{\mathrm{y}}\left({ }^{13} \mathrm{C}\right)$ & $M_{\mathrm{y}}\left({ }^{14} \mathrm{~N}\right)$ & $M_{\mathrm{y}}\left({ }^{15} \mathrm{~N}\right)$ & $M_{\mathrm{y}}\left({ }^{16} \mathrm{O}\right)$ & $M_{\mathrm{y}}\left({ }^{17} \mathrm{O}\right)$ & $M_{\mathrm{y}}\left({ }^{18} \mathrm{O}\right)$ & $M_{\mathrm{y}}(\mathrm{CNO})$ \\
\hline 0.837 & $2.964 \mathrm{E}-01$ & $-4.920 \mathrm{E}-03$ & $5.905 \mathrm{E}-04$ & $4.312 \mathrm{E}-03$ & $-3.231 \mathrm{E}-05$ & $1.195 \mathrm{E}-05$ & $2.479 \mathrm{E}-05$ & $-1.512 \mathrm{E}-07$ & & $1.435 \mathrm{E}-09$ & & $4.216 \mathrm{E}-06$ \\
\hline 0.868 & $3.121 \mathrm{E}-01$ & $.044 \mathrm{E}-03$ & $6.444 \mathrm{E}-04$ & $4.402 \mathrm{E}-03$ & & & & & & $1.876 \mathrm{E}-09$ & & \\
\hline 0.934 & $3.987 \mathrm{E}-01$ & $.684 \mathrm{E}-03$ & $8.036 \mathrm{E}-04$ & $5.888 \mathrm{E}-03$ & $-5.188 \mathrm{E}-05$ & & & $-2.105 \mathrm{E}-07$ & & $4.914 \mathrm{E}-09$ & & \\
\hline 1.005 & $4.600 \mathrm{E}-01$ & $-7.748 \mathrm{E}-03$ & $8.049 \mathrm{E}-04$ & $6.997 \mathrm{E}-03$ & $-7.791 \mathrm{E}-05$ & $2.104 \mathrm{E}-05$ & $6.883 \mathrm{E}-05$ & $-2.866 \mathrm{E}-07$ & & $1.015 \mathrm{E}-08$ & & $1.152 \mathrm{E}-05$ \\
\hline 1.082 & $5.368 \mathrm{E}-01$ & $-8.912 \mathrm{E}-03$ & $7.924 \mathrm{E}-04$ & $8.125 \mathrm{E}-03$ & $-1.271 \mathrm{E}$ & $2.648 \mathrm{E}-05$ & $1.199 \mathrm{E}-04$ & $-3.908 \mathrm{E}-07$ & & $2.558 \mathrm{E}-08$ & $-2.573 \mathrm{E}-07$ & $1.862 \mathrm{E}-05$ \\
\hline 1.163 & $6.058 \mathrm{E}-01$ & $-9.950 \mathrm{E}-03$ & $6.330 \mathrm{E}-04$ & $9.328 \mathrm{E}-03$ & $-2.431 \mathrm{E}-04$ & $3.574 \mathrm{E}-05$ & $2.461 \mathrm{E}-04$ & $-5.973 \mathrm{E}-07$ & $-4.847 \mathrm{E}-08$ & $1.017 \mathrm{E}-07$ & $-6.674 \mathrm{E}-07$ & $3.749 \mathrm{E}-05$ \\
\hline 1.248 & $6.875 \mathrm{E}-01$ & $-1.108 \mathrm{E}-02$ & $7.048 \mathrm{E}-04$ & $1.039 \mathrm{E}-02$ & $-2.801 \mathrm{E}$ & $4.077 \mathrm{E}$ & $2.841 \mathrm{E}$ & $-6.865 \mathrm{E}$ & & $1.322 \mathrm{E}-07$ & & \\
\hline 1.334 & $7.660 \mathrm{E}-01$ & $-9.562 \mathrm{E}-03$ & $6.023 \mathrm{E}-04$ & $8.999 \mathrm{E}-03$ & -3.7 & E-05 & $3.883 \mathrm{E}-04$ & -8.854 & E-08 & E-07 & & Q-05 \\
\hline 1.420 & $8.352 \mathrm{E}-01$ & $-1.043 \mathrm{E}-02$ & $6.470 \mathrm{E}-04$ & $9.831 \mathrm{E}-03$ & $-4.213 \mathrm{E}-04$ & $5.277 \mathrm{E}-05$ & $4.366 \mathrm{E}-04$ & $-9.843 \mathrm{E}-07$ & $8 \mathrm{E}-07$ & $4.622 \mathrm{E}-07$ & $18 \mathrm{E}-06$ & E-05 \\
\hline 1.504 & $9.211 \mathrm{E}-01$ & $-2.083 \mathrm{E}-02$ & $6.249 \mathrm{E}-04$ & $1.721 \mathrm{E}-02$ & 2.4 & E-05 & 5.6 & $-1.249 \mathrm{E}$ & -04 & E-07 & & $E-03$ \\
\hline 1.588 & $1.008 \mathrm{E}+00$ & $-3.060 \mathrm{E}-02$ & $5.831 \mathrm{E}-04$ & $2.451 \mathrm{E}-02$ & $4.643 \mathrm{E}$ & $6.975 \mathrm{E}-05$ & $8.031 \mathrm{E}-04$ & $-1.618 \mathrm{E}-06$ & -04 & E-06 & $55 \mathrm{E}-06$ & E-03 \\
\hline 1.672 & $1.080 \mathrm{E}+00$ & $-3.862 \mathrm{E}-02$ & $4.707 \mathrm{E}-04$ & $3.025 \mathrm{E}-02$ & $6.636 \mathrm{E}-03$ & $7.264 \mathrm{E}-05$ & $1.026 \mathrm{E}-03$ & $-1.899 \mathrm{E}-06$ & E-04 & $2.531 \mathrm{E}-05$ & $-4.548 \mathrm{E}-06$ & $64 \mathrm{E}-03$ \\
\hline 1.756 & $1.161 \mathrm{E}+00$ & $-4.737 \mathrm{E}-02$ & $4.995 \mathrm{E}-04$ & 3.675E-02 & $9.013 \mathrm{E}-03$ & $7.708 \mathrm{E}-05$ & $1.091 \mathrm{E}-03$ & $-2.060 \mathrm{E}-06$ & $4.251 \mathrm{E}-04$ & $2.761 \mathrm{E}-05$ & $-5.051 \mathrm{E}-06$ & $1.063 \mathrm{E}-02$ \\
\hline 1.839 & $1.224 \mathrm{E}+00$ & $-5.690 \mathrm{E}-02$ & $4.570 \mathrm{E}-04$ & $4.386 \mathrm{E}-02$ & $1.122 \mathrm{E}-02$ & $7.890 \mathrm{E}-05$ & $1.228 \mathrm{E}-03$ & $-2.225 \mathrm{E}-06$ & $4.649 \mathrm{E}-04$ & 3.983E-05 & $-5.724 \mathrm{E}-06$ & $1.303 \mathrm{E}-02$ \\
\hline 1.923 & $1.307 \mathrm{E}+00$ & $-6.735 \mathrm{E}-02$ & $5.081 \mathrm{E}-04$ & $5.223 \mathrm{E}-02$ & $1.343 \mathrm{E}-02$ & $8.344 \mathrm{E}-05$ & $1.405 \mathrm{E}-03$ & $-2.425 \mathrm{E}-06$ & $4.757 \mathrm{E}-04$ & $5.335 \mathrm{E}-05$ & $-6.410 \mathrm{E}-06$ & $1.543 \mathrm{E}-02$ \\
\hline 2.000 & $1.373 \mathrm{E}+00$ & $-7.811 \mathrm{E}-02$ & $3.968 \mathrm{E}-04$ & $6.002 \mathrm{E}-02$ & $1.600 \mathrm{E}-02$ & $8.822 \mathrm{E}-05$ & $1.533 \mathrm{E}-03$ & $-2.602 \mathrm{E}-06$ & $5.288 \mathrm{E}-04$ & $5.884 \mathrm{E}-05$ & $-7.019 \mathrm{E}-06$ & $1.820 \mathrm{E}-02$ \\
\hline 2.200 & $1.549 \mathrm{E}+00$ & $-1.035 \mathrm{E}-01$ & $3.519 \mathrm{E}-04$ & $8.037 \mathrm{E}-02$ & $2.070 \mathrm{E}-02$ & $9.817 \mathrm{E}-05$ & $1.966 \mathrm{E}-03$ & $-3.020 \mathrm{E}-06$ & $4.966 \mathrm{E}-04$ & $7.316 \mathrm{E}-05$ & $-8.478 \mathrm{E}-06$ & $2.332 \mathrm{E}-02$ \\
\hline 2.500 & $1.815 \mathrm{E}+00$ & $-1.383 \mathrm{E}-01$ & $3.009 \mathrm{E}-04$ & $1.078 \mathrm{E}-01$ & $2.740 \mathrm{E}-02$ & $1.124 \mathrm{E}-04$ & $2.561 \mathrm{E}-03$ & $-3.638 \mathrm{E}-06$ & $5.008 \mathrm{E}-04$ & $7.367 \mathrm{E}-05$ & $-1.058 \mathrm{E}-05$ & $3.064 \mathrm{E}-02$ \\
\hline 3.000 & $2.214 \mathrm{E}+00$ & $-1.800 \mathrm{E}-01$ & $2.341 \mathrm{E}-04$ & $1.401 \mathrm{E}-01$ & 3.613E-02 & $1.376 \mathrm{E}-04$ & 3.362E-03 & $-4.570 \mathrm{E}-06$ & $5.768 \mathrm{E}-04$ & $5.558 \mathrm{E}-05$ & $-1.343 \mathrm{E}-05$ & $4.024 \mathrm{E}-02$ \\
\hline
\end{tabular}

Table A8. TOTAL STELLAR YIELDS - MIXING-LENGTH PARAMETER $\alpha=1.68$ - INITIAL METALLICITY $Z=0.008$

\begin{tabular}{|c|c|c|c|c|c|c|c|c|c|c|c|c|}
\hline$M_{\mathrm{i}}$ & $\Delta M_{\mathrm{ej}}$ & $M_{\mathrm{y}}(\mathrm{H})$ & $M_{\mathrm{y}}\left({ }^{3} \mathrm{He}\right)$ & $M_{\mathrm{y}}\left({ }^{4} \mathrm{He}\right)$ & $M_{\mathrm{y}}\left({ }^{12} \mathrm{C}\right)$ & $M_{\mathrm{y}}\left({ }^{13} \mathrm{C}\right)$ & $M_{\mathrm{y}}\left({ }^{14} \mathrm{~N}\right)$ & $M_{\mathrm{y}}\left({ }^{15} \mathrm{~N}\right)$ & $M_{\mathrm{y}}\left({ }^{16} \mathrm{O}\right)$ & $M_{\mathrm{y}}\left({ }^{17} \mathrm{O}\right)$ & $M_{\mathrm{y}}\left({ }^{18} \mathrm{O}\right)$ & $M_{\mathrm{y}}(\mathrm{CNO})$ \\
\hline 0.850 & $2.788 \mathrm{E}-01$ & $-4.533 \mathrm{E}-03$ & $5.251 \mathrm{E}-04$ & $4.016 \mathrm{E}-03$ & $-1.484 \mathrm{E}-05$ & $4.911 \mathrm{E}-06$ & $1.185 \mathrm{E}-05$ & $-6.660 \mathrm{E}-08$ & $-1.721 \mathrm{E}-08$ & $7.500 \mathrm{E}-10$ & $-1.848 \mathrm{E}-08$ & $1.940 \mathrm{E}-06$ \\
\hline 0.918 & $3.398 \mathrm{E}-01$ & $-5.534 \mathrm{E}-03$ & $6.473 \mathrm{E}-04$ & $4.893 \mathrm{E}-03$ & $-2.059 \mathrm{E}-05$ & $5.794 \mathrm{E}-06$ & $1.785 \mathrm{E}-05$ & $-8.529 \mathrm{E}-08$ & $-1.641 \mathrm{E}-07$ & $1.744 \mathrm{E}-09$ & $-3.280 \mathrm{E}-08$ & $2.958 \mathrm{E}-06$ \\
\hline 0.992 & $4.263 \mathrm{E}-01$ & $-6.902 \mathrm{E}-03$ & $7.189 \mathrm{E}-04$ & $6.207 \mathrm{E}-03$ & $-3.127 \mathrm{E}-05$ & $8.875 \mathrm{E}-06$ & $2.704 \mathrm{E}-05$ & $-1.218 \mathrm{E}-07$ & $-2.157 \mathrm{E}-07$ & $4.074 \mathrm{E}-09$ & $-5.552 \mathrm{E}-08$ & $4.431 \mathrm{E}-06$ \\
\hline 1.071 & $4.986 \mathrm{E}-01$ & $-8.191 \mathrm{E}-03$ & $7.148 \mathrm{E}-04$ & 7.462E-03 & $-5.323 \mathrm{E}-05$ & $1.116 \mathrm{E}-05$ & $5.031 \mathrm{E}-05$ & $-1.670 \mathrm{E}-07$ & $-2.587 \mathrm{E}-07$ & $1.120 \mathrm{E}-08$ & $-1.082 \mathrm{E}-07$ & $7.870 \mathrm{E}-06$ \\
\hline 1.154 & $5.665 \mathrm{E}-01$ & $-9.069 \mathrm{E}-03$ & $6.860 \mathrm{E}-04$ & $8.462 \mathrm{E}-03$ & $-7.925 \mathrm{E}-05$ & $1.390 \mathrm{E}-05$ & $7.785 \mathrm{E}-05$ & $-2.195 \mathrm{E}-07$ & $-2.987 \mathrm{E}-07$ & $2.802 \mathrm{E}-08$ & $-1.983 \mathrm{E}-07$ & $1.195 \mathrm{E}-05$ \\
\hline 1.239 & $6.448 \mathrm{E}-01$ & $-1.017 \mathrm{E}-02$ & $6.635 \mathrm{E}-04$ & $9.491 \mathrm{E}-03$ & $-1.151 \mathrm{E}-04$ & $1.654 \mathrm{E}-05$ & $1.170 \mathrm{E}-04$ & $-2.839 \mathrm{E}-07$ & $-3.612 \mathrm{E}-07$ & $6.739 \mathrm{E}-08$ & $-3.304 \mathrm{E}-07$ & $1.756 \mathrm{E}-05$ \\
\hline 1.315 & $7.134 \mathrm{E}-01$ & $-2.421 \mathrm{E}-02$ & $5.336 \mathrm{E}-04$ & $1.911 \mathrm{E}-02$ & $4.141 \mathrm{E}-03$ & $1.917 \mathrm{E}-05$ & $1.615 \mathrm{E}-04$ & $-3.989 \mathrm{E}-07$ & $3.177 \mathrm{E}-04$ & $2.187 \mathrm{E}-07$ & $-7.370 \mathrm{E}-07$ & $4.638 \mathrm{E}-03$ \\
\hline 1.407 & $7.971 \mathrm{E}-01$ & $-2.921 \mathrm{E}-02$ & $5.834 \mathrm{E}-04$ & $2.281 \mathrm{E}-02$ & $5.290 \mathrm{E}-03$ & $2.144 \mathrm{E}-05$ & $1.836 \mathrm{E}-04$ & $-4.558 \mathrm{E}-07$ & $4.041 \mathrm{E}-04$ & $2.748 \mathrm{E}-07$ & $-8.675 \mathrm{E}-07$ & $5.899 \mathrm{E}-03$ \\
\hline 1.499 & $8.895 \mathrm{E}-01$ & $-4.291 \mathrm{E}-02$ & $4.984 \mathrm{E}-04$ & 3.303E-02 & $8.432 \mathrm{E}-03$ & $2.523 \mathrm{E}-05$ & $3.218 \mathrm{E}-04$ & $-6.574 \mathrm{E}-07$ & $6.443 \mathrm{E}-04$ & $1.298 \mathrm{E}-06$ & $-1.605 \mathrm{E}-06$ & $9.422 \mathrm{E}-03$ \\
\hline 1.583 & $9.631 \mathrm{E}-01$ & $-5.837 \mathrm{E}-02$ & $5.242 \mathrm{E}-04$ & $4.392 \mathrm{E}-02$ & $1.273 \mathrm{E}-02$ & $2.648 \mathrm{E}-05$ & $3.367 \mathrm{E}-04$ & $-7.295 \mathrm{E}-07$ & $9.634 \mathrm{E}-04$ & $1.649 \mathrm{E}-06$ & $-1.869 \mathrm{E}-06$ & $1.406 \mathrm{E}-02$ \\
\hline 1.667 & $1.038 \mathrm{E}+00$ & $-7.217 \mathrm{E}-02$ & $4.870 \mathrm{E}-04$ & $5.362 \mathrm{E}-02$ & $1.663 \mathrm{E}-02$ & $2.764 \mathrm{E}-05$ & $3.853 \mathrm{E}-04$ & $-8.263 \mathrm{E}-07$ & $1.244 \mathrm{E}-03$ & $6.070 \mathrm{E}-06$ & $-2.265 \mathrm{E}-06$ & $1.829 \mathrm{E}-02$ \\
\hline 1.750 & $1.112 \mathrm{E}+00$ & $-8.386 \mathrm{E}-02$ & $4.550 \mathrm{E}-04$ & $6.202 \mathrm{E}-02$ & $1.976 \mathrm{E}-02$ & $2.920 \mathrm{E}-05$ & $4.463 \mathrm{E}-04$ & $-9.113 \mathrm{E}-07$ & $1.442 \mathrm{E}-03$ & $1.047 \mathrm{E}-05$ & $-2.579 \mathrm{E}-06$ & $2.168 \mathrm{E}-02$ \\
\hline 1.832 & $1.177 \mathrm{E}+00$ & $-9.896 \mathrm{E}-02$ & $4.242 \mathrm{E}-04$ & $7.301 \mathrm{E}-02$ & $2.362 \mathrm{E}-02$ & $2.935 \mathrm{E}-05$ & $5.119 \mathrm{E}-04$ & $-9.829 \mathrm{E}-07$ & $1.678 \mathrm{E}-03$ & $1.148 \mathrm{E}-05$ & $-2.875 \mathrm{E}-06$ & $2.584 \mathrm{E}-02$ \\
\hline 1.850 & $1.189 \mathrm{E}+00$ & $-1.036 \mathrm{E}-01$ & $3.986 \mathrm{E}-04$ & $7.657 \mathrm{E}-02$ & $2.485 \mathrm{E}-02$ & $2.921 \mathrm{E}-05$ & $5.337 \mathrm{E}-04$ & $-1.005 \mathrm{E}-06$ & $1.761 \mathrm{E}-03$ & $1.496 \mathrm{E}-05$ & $-2.991 \mathrm{E}-06$ & $2.718 \mathrm{E}-02$ \\
\hline 1.900 & $1.231 \mathrm{E}+00$ & $-1.111 \mathrm{E}-01$ & $3.872 \mathrm{E}-04$ & $8.158 \mathrm{E}-02$ & $2.679 \mathrm{E}-02$ & $2.998 \mathrm{E}-05$ & $5.719 \mathrm{E}-04$ & $-1.052 \mathrm{E}-06$ & $1.887 \mathrm{E}-03$ & $1.421 \mathrm{E}-05$ & $-3.183 \mathrm{E}-06$ & $2.929 \mathrm{E}-02$ \\
\hline 2.000 & $1.317 \mathrm{E}+00$ & $-1.209 \mathrm{E}-01$ & $3.680 \mathrm{E}-04$ & $8.968 \mathrm{E}-02$ & $2.856 \mathrm{E}-02$ & $3.208 \mathrm{E}-05$ & $6.742 \mathrm{E}-04$ & $-1.137 \mathrm{E}-06$ & $1.957 \mathrm{E}-03$ & $1.524 \mathrm{E}-05$ & $-3.475 \mathrm{E}-06$ & $3.124 \mathrm{E}-02$ \\
\hline 2.200 & $1.490 \mathrm{E}+00$ & $-1.511 \mathrm{E}-01$ & $3.301 \mathrm{E}-04$ & $1.134 \mathrm{E}-01$ & $3.446 \mathrm{E}-02$ & $3.577 \mathrm{E}-05$ & $8.935 \mathrm{E}-04$ & $-1.341 \mathrm{E}-06$ & $2.266 \mathrm{E}-03$ & $1.622 \mathrm{E}-05$ & $-4.239 \mathrm{E}-06$ & $3.767 \mathrm{E}-02$ \\
\hline 2.500 & $1.735 \mathrm{E}+00$ & $-1.798 \mathrm{E}-01$ & $2.845 \mathrm{E}-04$ & $1.360 \mathrm{E}-01$ & $3.998 \mathrm{E}-02$ & $4.277 \mathrm{E}-05$ & $1.143 \mathrm{E}-03$ & $-1.586 \mathrm{E}-06$ & $2.535 \mathrm{E}-03$ & $1.320 \mathrm{E}-05$ & $-5.052 \mathrm{E}-06$ & $4.370 \mathrm{E}-02$ \\
\hline 3.000 & $2.106 \mathrm{E}+00$ & $-2.114 \mathrm{E}-01$ & $2.296 \mathrm{E}-04$ & $1.602 \mathrm{E}-01$ & $4.692 \mathrm{E}-02$ & $5.376 \mathrm{E}-05$ & $1.458 \mathrm{E}-03$ & $-1.939 \mathrm{E}-06$ & $2.896 \mathrm{E}-03$ & $1.172 \mathrm{E}-05$ & $-6.069 \mathrm{E}-06$ & $5.133 \mathrm{E}-02$ \\
\hline
\end{tabular}

Table A9. TOTAL STELLAR YIELDS - MIXING-LENGTH PARAMETER $\alpha=1.68$ - INITIAL METALLICITY $Z=0.004$

\begin{tabular}{|c|c|c|c|c|c|c|c|c|c|c|c|c|}
\hline$M_{\mathrm{i}}$ & $\Delta M_{\mathrm{ej}}$ & $M_{\mathrm{y}}(\mathrm{H})$ & $M_{\mathrm{y}}\left({ }^{3} \mathrm{He}\right)$ & $M_{\mathrm{y}}\left({ }^{4} \mathrm{He}\right)$ & $M_{\mathrm{y}}\left({ }^{12} \mathrm{C}\right)$ & $M_{\mathrm{y}}\left({ }^{13} \mathrm{C}\right)$ & $M_{\mathrm{y}}\left({ }^{14} \mathrm{~N}\right)$ & $M_{\mathrm{y}}\left({ }^{15} \mathrm{~N}\right)$ & $M_{\mathrm{y}}\left({ }^{16} \mathrm{O}\right)$ & $M_{\mathrm{y}}\left({ }^{17} \mathrm{O}\right)$ & $M_{\mathrm{y}}\left({ }^{18} \mathrm{O}\right)$ & $M_{\mathrm{y}}(\mathrm{CNO})$ \\
\hline 0.817 & $2.314 \mathrm{E}-01$ & $-3.513 \mathrm{E}-03$ & $520 \mathrm{E}-04$ & $3.081 \mathrm{E}-03$ & $-4.974 \mathrm{E}-06$ & $2.090 \mathrm{E}-06$ & $3.524 \mathrm{E}-06$ & $-2.592 \mathrm{E}-08$ & & & & \\
\hline & & & & & & & & & & & & \\
\hline 0.966 & & & & & & & & & & & & \\
\hline 1.046 & & & & & & & & & & & & \\
\hline 1.131 & 4.99 & & & & & & & & & & & \\
\hline 1.218 & $5.834 \mathrm{E}$ & 2 & & & & & & & & & & \\
\hline 1.307 & $6.803 \mathrm{I}$ & 2 & & & & & & & & & & \\
\hline 1.396 & $7.556 \mathrm{E}-01$ & -02 & & 6.7 & & & & & & & & \\
\hline 1.481 & $8.362 \mathrm{E}-01$ & 01 & & & & & & & & & & \\
\hline 1.564 & $9.034 \mathrm{E}-01$ & & & & & & & & & & & \\
\hline 1.647 & $9.695 \mathrm{E}-01$ & -01 & & & & & & & & & & -02 \\
\hline 1.729 & $1.033 \mathrm{E}+00$ & $.929 \mathrm{E}-01$ & 347E-04 & & & E-06 & & & & & & -02 \\
\hline 1.800 & $1.089 \mathrm{E}+00$ & $.168 \mathrm{E}-01$ & $3.094 \mathrm{E}-04$ & & & & & & & & -1.96 & $\mathrm{E}-02$ \\
\hline 1.900 & $1.171 \mathrm{E}+00$ & $-2.371 \mathrm{E}-01$ & $2.915 \mathrm{E}-04$ & $1.677 \mathrm{E}-01$ & $6.400 \mathrm{E}-02$ & $1.015 \mathrm{E}-05$ & $2.107 \mathrm{E}-04$ & $-5.926 \mathrm{E}-07$ & $5.232 \mathrm{E}-03$ & $2.772 \mathrm{E}-06$ & $-2.178 \mathrm{E}-06$ & $6.945 \mathrm{E}-02$ \\
\hline 2.000 & $1.250 \mathrm{E}+00$ & $-2.622 \mathrm{E}-01$ & $2.737 \mathrm{E}-04$ & $1.852 \mathrm{E}-01$ & $7.105 \mathrm{E}-02$ & $1.076 \mathrm{E}-05$ & $2.253 \mathrm{E}-04$ & $-6.417 \mathrm{E}-07$ & $5.801 \mathrm{E}-03$ & $3.732 \mathrm{E}-06$ & $-2.370 \mathrm{E}-06$ & $7.709 \mathrm{E}-02$ \\
\hline 2.200 & $1.420 \mathrm{E}+00$ & $-2.962 \mathrm{E}-01$ & $2.485 \mathrm{E}-04$ & $2.105 \mathrm{E}-01$ & $7.898 \mathrm{E}-02$ & $1.229 \mathrm{E}-05$ & $3.223 \mathrm{E}-04$ & $-7.443 \mathrm{E}-07$ & $6.402 \mathrm{E}-03$ & $3.523 \mathrm{E}-06$ & $-2.768 \mathrm{E}-06$ & $8.572 \mathrm{E}-02$ \\
\hline 2.500 & $1.690 \mathrm{E}+00$ & $-3.105 \mathrm{E}-01$ & $2.308 \mathrm{E}-04$ & $2.229 \mathrm{E}-01$ & $8.066 \mathrm{E}-02$ & $1.620 \mathrm{E}-05$ & & & & 3.403E-06 & $-3.187 \mathrm{E}-06$ & $8.762 \mathrm{E}-02$ \\
\hline 3.000 & $2.034 \mathrm{E}+00$ & $-3.062 \mathrm{E}-01$ & $1.998 \mathrm{E}-04$ & $2.214 \mathrm{E}-01$ & $7.801 \mathrm{E}-02$ & $5.752 \mathrm{E}-05$ & $6.151 \mathrm{E}-04$ & $-1.135 \mathrm{E}-06$ & $6.212 \mathrm{E}-03$ & $3.330 \mathrm{E}-06$ & $-3.488 \mathrm{E}-06$ & $8.489 \mathrm{E}-02$ \\
\hline
\end{tabular}


Table A10. TOTAL STELLAR YIELDS - INITIAL METALLICITY $Z=0.019$

\begin{tabular}{|c|c|c|c|c|c|c|c|c|c|c|c|c|c|c|}
\hline$\alpha$ & $M_{\mathrm{i}}$ & $\Delta M_{\mathrm{ej}}$ & $M_{\mathrm{y}}(\mathrm{H})$ & $M_{\mathrm{y}}\left({ }^{3} \mathrm{He}\right)$ & $M_{\mathrm{y}}\left({ }^{4} \mathrm{He}\right)$ & $\mathrm{T} / \mathrm{S} / \mathrm{P}$ & $M_{\mathrm{y}}\left({ }^{12} \mathrm{C}\right)$ & $M_{\mathrm{y}}\left({ }^{13} \mathrm{C}\right)$ & $M_{\mathrm{y}}\left({ }^{14} \mathrm{~N}\right)$ & $M_{\mathrm{y}}\left({ }^{15} \mathrm{~N}\right)$ & $M_{\mathrm{y}}\left({ }^{16} \mathrm{O}\right)$ & $M_{\mathrm{y}}\left({ }^{17} \mathrm{O}\right)$ & $M_{\mathrm{y}}\left({ }^{18} \mathrm{O}\right)$ & $M_{\mathrm{y}}(\mathrm{CNO})$ \\
\hline \multirow[t]{12}{*}{1.68} & \multirow[t]{3}{*}{3.5} & \multirow[t]{3}{*}{$2.657 \mathrm{E}+00$} & \multirow[t]{3}{*}{$-1.681 \mathrm{E}-01$} & \multirow[t]{3}{*}{$2.022 \mathrm{E}-04$} & \multirow[t]{3}{*}{$1.358 \mathrm{E}-01$} & $\mathrm{~T}$ & $2.816 \mathrm{E}-02$ & $1.784 \mathrm{E}-04$ & $4.241 \mathrm{E}-03$ & $-5.346 \mathrm{E}-06$ & $-1.735 \mathrm{E}-04$ & $4.764 \mathrm{E}-05$ & $-1.476 \mathrm{E}-05$ & $3.244 \mathrm{E}-02$ \\
\hline & & & & & & S & $-3.122 \mathrm{E}-03$ & $1.777 \mathrm{E}-04$ & $4.238 \mathrm{E}-03$ & $-5.343 \mathrm{E}-06$ & $-3.022 \mathrm{E}-03$ & $4.760 \mathrm{E}-05$ & $-1.480 \mathrm{E}-05$ & $-1.701 \mathrm{E}-03$ \\
\hline & & & & & & $\mathrm{P}$ & $3.129 \mathrm{E}-02$ & $7.097 \mathrm{E}-07$ & $2.211 \mathrm{E}-06$ & $-3.231 \mathrm{E}-09$ & $2.849 \mathrm{E}-03$ & $3.493 \mathrm{E}-08$ & $4.565 \mathrm{E}-08$ & $3.414 \mathrm{E}-02$ \\
\hline & \multirow[t]{3}{*}{4.0} & \multirow[t]{3}{*}{$3.098 \mathrm{E}+00$} & \multirow[t]{3}{*}{$-1.514 \mathrm{E}-01$} & \multirow[t]{3}{*}{$1.769 \mathrm{E}-04$} & \multirow[t]{3}{*}{$1.315 \mathrm{E}-01$} & $\mathrm{~T}$ & $1.622 \mathrm{E}-02$ & $2.258 \mathrm{E}-04$ & $5.253 \mathrm{E}-03$ & $-6.181 \mathrm{E}-06$ & $-1.212 \mathrm{E}-03$ & $4.033 \mathrm{E}-05$ & $-1.585 \mathrm{E}-05$ & $2.050 \mathrm{E}-02$ \\
\hline & & & & & & $\mathrm{S}$ & $-3.461 \mathrm{E}-03$ & $2.256 \mathrm{E}-04$ & $5.251 \mathrm{E}-03$ & $-6.178 \mathrm{E}-06$ & $-2.998 \mathrm{E}-03$ & $4.030 \mathrm{E}-05$ & $-1.586 \mathrm{E}-05$ & $-9.638 \mathrm{E}-04$ \\
\hline & & & & & & $\mathrm{P}$ & $1.968 \mathrm{E}-02$ & $2.518 \mathrm{E}-07$ & $2.122 \mathrm{E}-06$ & $-3.457 \mathrm{E}-09$ & $1.786 \mathrm{E}-03$ & $2.752 \mathrm{E}-08$ & $7.803 \mathrm{E}-09$ & $2.147 \mathrm{E}-02$ \\
\hline & \multirow[t]{3}{*}{4.5} & \multirow[t]{3}{*}{$3.542 \mathrm{E}+00$} & \multirow[t]{3}{*}{$-1.975 \mathrm{E}-01$} & \multirow[t]{3}{*}{$1.427 \mathrm{E}-04$} & \multirow[t]{3}{*}{$1.828 \mathrm{E}-01$} & $\mathrm{~T}$ & $1.065 \mathrm{E}-02$ & $3.213 \mathrm{E}-04$ & $6.904 \mathrm{E}-03$ & $-1.257 \mathrm{E}-05$ & $-2.487 \mathrm{E}-03$ & $3.479 \mathrm{E}-05$ & $-1.897 \mathrm{E}-05$ & $1.539 \mathrm{E}-02$ \\
\hline & & & & & & $\mathrm{S}$ & $-4.044 \mathrm{E}-03$ & $2.783 \mathrm{E}-04$ & $6.905 \mathrm{E}-03$ & $-1.257 \mathrm{E}-05$ & $-3.824 \mathrm{E}-03$ & E-05 & $-1.894 \mathrm{I}$ & $-6.807 \mathrm{E}-04$ \\
\hline & & & & & & P & $1.469 \mathrm{E}-02$ & $4.302 \mathrm{E}-05$ & $-1.647 \mathrm{E}-06$ & $-5.404 \mathrm{E}-12$ & $1.337 \mathrm{E}-03$ & $1.834 \mathrm{E}-08$ & $-3.064 \mathrm{E}-08$ & $1.607 \mathrm{E}-02$ \\
\hline & \multirow[t]{3}{*}{5.0} & \multirow[t]{3}{*}{$4.003 \mathrm{E}+00$} & \multirow{3}{*}{$\begin{array}{r}-3.028 \mathrm{E}-01 \\
-\end{array}$} & \multirow[t]{3}{*}{$-2.244 \mathrm{E}-05$} & \multirow[t]{3}{*}{$2.866 \mathrm{E}-01$} & $\mathrm{~T}$ & $4.127 \mathrm{E}-03$ & $3.735 \mathrm{E}-03$ & $1.327 \mathrm{E}-02$ & $-1.534 \mathrm{E}-05$ & $-3.970 \mathrm{E}-03$ & $5.898 \mathrm{E}-05$ & $-8.141 \mathrm{E}-05$ & $1.712 \mathrm{E}-02$ \\
\hline & & & & & & $\mathrm{S}$ & -7.20 & $1.455 \mathrm{E}-03$ & & $-1.542 \mathrm{E}-05$ & E-03 & & $1 \mathrm{E}-05$ & E-04 \\
\hline & & & & & & $\mathrm{P}$ & $1.133 \mathrm{E}-02$ & $2.280 \mathrm{E}-03$ & $2.597 \mathrm{E}-03$ & $8.058 \mathrm{E}-08$ & $1.423 \mathrm{E}-03$ & $9.831 \mathrm{E}-07$ & -10 & $1.763 \mathrm{E}-02$ \\
\hline \multirow[t]{12}{*}{2.00} & \multirow[t]{3}{*}{3.5} & $2.590 \mathrm{E}+00$ & $-2.091 \mathrm{E}-01$ & $1.895 \mathrm{E}-04$ & $1.628 \mathrm{E}-01$ & $\mathrm{~T}$ & $4.194 \mathrm{E}-02$ & $1.702 \mathrm{E}-04$ & $3.950 \mathrm{E}-03$ & $-5.483 \mathrm{E}-06$ & $5.987 \mathrm{E}-04$ & $4.491 \mathrm{E}-05$ & $-1.545 \mathrm{E}-05$ & $4.668 \mathrm{E}-02$ \\
\hline & & & & & & $\mathrm{S}$ & $-3.190 \mathrm{E}-03$ & & & $-5.484 \mathrm{E}-06$ & & & & $-2.556 \mathrm{E}-03$ \\
\hline & & & & & & $\mathrm{P}$ & & & & & 4.1 & & & -02 \\
\hline & 4.0 & $3.032 \mathrm{E}+00$ & $-1.915 \mathrm{E}-01$ & $4.442 \mathrm{E}-05$ & $1.574 \mathrm{E}-01$ & $\mathrm{~T}$ & $2.363 \mathrm{E}-02$ & $4.839 \mathrm{E}-03$ & $6.971 \mathrm{E}-03$ & $-1.161 \mathrm{E}-05$ & $-4.628 \mathrm{E}-04$ & $4.568 \mathrm{E}-05$ & $-4.804 \mathrm{E}-05$ & $3.496 \mathrm{E}-02$ \\
\hline & & & & & & $\mathrm{S}$ & $-4.073 \mathrm{E}-03$ & $6.606 \mathrm{E}-04$ & $5.150 \mathrm{E}-03$ & $-1.167 \mathrm{E}-05$ & $-3.471 \mathrm{E}-03$ & $4.486 \mathrm{E}-05$ & $-4.804 \mathrm{E}-05$ & $-1.749 \mathrm{E}-03$ \\
\hline & & & & & & $\mathrm{P}$ & & & & & & & & $3.671 \mathrm{E}-02$ \\
\hline & 4.5 & $3.512 \mathrm{E}+00$ & $-2.213 \mathrm{E}-01$ & $-8.370 \mathrm{E}-05$ & $1.961 \mathrm{E}-01$ & $\mathrm{~T}$ & $-5.882 \mathrm{E}-03$ & $1.335 \mathrm{E}-03$ & $3.291 \mathrm{E}-02$ & $-1.283 \mathrm{E}-05$ & $-2.275 \mathrm{E}-03$ & E-04 & $-7.223 \mathrm{E}-05$ & $2.623 \mathrm{E}-02$ \\
\hline & & & & & & $\mathrm{S}$ & $-1.010 \mathrm{E}-02$ & $3.414 \mathrm{E}-04$ & $1.375 \mathrm{E}-02$ & $-1.341 \mathrm{E}-05$ & $-4.225 \mathrm{E}-03$ & $2.114 \mathrm{E}-04$ & $-7.223 \mathrm{E}-05$ & $-1.112 \mathrm{E}-04$ \\
\hline & & & & & & $\mathrm{P}$ & $4.223 \mathrm{E}-03$ & $9.938 \mathrm{E}-04$ & $1.916 \mathrm{E}-02$ & $5.844 \mathrm{E}-07$ & $1.950 \mathrm{E}-03$ & $1.130 \mathrm{E}-05$ & $1.330 \mathrm{E}-09$ & $2.634 \mathrm{E}-02$ \\
\hline & 5.0 & $3.987 \mathrm{E}+00$ & $-3.196 \mathrm{E}-01$ & $-1.149 \mathrm{E}-04$ & $2.968 \mathrm{E}-01$ & $\mathrm{~T}$ & $-9.665 \mathrm{E}-03$ & $4.570 \mathrm{E}-04$ & $3.683 \mathrm{E}-02$ & $-1.463 \mathrm{E}-05$ & $-4.890 \mathrm{E}-03$ & $1.118 \mathrm{E}-03$ & $-8.209 \mathrm{E}-05$ & $2.376 \mathrm{E}-02$ \\
\hline & & & & & & $\mathrm{S}$ & -1.21 & $\mathrm{E}-05$ & $1.798 \mathrm{E}-02$ & $19 \mathrm{E}-05$ & E- 03 & $1.069 \mathrm{E}-03$ & -8.20 & $2.716 \mathrm{E}-04$ \\
\hline & & & & & & P & $2.529 \mathrm{E}-03$ & $3.703 \mathrm{E}-04$ & $1.885 \mathrm{E}-02$ & $5.521 \mathrm{E}-07$ & $1.688 \mathrm{E}-03$ & $4.921 \mathrm{E}-05$ & $3.392 \mathrm{E}-09$ & $2.348 \mathrm{E}-02$ \\
\hline 2.50 & 3.5 & $2.530 \mathrm{E}+00$ & $-2.449 \mathrm{E}-01$ & $-1.387 \mathrm{E}-05$ & $1.847 \mathrm{E}-01$ & $\mathrm{~T}$ & $3.151 \mathrm{E}-02$ & $1.091 \mathrm{E}-02$ & $1.733 \mathrm{E}-02$ & $-9.419 \mathrm{E}-06$ & $1.210 \mathrm{E}-03$ & $5.953 \mathrm{E}-05$ & $-5.055 \mathrm{E}-05$ & $6.096 \mathrm{E}-02$ \\
\hline & & & & & & $\mathrm{S}$ & $-3.555 \mathrm{E}-03$ & & & $-9.852 \mathrm{E}-06$ & & Q-05 & $-5.055 \mathrm{E}-05$ & $-3.255 \mathrm{E}-03$ \\
\hline & & & & & & $\mathrm{P}$ & $3.507 \mathrm{E}-02$ & $1.006 \mathrm{E}-02$ & $1.396 \mathrm{E}-02$ & $4.334 \mathrm{E}-07$ & $5.118 \mathrm{E}-03$ & $3.747 \mathrm{E}-06$ & $7.791 \mathrm{E}-10$ & $6.421 \mathrm{E}-02$ \\
\hline & 4.0 & $3.016 \mathrm{E}+00$ & $-2.121 \mathrm{E}-01$ & $-8.480 \mathrm{E}-05$ & $1.686 \mathrm{E}-01$ & $\mathrm{~T}$ & $-6.513 \mathrm{E}-03$ & $6.709 \mathrm{E}-04$ & $5.069 \mathrm{E}-02$ & $-1.038 \mathrm{E}-05$ & $-8.613 \mathrm{E}-04$ & $6.273 \mathrm{E}-04$ & $-6.208 \mathrm{E}-05$ & $4.454 \mathrm{E}-02$ \\
\hline & & & & & & $\mathrm{S}$ & $-9.241 \mathrm{E}-03$ & $6.233 \mathrm{E}-05$ & $1.179 \mathrm{E}-02$ & $-1.154 \mathrm{E}-05$ & $-4.126 \mathrm{E}-03$ & $5.540 \mathrm{E}-04$ & $-6.209 \mathrm{E}-05$ & $-1.039 \mathrm{E}-03$ \\
\hline & & & & & & $\mathrm{P}$ & $2.728 \mathrm{E}-03$ & $6.086 \mathrm{E}-04$ & 3.891E-02 & $1.152 \mathrm{E}-06$ & $3.264 \mathrm{E}-03$ & $7.332 \mathrm{E}-05$ & $6.759 \mathrm{E}-09$ & $4.558 \mathrm{E}-02$ \\
\hline & 4.5 & $3.504 \mathrm{E}+00$ & $-2.390 \mathrm{E}-01$ & $-1.023 \mathrm{E}-04$ & $2.107 \mathrm{E}-01$ & $\mathrm{~T}$ & $-8.875 \mathrm{E}-03$ & $4.439 \mathrm{E}-04$ & $4.007 \mathrm{E}-02$ & $-1.267 \mathrm{E}-05$ & $-4.329 \mathrm{E}-03$ & $1.976 \mathrm{E}-03$ & $-7.214 \mathrm{E}-05$ & $2.920 \mathrm{E}-02$ \\
\hline & & & & & & S & $-1.075 \mathrm{E}-02$ & $6.680 \mathrm{E}-05$ & $1.518 \mathrm{E}-02$ & $-1.338 \mathrm{E}-05$ & $-6.334 \mathrm{E}-03$ & $1.851 \mathrm{E}-03$ & $-7.215 \mathrm{E}-05$ & $-7.228 \mathrm{E}-05$ \\
\hline & & & & & & $\mathrm{P}$ & $1.879 \mathrm{E}-03$ & $3.771 \mathrm{E}-04$ & $2.488 \mathrm{E}-02$ & $7.129 \mathrm{E}-07$ & $2.006 \mathrm{E}-03$ & $1.255 \mathrm{E}-04$ & $7.529 \mathrm{E}-09$ & $2.927 \mathrm{E}-02$ \\
\hline & 5.0 & $3.980 \mathrm{E}+00$ & $-3.336 \mathrm{E}-01$ & $-1.162 \mathrm{E}-04$ & 3.103E-01 & $\mathrm{T}$ & $-1.047 \mathrm{E}-02$ & $4.253 \mathrm{E}-04$ & $3.915 \mathrm{E}-02$ & $-1.459 \mathrm{E}-05$ & $-7.885 \mathrm{E}-03$ & $3.068 \mathrm{E}-03$ & $-8.190 \mathrm{E}-05$ & $2.419 \mathrm{E}-02$ \\
\hline & & & & & & $\mathrm{S}$ & & & & & & & $-8.190 \mathrm{E}-05$ & $1.921 \mathrm{E}-04$ \\
\hline & & & & & & $\mathrm{P}$ & $1.659 \mathrm{E}-03$ & $3.258 \mathrm{E}-04$ & $2.029 \mathrm{E}-02$ & $5.684 \mathrm{E}-07$ & $1.588 \mathrm{E}-03$ & $1.393 \mathrm{E}-04$ & $6.291 \mathrm{E}-09$ & $2.400 \mathrm{E}-02$ \\
\hline
\end{tabular}

Table A11. TOTAL STELLAR YIELDS - INITIAL METALLICITY $Z=0.008$

\begin{tabular}{|c|c|c|c|c|c|c|c|c|c|c|c|c|c|c|}
\hline$\alpha$ & $M_{\mathrm{i}}$ & $\Delta M_{\mathrm{ej}}$ & $M_{\mathrm{y}}(\mathrm{H})$ & $M_{\mathrm{y}}\left({ }^{3} \mathrm{He}\right)$ & $M_{\mathrm{y}}\left({ }^{4} \mathrm{He}\right)$ & $\mathrm{T} / \mathrm{S} / \mathrm{P}$ & $M_{\mathrm{y}}\left({ }^{12} \mathrm{C}\right)$ & $M_{\mathrm{y}}\left({ }^{13} \mathrm{C}\right)$ & $M_{\mathrm{y}}\left({ }^{14} \mathrm{~N}\right)$ & $M_{\mathrm{y}}\left({ }^{15} \mathrm{~N}\right)$ & $M_{\mathrm{y}}\left({ }^{16} \mathrm{O}\right)$ & $M_{\mathrm{y}}\left({ }^{17} \mathrm{O}\right)$ & $M_{\mathrm{y}}\left({ }^{18} \mathrm{O}\right)$ & $M_{\mathrm{y}}(\mathrm{CNO})$ \\
\hline \multirow[t]{12}{*}{1.68} & \multirow[t]{3}{*}{3.5} & \multirow{3}{*}{$2.561 \mathrm{E}+00$} & \multirow[t]{3}{*}{$-1.800 \mathrm{E}-01$} & \multirow{3}{*}{$2.044 \mathrm{E}-04$} & \multirow{3}{*}{$1.415 \mathrm{E}-01$} & $\mathrm{~T}$ & $3.450 \mathrm{E}-02$ & $1.592 \mathrm{E}-04$ & $1.836 \mathrm{E}-03$ & $-3.607 \mathrm{E}-06$ & $1.857 \mathrm{E}-03$ & $9.426 \mathrm{E}-06$ & $-6.499 \mathrm{E}-06$ & $3.836 \mathrm{E}-02$ \\
\hline & & & & & & S & $-1.338 \mathrm{E}-03$ & $6.942 \mathrm{E}-05$ & $1.836 \mathrm{E}-03$ & $-3.607 \mathrm{E}-06$ & $-1.411 \mathrm{E}-03$ & $9.419 \mathrm{E}-06$ & $-6.498 \mathrm{E}-06$ & $-8.445 \mathrm{E}-04$ \\
\hline & & & & & & $P$ & $3.584 \mathrm{E}-02$ & $8.978 \mathrm{E}-05$ & $3.208 \mathrm{E}-07$ & $2.783 \mathrm{E}-10$ & $3.267 \mathrm{E}-03$ & $6.437 \mathrm{E}-09$ & $-8.978 \mathrm{E}-10$ & $3.920 \mathrm{E}-02$ \\
\hline & \multirow[t]{3}{*}{4.0} & \multirow[t]{3}{*}{$3.022 \mathrm{E}+00$} & \multirow[t]{3}{*}{$-1.646 \mathrm{E}-01$} & \multirow[t]{3}{*}{$-3.100 \mathrm{E}-05$} & \multirow[t]{3}{*}{$1.396 \mathrm{E}-01$} & $\mathrm{~T}$ & $7.742 \mathrm{E}-03$ & $3.390 \mathrm{E}-03$ & $1.360 \mathrm{E}-02$ & $-4.591 \mathrm{E}-06$ & $4.882 \mathrm{E}-04$ & $3.209 \mathrm{E}-05$ & $-2.607 \mathrm{E}-05$ & $2.523 \mathrm{E}-02$ \\
\hline & & & & & & $\mathrm{S}$ & $-2.433 \mathrm{E}-03$ & $5.190 \mathrm{E}-04$ & $3.054 \mathrm{E}-03$ & $-4.917 \mathrm{E}-06$ & $-1.497 \mathrm{E}-03$ & $2.864 \mathrm{E}-05$ & $-2.607 \mathrm{E}-05$ & $-3.586 \mathrm{E}-04$ \\
\hline & & & & & & $\mathrm{P}$ & $1.017 \mathrm{E}-02$ & $2.871 \mathrm{E}-03$ & $1.055 \mathrm{E}-02$ & $3.265 \mathrm{E}-07$ & $1.985 \mathrm{E}-03$ & $3.450 \mathrm{E}-06$ & $5.289 \mathrm{E}-10$ & $2.558 \mathrm{E}-02$ \\
\hline & \multirow[t]{3}{*}{4.5} & \multirow{3}{*}{$3.487 \mathrm{E}+00$} & \multirow{3}{*}{$-2.454 \mathrm{E}-01$} & \multirow[t]{3}{*}{$-9.121 \mathrm{E}-05$} & \multirow[t]{3}{*}{$2.225 \mathrm{E}-01$} & $\mathrm{~T}$ & $-1.824 \mathrm{E}-03$ & $3.996 \mathrm{E}-04$ & $2.500 \mathrm{E}-02$ & $-5.052 \mathrm{E}-06$ & $-7.621 \mathrm{E}-04$ & $4.696 \mathrm{E}-04$ & $-3.021 \mathrm{E}-05$ & $2.324 \mathrm{E}-02$ \\
\hline & & & & & & $\mathrm{S}$ & $-4.460 \mathrm{E}-03$ & $4.048 \mathrm{E}-05$ & $6.507 \mathrm{E}-03$ & $-5.595 \mathrm{E}-06$ & $-2.425 \mathrm{E}-03$ & $4.184 \mathrm{E}-04$ & $-3.022 \mathrm{E}-05$ & $4.575 \mathrm{E}-05$ \\
\hline & & & & & & $\mathrm{P}$ & $2.636 \mathrm{E}-03$ & $3.591 \mathrm{E}-04$ & $1.849 \mathrm{E}-02$ & $5.425 \mathrm{E}-07$ & $1.662 \mathrm{E}-03$ & $5.120 \mathrm{E}-05$ & $3.510 \mathrm{E}-09$ & $2.320 \mathrm{E}-02$ \\
\hline & \multirow[t]{3}{*}{5.0} & \multirow{3}{*}{$3.968 \mathrm{E}+00$} & \multirow[t]{3}{*}{$-3.353 \mathrm{E}-01$} & \multirow[t]{3}{*}{$-1.061 \mathrm{E}-04$} & \multirow[t]{3}{*}{$3.168 \mathrm{E}-01$} & $\mathrm{~T}$ & $-2.519 \mathrm{E}-03$ & $3.233 \mathrm{E}-04$ & $2.206 \mathrm{E}-02$ & $-5.962 \mathrm{E}-06$ & $-2.706 \mathrm{E}-03$ & $1.197 \mathrm{E}-03$ & $-3.440 \mathrm{E}-05$ & $1.831 \mathrm{E}-02$ \\
\hline & & & & & & $\mathrm{S}$ & $-5.066 \mathrm{E}-03$ & $5.023 \mathrm{E}-05$ & $8.072 \mathrm{E}-03$ & $-6.359 \mathrm{E}-06$ & $-3.958 \mathrm{E}-03$ & $1.114 \mathrm{E}-03$ & $-3.440 \mathrm{E}-05$ & $1.720 \mathrm{E}-04$ \\
\hline & & & & & & $\mathrm{P}$ & $2.547 \mathrm{E}-03$ & $2.730 \mathrm{E}-04$ & $1.399 \mathrm{E}-02$ & $3.972 \mathrm{E}-07$ & $1.252 \mathrm{E}-03$ & $8.301 \mathrm{E}-05$ & $3.860 \mathrm{E}-09$ & $1.814 \mathrm{E}-02$ \\
\hline \multirow[t]{12}{*}{2.00} & \multirow[t]{3}{*}{3.5} & $2.524 \mathrm{E}+00$ & $-2.013 \mathrm{E}-01$ & $-2.423 \mathrm{E}-05$ & $1.535 \mathrm{E}-01$ & $\mathrm{~T}$ & $1.672 \mathrm{E}-02$ & $6.773 \mathrm{E}-03$ & $2.210 \mathrm{E}-02$ & $-3.500 \mathrm{E}-06$ & $2.281 \mathrm{E}-03$ & $2.816 \mathrm{E}-05$ & $-2.180 \mathrm{E}-05$ & $4.788 \mathrm{E}-02$ \\
\hline & & & & & & $\mathrm{S}$ & $-1.154 \mathrm{E}-03$ & $6.575 \mathrm{E}-04$ & $9.291 \mathrm{E}-04$ & $-4.157 \mathrm{E}-06$ & $-1.500 \mathrm{E}-03$ & $2.183 \mathrm{E}-05$ & $-2.180 \mathrm{E}-05$ & $-1.072 \mathrm{E}-03$ \\
\hline & & & & & & $\mathrm{P}$ & $1.788 \mathrm{E}-02$ & $6.116 \mathrm{E}-03$ & $2.117 \mathrm{E}-02$ & $6.571 \mathrm{E}-07$ & $3.781 \mathrm{E}-03$ & $6.328 \mathrm{E}-06$ & $1.033 \mathrm{E}-09$ & $4.895 \mathrm{E}-02$ \\
\hline & 4.0 & $3.005 \mathrm{E}+00$ & $-1.820 \mathrm{E}-01$ & $-7.987 \mathrm{E}-05$ & $1.518 \mathrm{E}-01$ & $\mathrm{~T}$ & $-1.424 \mathrm{E}-03$ & $4.168 \mathrm{E}-04$ & $3.084 \mathrm{E}-02$ & $-4.089 \mathrm{E}-06$ & $-4.333 \mathrm{E}-05$ & $6.806 \mathrm{E}-04$ & $-2.602 \mathrm{E}-05$ & $3.044 \mathrm{E}-02$ \\
\hline & & & & & & $\mathrm{S}$ & $-3.864 \mathrm{E}-03$ & $2.831 \mathrm{E}-05$ & $5.322 \mathrm{E}-03$ & $-4.831 \mathrm{E}-06$ & $-2.170 \mathrm{E}-03$ & $5.682 \mathrm{E}-04$ & $-2.603 \mathrm{E}-05$ & $-1.469 \mathrm{E}-04$ \\
\hline & & & & & & $\mathrm{P}$ & $2.440 \mathrm{E}-03$ & $3.885 \mathrm{E}-04$ & $2.551 \mathrm{E}-02$ & $7.424 \mathrm{E}-07$ & $2.126 \mathrm{E}-03$ & $1.123 \mathrm{E}-04$ & $7.704 \mathrm{E}-09$ & $3.058 \mathrm{E}-02$ \\
\hline & 4.5 & $3.477 \mathrm{E}+00$ & $-2.561 \mathrm{E}-01$ & $-9.298 \mathrm{E}-05$ & $2.327 \mathrm{E}-01$ & $\mathrm{~T}$ & $-2.672 \mathrm{E}-03$ & $3.553 \mathrm{E}-04$ & $2.680 \mathrm{E}-02$ & $-5.015 \mathrm{E}-06$ & $-2.244 \mathrm{E}-03$ & $1.379 \mathrm{E}-03$ & $-3.012 \mathrm{E}-05$ & $2.358 \mathrm{E}-02$ \\
\hline & & & & & & $\mathrm{S}$ & $-4.446 \mathrm{E}-03$ & $4.183 \mathrm{E}-05$ & $6.999 \mathrm{E}-03$ & $-5.574 \mathrm{E}-06$ & $-3.777 \mathrm{E}-03$ & $1.225 \mathrm{E}-03$ & & $8.273 \mathrm{E}-06$ \\
\hline & & & & & & $\mathrm{P}$ & $1.774 \mathrm{E}-03$ & $3.135 \mathrm{E}-04$ & $1.980 \mathrm{E}-02$ & $5.588 \mathrm{E}-07$ & $1.534 \mathrm{E}-03$ & $1.532 \mathrm{E}-04$ & $7.254 \mathrm{E}-09$ & $2.357 \mathrm{E}-02$ \\
\hline & 5.0 & $3.968 \mathrm{E}+00$ & $-3.458 \mathrm{E}-01$ & $-1.062 \mathrm{E}-04$ & $3.276 \mathrm{E}-01$ & $\mathrm{~T}$ & $-3.156 \mathrm{E}-03$ & $3.058 \mathrm{E}-04$ & $2.357 \mathrm{E}-02$ & $-5.939 \mathrm{E}-06$ & $-4.779 \mathrm{E}-03$ & $1.933 \mathrm{E}-03$ & $-3.438 \mathrm{E}-05$ & $1.784 \mathrm{E}-02$ \\
\hline & & & & & & $\mathrm{S}$ & $-5.025 \mathrm{E}-03$ & $6.338 \mathrm{E}-05$ & $9.140 \mathrm{E}-03$ & $-6.336 \mathrm{E}-06$ & $-5.880 \mathrm{E}-03$ & $1.796 \mathrm{E}-03$ & $-3.439 \mathrm{E}-05$ & $5.299 \mathrm{E}-05$ \\
\hline & & & & & & $\mathrm{P}$ & $1.869 \mathrm{E}-03$ & $2.424 \mathrm{E}-04$ & $1.444 \mathrm{E}-02$ & $3.971 \mathrm{E}-07$ & $1.100 \mathrm{E}-03$ & $1.376 \mathrm{E}-04$ & 4.809E-09 & $1.778 \mathrm{E}-02$ \\
\hline 2.50 & 3.5 & $2.523 \mathrm{E}+00$ & $-2.217 \mathrm{E}-01$ & $-6.659 \mathrm{E}-05$ & $1.675 \mathrm{E}-01$ & $\mathrm{~T}$ & $-3.229 \mathrm{E}-04$ & $6.600 \mathrm{E}-04$ & $5.158 \mathrm{E}-02$ & $-2.685 \mathrm{E}-06$ & $1.964 \mathrm{E}-03$ & $5.020 \mathrm{E}-04$ & $-2.185 \mathrm{E}-05$ & $5.435 \mathrm{E}-02$ \\
\hline & & & & & & $\mathrm{S}$ & $-3.241 \mathrm{E}-03$ & $2.583 \mathrm{E}-05$ & $4.066 \mathrm{E}-03$ & $-4.070 \mathrm{E}-06$ & $-1.888 \mathrm{E}-03$ & $3.337 \mathrm{E}-04$ & $-2.187 \mathrm{E}-05$ & $-7.293 \mathrm{E}-04$ \\
\hline & & & & & & $\mathrm{P}$ & $2.918 \mathrm{E}-03$ & $6.342 \mathrm{E}-04$ & $4.751 \mathrm{E}-02$ & $1.385 \mathrm{E}-06$ & $3.852 \mathrm{E}-03$ & $1.684 \mathrm{E}-04$ & $1.347 \mathrm{E}-08$ & $5.508 \mathrm{E}-02$ \\
\hline & 4.0 & $2.991 \mathrm{E}+00$ & $-1.932 \mathrm{E}-01$ & $-7.998 \mathrm{E}-05$ & $1.641 \mathrm{E}-01$ & $\mathrm{~T}$ & $-2.361 \mathrm{E}-03$ & $3.846 \mathrm{E}-04$ & $3.155 \mathrm{E}-02$ & $-4.086 \mathrm{E}-06$ & $-1.752 \mathrm{E}-03$ & $1.429 \mathrm{E}-03$ & $-2.589 \mathrm{E}-05$ & $2.922 \mathrm{E}-02$ \\
\hline & & & & & & $\mathrm{S}$ & $-3.823 \mathrm{E}-03$ & $3.242 \mathrm{E}-05$ & $5.999 \mathrm{E}-03$ & $-4.796 \mathrm{E}-06$ & $-3.555 \mathrm{E}-03$ & $1.198 \mathrm{E}-03$ & $-2.590 \mathrm{E}-05$ & $-1.786 \mathrm{E}-04$ \\
\hline & & & & & & $P$ & $1.462 \mathrm{E}-03$ & $3.522 \mathrm{E}-04$ & $2.555 \mathrm{E}-02$ & $7.099 \mathrm{E}-07$ & $1.803 \mathrm{E}-03$ & $2.306 \mathrm{E}-04$ & $1.179 \mathrm{E}-08$ & $2.940 \mathrm{E}-02$ \\
\hline & 4.5 & $3.490 \mathrm{E}+00$ & $-2.730 \mathrm{E}-01$ & $-9.336 \mathrm{E}-05$ & $2.497 \mathrm{E}-01$ & $\mathrm{~T}$ & $-2.722 \mathrm{E}-03$ & $3.305 \mathrm{E}-04$ & $2.832 \mathrm{E}-02$ & $-5.019 \mathrm{E}-06$ & $-4.337 \mathrm{E}-03$ & $1.822 \mathrm{E}-03$ & $-3.024 \mathrm{E}-05$ & $2.338 \mathrm{E}-02$ \\
\hline & & & & & & $\mathrm{S}$ & $-4.418 \mathrm{E}-03$ & $5.714 \mathrm{E}-05$ & $8.293 \mathrm{E}-03$ & $-5.566 \mathrm{E}-06$ & $-5.683 \mathrm{E}-03$ & $1.616 \mathrm{E}-03$ & $-3.024 \mathrm{E}-05$ & $-1.709 \mathrm{E}-04$ \\
\hline & & & & & & $\mathrm{P}$ & $1.696 \mathrm{E}-03$ & $2.734 \mathrm{E}-04$ & $2.003 \mathrm{E}-02$ & $5.471 \mathrm{E}-07$ & $1.346 \mathrm{E}-03$ & $2.060 \mathrm{E}-04$ & $7.091 \mathrm{E}-09$ & $2.355 \mathrm{E}-02$ \\
\hline & 5.0 & $3.974 \mathrm{E}+00$ & $-3.582 \mathrm{E}-01$ & $-1.063 \mathrm{E}-04$ & $3.411 \mathrm{E}-01$ & $\mathrm{~T}$ & $-3.436 \mathrm{E}-03$ & $3.013 \mathrm{E}-04$ & $2.479 \mathrm{E}-02$ & $-5.935 \mathrm{E}-06$ & $-6.937 \mathrm{E}-03$ & $2.021 \mathrm{E}-03$ & $-3.445 \mathrm{E}-05$ & $1.670 \mathrm{E}-02$ \\
\hline & & & & & & $\mathrm{S}$ & $-4.969 \mathrm{E}-03$ & $8.400 \mathrm{E}-05$ & $1.074 \mathrm{E}-02$ & $-6.311 \mathrm{E}-06$ & $-7.866 \mathrm{E}-03$ & $1.872 \mathrm{E}-03$ & $-3.446 \mathrm{E}-05$ & $-1.770 \mathrm{E}-04$ \\
\hline & & & & & & $\mathrm{P}$ & $1.533 \mathrm{E}-03$ & $2.173 \mathrm{E}-04$ & $1.405 \mathrm{E}-02$ & $3.753 \mathrm{E}-07$ & $9.287 \mathrm{E}-04$ & $1.498 \mathrm{E}-04$ & $3.860 \mathrm{E}-09$ & $1.688 \mathrm{E}-02$ \\
\hline
\end{tabular}


Table A12. TOTAL STELLAR YIELDS - INITIAL METALLICITY $Z=0.004$

\begin{tabular}{|c|c|c|c|c|c|c|c|c|c|c|c|c|c|c|}
\hline$\alpha$ & $M_{\mathrm{i}}$ & $\Delta M_{\mathrm{ej}}$ & $M_{\mathrm{y}}(\mathrm{H})$ & $M_{\mathrm{y}}\left({ }^{3} \mathrm{He}\right)$ & $M_{\mathrm{y}}\left({ }^{4} \mathrm{He}\right)$ & $\mathrm{T} / \mathrm{S} / \mathrm{P}$ & $M_{\mathrm{y}}\left({ }^{12} \mathrm{C}\right)$ & $M_{\mathrm{y}}\left({ }^{13} \mathrm{C}\right)$ & $M_{\mathrm{y}}\left({ }^{14} \mathrm{~N}\right)$ & $M_{\mathrm{y}}\left({ }^{15} \mathrm{~N}\right)$ & $M_{\mathrm{y}}\left({ }^{16} \mathrm{O}\right)$ & $M_{\mathrm{y}}\left({ }^{17} \mathrm{O}\right)$ & $M_{\mathrm{y}}\left({ }^{18} \mathrm{O}\right)$ & $M_{\mathrm{y}}(\mathrm{CNO})$ \\
\hline \multirow[t]{11}{*}{1.68} & \multirow{3}{*}{3.5} & \multirow{3}{*}{$2.529 \mathrm{E}+00$} & \multirow[t]{3}{*}{$-2.266 \mathrm{E}-01$} & \multirow[t]{3}{*}{$-2.379 \mathrm{E}-05$} & \multirow{3}{*}{$1.676 \mathrm{E}-01$} & $\mathrm{~T}$ & $2.301 \mathrm{E}-02$ & $7.757 \mathrm{E}-03$ & $2.500 \mathrm{E}-02$ & $-1.319 \mathrm{E}-06$ & $3.806 \mathrm{E}-03$ & $1.721 \mathrm{E}-05$ & $-1.090 \mathrm{E}-05$ & $5.958 \mathrm{E}-02$ \\
\hline & & & & & & S & $3.248 \mathrm{E}-04$ & $5.628 \mathrm{E}-04$ & $-4.983 \mathrm{E}-04$ & $-2.112 \mathrm{E}-06$ & $-8.406 \mathrm{E}-04$ & $9.733 \mathrm{E}-06$ & $-1.090 \mathrm{E}-05$ & $-4.546 \mathrm{E}-04$ \\
\hline & & & & & & $\mathrm{P}$ & $2.269 \mathrm{E}-02$ & $7.194 \mathrm{E}-03$ & $2.550 \mathrm{E}-02$ & $7.930 \mathrm{E}-07$ & $4.646 \mathrm{E}-03$ & $7.481 \mathrm{E}-06$ & $1.302 \mathrm{E}-09$ & $6.004 \mathrm{E}-02$ \\
\hline & \multirow[t]{3}{*}{4.0} & \multirow[t]{3}{*}{$3.001 \mathrm{E}+00$} & \multirow[t]{3}{*}{$-2.488 \mathrm{E}-01$} & \multirow[t]{3}{*}{$-7.640 \mathrm{E}-05$} & \multirow[t]{3}{*}{$1.996 \mathrm{E}-01$} & $\mathrm{~T}$ & $2.019 \mathrm{E}-03$ & $7.009 \mathrm{E}-04$ & $4.413 \mathrm{E}-02$ & $-1.198 \mathrm{E}-06$ & $2.267 \mathrm{E}-03$ & $3.864 \mathrm{E}-04$ & $-1.299 \mathrm{E}-05$ & $4.949 \mathrm{E}-02$ \\
\hline & & & & & & $\mathrm{S}$ & $-1.881 \mathrm{E}-03$ & $2.804 \mathrm{E}-05$ & $2.565 \mathrm{E}-03$ & $-2.417 \mathrm{E}-06$ & $-1.221 \mathrm{E}-03$ & $2.282 \mathrm{E}-04$ & $-1.301 \mathrm{E}-05$ & $-2.960 \mathrm{E}-04$ \\
\hline & & & & & & P & $3.900 \mathrm{E}-03$ & $6.728 \mathrm{E}-04$ & $4.156 \mathrm{E}-02$ & $1.219 \mathrm{E}-06$ & $3.488 \mathrm{E}-03$ & $1.582 \mathrm{E}-04$ & $1.099 \mathrm{E}-08$ & $4.978 \mathrm{E}-02$ \\
\hline & \multirow[t]{3}{*}{4.5} & \multirow[t]{3}{*}{$3.481 \mathrm{E}+00$} & \multirow[t]{3}{*}{$-3.192 \mathrm{E}-01$} & \multirow[t]{3}{*}{$-8.936 \mathrm{E}-05$} & \multirow[t]{3}{*}{$2.791 \mathrm{E}-01$} & $\mathrm{~T}$ & $1.234 \mathrm{E}-03$ & $5.590 \mathrm{E}-04$ & $3.707 \mathrm{E}-02$ & $-1.839 \mathrm{E}-06$ & $5.975 \mathrm{E}-04$ & $8.410 \mathrm{E}-04$ & $-1.507 \mathrm{E}-05$ & $4.028 \mathrm{E}-02$ \\
\hline & & & & & & $\mathrm{S}$ & $-2.198 \mathrm{E}-03$ & $2.817 \mathrm{E}-05$ & $3.458 \mathrm{E}-03$ & $-2.792 \mathrm{E}-06$ & $-2.047 \mathrm{E}-03$ & $5.871 \mathrm{E}-04$ & $-1.508 \mathrm{E}-05$ & $-1.900 \mathrm{E}-04$ \\
\hline & & & & & & $\mathrm{P}$ & $3.432 \mathrm{E}-03$ & $5.308 \mathrm{E}-04$ & $3.361 \mathrm{E}-02$ & $9.528 \mathrm{E}-07$ & $2.645 \mathrm{E}-03$ & $2.539 \mathrm{E}-04$ & $1.186 \mathrm{E}-08$ & $4.047 \mathrm{E}-02$ \\
\hline & \multirow{2}{*}{5.0} & \multirow{2}{*}{$3.960 \mathrm{E}+00$} & \multirow{2}{*}{$-5.201 \mathrm{E}-01$} & \multirow{2}{*}{$-1.017 \mathrm{E}-04$} & \multirow{2}{*}{$4.716 \mathrm{E}-01$} & S & $-2.483 \mathrm{E}-03$ & $3.717 \mathrm{E}-05$ & $4.369 \mathrm{E}-03$ & $-3.167 \mathrm{E}-06$ & $-3.003 \mathrm{E}-03$ & $7.668 \mathrm{E}-04$ & $-1.716 \mathrm{E}-05$ & $-3.343 \mathrm{E}-04$ \\
\hline & & & & & & $\mathrm{P}$ & $3.776 \mathrm{E}-03$ & $6.529 \mathrm{E}-04$ & $4.263 \mathrm{E}-02$ & $1.185 \mathrm{E}-06$ & $3.104 \mathrm{E}-03$ & $4.005 \mathrm{E}-04$ & $1.484 \mathrm{E}-08$ & $5.057 \mathrm{E}-02$ \\
\hline \multirow[t]{10}{*}{2.00} & \multirow[t]{3}{*}{3.5} & $2.517 \mathrm{E}+00$ & $-2.526 \mathrm{E}-01$ & $-6.373 \mathrm{E}-05$ & $1.849 \mathrm{E}-01$ & $\mathrm{~T}$ & $2.487 \mathrm{E}-03$ & $8.817 \mathrm{E}-04$ & $6.086 \mathrm{E}-02$ & $-2.934 \mathrm{E}-07$ & $3.785 \mathrm{E}-03$ & $3.386 \mathrm{E}-04$ & $-1.089 \mathrm{E}-05$ & $6.834 \mathrm{E}-02$ \\
\hline & & & & & & $\mathrm{S}$ & $-1.548 \mathrm{E}-03$ & $3.282 \mathrm{E}-05$ & $2.385 \mathrm{E}-03$ & $-2.019 \mathrm{E}-06$ & $-1.020 \mathrm{E}-03$ & $1.476 \mathrm{E}-04$ & $-1.090 \mathrm{E}-05$ & $-1.548 \mathrm{E}-05$ \\
\hline & & & & & & $\mathrm{P}$ & $4.035 \mathrm{E}-03$ & $8.489 \mathrm{E}-04$ & $5.847 \mathrm{E}-02$ & $1.726 \mathrm{E}-06$ & $4.805 \mathrm{E}-03$ & $1.910 \mathrm{E}-04$ & $1.595 \mathrm{E}-08$ & $6.836 \mathrm{E}-02$ \\
\hline & 4.0 & $3.000 \mathrm{E}+00$ & $-2.666 \mathrm{E}-01$ & $-7.704 \mathrm{E}-05$ & $2.166 \mathrm{E}-01$ & $\mathrm{~T}$ & $1.175 \mathrm{E}-03$ & $6.264 \mathrm{E}-04$ & $4.601 \mathrm{E}-02$ & $-1.183 \mathrm{E}-06$ & $1.484 \mathrm{E}-03$ & $8.418 \mathrm{E}-04$ & $-1.298 \mathrm{E}-05$ & $5.013 \mathrm{E}-02$ \\
\hline & & & & & & $\mathrm{S}$ & $-1.902 \mathrm{E}-03$ & $2.237 \mathrm{E}-05$ & $2.813 \mathrm{E}-03$ & $-2.412 \mathrm{E}-06$ & $-1.742 \mathrm{E}-03$ & $5.041 \mathrm{E}-04$ & $-1.300 \mathrm{E}-05$ & $-3.193 \mathrm{E}-04$ \\
\hline & & & & & & $\mathrm{P}$ & $3.077 \mathrm{E}-03$ & $6.040 \mathrm{E}-04$ & $4.320 \mathrm{E}-02$ & $1.229 \mathrm{E}-06$ & $3.226 \mathrm{E}-03$ & $3.378 \mathrm{E}-04$ & $1.797 \mathrm{E}-08$ & $5.044 \mathrm{E}-02$ \\
\hline & 4.5 & $3.483 \mathrm{E}+00$ & $-3.334 \mathrm{E}-01$ & $-8.941 \mathrm{E}-05$ & $2.945 \mathrm{E}-01$ & $\mathrm{~T}$ & $6.047 \mathrm{E}-04$ & $5.215 \mathrm{E}-04$ & 3.733E-02 & $-1.860 \mathrm{E}-06$ & $-6.261 \mathrm{E}-04$ & $1.106 \mathrm{E}-03$ & $-1.507 \mathrm{E}-05$ & $3.892 \mathrm{E}-02$ \\
\hline & & & & & & $\mathrm{S}$ & $-2.185 \mathrm{E}-03$ & $3.313 \mathrm{E}-05$ & $4.040 \mathrm{E}-03$ & $-2.778 \mathrm{E}-06$ & $-2.880 \mathrm{E}-03$ & $7.686 \mathrm{E}-04$ & $-1.508 \mathrm{E}-05$ & $-2.417 \mathrm{E}-04$ \\
\hline & & & & & & S & $-2.465 \mathrm{E}-03$ & $4.335 \mathrm{E}-05$ & $5.018 \mathrm{E}-03$ & $-3.148 \mathrm{E}-06$ & $-3.841 \mathrm{E}-03$ & $8.540 \mathrm{E}-04$ & $-1.715 \mathrm{E}-05$ & $-4.105 \mathrm{E}-04$ \\
\hline & & & & & & $\mathrm{P}$ & $3.263 \mathrm{E}-03$ & $6.057 \mathrm{E}-04$ & $4.183 \mathrm{E}-02$ & $1.138 \mathrm{E}-06$ & $2.657 \mathrm{E}-03$ & $4.505 \mathrm{E}-04$ & $1.384 \mathrm{E}-08$ & $4.880 \mathrm{E}-02$ \\
\hline 2.50 & 3.5 & $2.516 \mathrm{E}+00$ & $-2.774 \mathrm{E}-01$ & $-6.456 \mathrm{E}-05$ & $2.085 \mathrm{E}-01$ & $\mathrm{~T}$ & $1.656 \mathrm{E}-03$ & $7.712 \mathrm{E}-04$ & $6.256 \mathrm{E}-02$ & $-3.013 \mathrm{E}-07$ & $3.037 \mathrm{E}-03$ & $8.129 \mathrm{E}-04$ & $-1.087 \mathrm{E}-05$ & $6.882 \mathrm{E}-02$ \\
\hline & & & & & & $\mathrm{S}$ & $-1.600 \mathrm{E}-03$ & $1.750 \mathrm{E}-05$ & $2.124 \mathrm{E}-03$ & $-2.028 \mathrm{E}-06$ & $-1.409 \mathrm{E}-03$ & $3.640 \mathrm{E}-04$ & $-1.090 \mathrm{E}-05$ & $-5.169 \mathrm{E}-04$ \\
\hline & & & & & & $\mathrm{P}$ & $3.255 \mathrm{E}-03$ & $7.537 \mathrm{E}-04$ & $6.044 \mathrm{E}-02$ & $1.727 \mathrm{E}-06$ & $4.446 \mathrm{E}-03$ & $4.489 \mathrm{E}-04$ & $2.778 \mathrm{E}-08$ & $6.934 \mathrm{E}-02$ \\
\hline & 4.0 & $3.003 \mathrm{E}+00$ & $-2.887 \mathrm{E}-01$ & $-7.711 \mathrm{E}-05$ & $2.396 \mathrm{E}-01$ & $\mathrm{~T}$ & $8.392 \mathrm{E}-04$ & $5.860 \mathrm{E}-04$ & 4.637E-02 & $-1.210 \mathrm{E}-06$ & $2.597 \mathrm{E}-04$ & $1.058 \mathrm{E}-03$ & $-1.299 \mathrm{E}-05$ & $4.910 \mathrm{E}-02$ \\
\hline & & & & & & $\mathrm{S}$ & $-1.892 \mathrm{E}-03$ & $2.684 \mathrm{E}-05$ & $3.363 \mathrm{E}-03$ & $-2.399 \mathrm{E}-06$ & $-2.496 \mathrm{E}-03$ & $6.325 \mathrm{E}-04$ & $-1.301 \mathrm{E}-05$ & $-3.819 \mathrm{E}-04$ \\
\hline & & & & & & $\mathrm{P}$ & $2.732 \mathrm{E}-03$ & $5.592 \mathrm{E}-04$ & $4.301 \mathrm{E}-02$ & $1.189 \mathrm{E}-06$ & $2.756 \mathrm{E}-03$ & $4.252 \mathrm{E}-04$ & $1.653 \mathrm{E}-08$ & $4.948 \mathrm{E}-02$ \\
\hline & 4.5 & $3.487 \mathrm{E}+00$ & $-3.520 \mathrm{E}-01$ & $-8.953 \mathrm{E}-05$ & $3.151 \mathrm{E}-01$ & $\mathrm{~T}$ & $1.491 \mathrm{E}-04$ & $4.774 \mathrm{E}-04$ & 3.713E-02 & $-1.894 \mathrm{E}-06$ & $-2.051 \mathrm{E}-03$ & $1.061 \mathrm{E}-03$ & $-1.510 \mathrm{E}-05$ & $3.675 \mathrm{E}-02$ \\
\hline & & & & & & $\mathrm{S}$ & $-2.164 \mathrm{E}-03$ & $4.220 \mathrm{E}-05$ & $4.906 \mathrm{E}-03$ & $-2.762 \mathrm{E}-06$ & $-3.860 \mathrm{E}-03$ & $7.231 \mathrm{E}-04$ & $-1.511 \mathrm{E}-05$ & $-3.706 \mathrm{E}-04$ \\
\hline & & & & & & $\mathrm{P}$ & $2.313 \mathrm{E}-03$ & $4.352 \mathrm{E}-04$ & $3.222 \mathrm{E}-02$ & $8.678 \mathrm{E}-07$ & $1.810 \mathrm{E}-03$ & $3.379 \mathrm{E}-04$ & $9.610 \mathrm{E}-09$ & $3.712 \mathrm{E}-02$ \\
\hline & 5.0 & $3.970 \mathrm{E}+00$ & $-5.596 \mathrm{E}-01$ & $-1.019 \mathrm{E}-04$ & $5.154 \mathrm{E}-01$ & $\mathrm{~T}$ & $2.089 \mathrm{E}-04$ & $5.982 \mathrm{E}-04$ & $4.629 \mathrm{E}-02$ & $-2.060 \mathrm{E}-06$ & $-2.654 \mathrm{E}-03$ & $1.166 \mathrm{E}-03$ & $-1.720 \mathrm{E}-05$ & $4.559 \mathrm{E}-02$ \\
\hline & & & & & & $\mathrm{S}$ & $-2.446 \mathrm{E}-03$ & $5.309 \mathrm{E}-05$ & $5.936 \mathrm{E}-03$ & $-3.137 \mathrm{E}-06$ & $-4.799 \mathrm{E}-03$ & $7.511 \mathrm{E}-04$ & $-1.721 \mathrm{E}-05$ & $-5.254 \mathrm{E}-04$ \\
\hline & & & & & & $\mathrm{P}$ & $2.655 \mathrm{E}-03$ & $5.452 \mathrm{E}-04$ & $4.035 \mathrm{E}-02$ & $1.076 \mathrm{E}-06$ & $2.145 \mathrm{E}-03$ & $4.152 \mathrm{E}-04$ & $1.027 \mathrm{E}-08$ & $4.612 \mathrm{E}-02$ \\
\hline
\end{tabular}

Table A13. PNe CHEMICAL COMPOSITION $-Z=0.019$

\begin{tabular}{|c|c|c|c|c|c|}
\hline$\alpha$ & $M_{\mathrm{i}}$ & $\mathrm{He} / \mathrm{H}$ & $\log (\mathrm{C} / \mathrm{H})$ & $\log (\mathrm{N} / \mathrm{H})$ & $\log (\mathrm{O} / \mathrm{H})$ \\
\hline \multirow[t]{22}{*}{1.68} & 0.868 & $1.026 \mathrm{E}-01$ & -3.400 & -3.980 & -3.080 \\
\hline & 0.934 & $1.047 \mathrm{E}-01$ & -3.398 & -3.976 & -3.078 \\
\hline & 1.005 & $1.049 \mathrm{E}-01$ & -3.403 & -3.957 & -3.078 \\
\hline & 1.082 & $1.048 \mathrm{E}-01$ & -3.415 & -3.919 & -3.078 \\
\hline & 1.163 & $1.052 \mathrm{E}-01$ & -3.445 & -3.835 & -3.078 \\
\hline & 1.248 & $1.052 \mathrm{E}-01$ & -3.445 & -3.835 & -3.078 \\
\hline & 1.334 & $1.031 \mathrm{E}-01$ & -3.461 & -3.806 & -3.081 \\
\hline & 1.420 & $1.031 \mathrm{E}-01$ & -3.461 & -3.806 & -3.081 \\
\hline & 1.504 & $1.077 \mathrm{E}-01$ & -3.100 & -3.775 & -3.065 \\
\hline & 1.588 & $1.114 \mathrm{E}-01$ & -2.969 & -3.719 & -3.054 \\
\hline & 1.672 & $1.136 \mathrm{E}-01$ & -2.897 & -3.678 & -3.049 \\
\hline & 1.756 & $1.160 \mathrm{E}-01$ & -2.824 & -3.678 & -3.042 \\
\hline & 1.839 & $1.184 \mathrm{E}-01$ & -2.776 & -3.660 & -3.037 \\
\hline & 1.923 & $1.208 \mathrm{E}-01$ & -2.741 & -3.641 & -3.035 \\
\hline & 2.000 & $1.231 \mathrm{E}-01$ & -2.701 & -3.629 & -3.031 \\
\hline & 2.200 & $1.282 \mathrm{E}-01$ & -2.648 & -3.592 & -3.027 \\
\hline & 2.500 & $1.333 \mathrm{E}-01$ & -2.597 & -3.560 & -3.022 \\
\hline & 3.000 & $1.354 \mathrm{E}-01$ & -2.575 & -3.537 & -3.022 \\
\hline & 3.500 & $1.271 \mathrm{E}-01$ & -2.729 & -3.537 & -3.049 \\
\hline & 4.000 & $1.218 \mathrm{E}-01$ & -2.914 & -3.530 & -3.072 \\
\hline & 4.500 & $1.270 \mathrm{E}-01$ & -3.007 & -3.487 & -3.081 \\
\hline & 5.000 & $1.387 \mathrm{E}-01$ & -3.085 & -3.302 & -3.084 \\
\hline \multirow[t]{4}{*}{2.00} & 3.500 & $1.354 \mathrm{E}-01$ & -2.573 & -3.537 & -3.023 \\
\hline & 4.000 & $1.282 \mathrm{E}-01$ & -2.754 & -3.425 & -3.051 \\
\hline & 4.500 & $1.292 \mathrm{E}-01$ & -3.516 & -2.925 & -3.075 \\
\hline & 5.000 & $1.406 \mathrm{E}-01$ & -3.626 & -2.926 & -3.081 \\
\hline \multirow[t]{4}{*}{2.50} & 3.500 & $1.427 \mathrm{E}-01$ & -2.566 & -3.029 & -3.002 \\
\hline & 4.000 & $1.307 \mathrm{E}-01$ & -3.653 & -2.690 & -3.046 \\
\hline & 4.500 & $1.319 \mathrm{E}-01$ & -3.776 & -2.848 & -3.078 \\
\hline & 5.000 & $1.423 \mathrm{E}-01$ & -3.873 & -2.896 & -3.098 \\
\hline
\end{tabular}

Table A14. PNe CHEMICAL COMPOSITION $-Z=0.008$

\begin{tabular}{cccccc}
\hline$\alpha$ & $M_{\mathrm{i}}$ & $\mathrm{He} / \mathrm{H}$ & $\log (\mathrm{C} / \mathrm{H})$ & $\log (\mathrm{N} / \mathrm{H})$ & $\log (\mathrm{O} / \mathrm{H})$ \\
\hline 1.68 & 0.850 & $9.140 \mathrm{E}-02$ & -3.796 & -4.372 & -3.475 \\
& 0.918 & $9.138 \mathrm{E}-02$ & -3.796 & -4.371 & -3.475 \\
& 0.992 & $9.163 \mathrm{E}-02$ & -3.801 & -4.351 & -3.475 \\
& 1.071 & $9.199 \mathrm{E}-02$ & -3.815 & -4.305 & -3.475 \\
& 1.154 & $9.197 \mathrm{E}-02$ & -3.827 & -4.269 & -3.475 \\
& 1.239 & $9.193 \mathrm{E}-02$ & -3.843 & -4.229 & -3.475 \\
& 1.315 & $9.995 \mathrm{E}-02$ & -2.999 & -4.180 & -3.406 \\
& 1.407 & $1.009 \mathrm{E}-01$ & -2.960 & -4.179 & -3.399 \\
& 1.499 & $1.061 \mathrm{E}-01$ & -2.824 & -4.088 & -3.368 \\
& 1.583 & $1.117 \mathrm{E}-01$ & -2.690 & -4.089 & -3.332 \\
& 1.667 & $1.164 \mathrm{E}-01$ & -2.600 & -4.071 & -3.303 \\
& 1.750 & $1.183 \mathrm{E}-01$ & -2.570 & -4.050 & -3.295 \\
& 1.832 & $1.220 \mathrm{E}-01$ & -2.525 & -4.027 & -3.281 \\
& 1.850 & $1.231 \mathrm{E}-01$ & -2.513 & -4.018 & -3.277 \\
& 1.900 & $1.238 \mathrm{E}-01$ & -2.503 & -4.008 & -3.274 \\
& 2.000 & $1.246 \mathrm{E}-01$ & -2.505 & -3.984 & -3.277 \\
& 2.200 & $1.297 \mathrm{E}-01$ & -2.472 & -3.939 & -3.267 \\
& 2.500 & $1.316 \mathrm{E}-01$ & -2.466 & -3.913 & -3.268 \\
& 3.000 & $1.284 \mathrm{E}-01$ & -2.502 & -3.902 & -3.286 \\
& 3.500 & $1.154 \mathrm{E}-01$ & -2.707 & -3.913 & -3.360 \\
& 4.000 & $1.098 \mathrm{E}-01$ & -3.145 & -3.270 & -3.423 \\
& 4.500 & $1.187 \mathrm{E}-01$ & -3.678 & -3.083 & -3.444 \\
& 5.000 & $1.276 \mathrm{E}-01$ & -3.674 & -3.176 & -3.471 \\
2.00 & 3.500 & $1.188 \mathrm{E}-01$ & -2.875 & -2.978 & -3.340 \\
& 4.000 & $1.123 \mathrm{E}-01$ & -3.644 & -2.941 & -3.418 \\
& 4.500 & $1.204 \mathrm{E}-01$ & -3.800 & -3.048 & -3.466 \\
& 5.000 & $1.291 \mathrm{E}-01$ & -3.776 & -3.139 & -3.519 \\
2.50 & 3.500 & $1.229 \mathrm{E}-01$ & -3.602 & -2.633 & -3.328 \\
& 4.000 & $1.138 \mathrm{E}-01$ & -3.974 & -2.927 & -3.461 \\
& 4.500 & $1.231 \mathrm{E}-01$ & -3.869 & -3.016 & -3.530 \\
& 5.000 & $1.311 \mathrm{E}-01$ & -3.861 & -3.108 & -3.603 \\
\hline \multirow{6}{*}{} & & & & &
\end{tabular}


Table A15. PNe CHEMICAL COMPOSITION $-Z=0.004$

\begin{tabular}{|c|c|c|c|c|c|}
\hline$\alpha$ & $M_{\mathrm{i}}$ & $\mathrm{He} / \mathrm{H}$ & $\log (\mathrm{C} / \mathrm{H})$ & $\log (\mathrm{N} / \mathrm{H})$ & $\log (\mathrm{O} / \mathrm{H})$ \\
\hline \multirow[t]{22}{*}{1.68} & 0.817 & $8.359 \mathrm{E}-02$ & -4.109 & -4.683 & -3.788 \\
\hline & 0.888 & $8.625 \mathrm{E}-02$ & -4.112 & -4.658 & -3.785 \\
\hline & 0.966 & $8.625 \mathrm{E}-02$ & -4.112 & -4.657 & -3.785 \\
\hline & 1.046 & $8.663 \mathrm{E}-02$ & -4.126 & -4.610 & -3.784 \\
\hline & 1.131 & $8.745 \mathrm{E}-02$ & -4.147 & -4.550 & -3.784 \\
\hline & 1.218 & $9.727 \mathrm{E}-02$ & -2.961 & -4.493 & -3.630 \\
\hline & 1.307 & $1.286 \mathrm{E}-01$ & -2.385 & -4.493 & -3.356 \\
\hline & 1.396 & $1.399 \mathrm{E}-01$ & -2.280 & -4.468 & -3.286 \\
\hline & 1.481 & $1.438 \mathrm{E}-01$ & -2.248 & -4.447 & -3.264 \\
\hline & 1.564 & $1.533 \mathrm{E}-01$ & -2.190 & -4.387 & -3.221 \\
\hline & 1.647 & $1.621 \mathrm{E}-01$ & -2.134 & -4.345 & -3.181 \\
\hline & 1.729 & $1.694 \mathrm{E}-01$ & -2.094 & -4.345 & -3.150 \\
\hline & 1.800 & $1.747 \mathrm{E}-01$ & -2.068 & -4.325 & -3.131 \\
\hline & 1.900 & $1.771 \mathrm{E}-01$ & -2.062 & -4.293 & -3.127 \\
\hline & 2.000 & $1.815 \mathrm{E}-01$ & -2.041 & -4.286 & -3.111 \\
\hline & 2.200 & $1.811 \mathrm{E}-01$ & -2.051 & -4.238 & -3.121 \\
\hline & 2.500 & $1.663 \mathrm{E}-01$ & -2.133 & -4.209 & -3.186 \\
\hline & 3.000 & $1.458 \mathrm{E}-01$ & -2.261 & -4.213 & -3.281 \\
\hline & 3.500 & $1.168 \mathrm{E}-01$ & -2.787 & -2.938 & -3.479 \\
\hline & 4.000 & $1.160 \mathrm{E}-01$ & -3.533 & -2.790 & -3.568 \\
\hline & 4.500 & $1.227 \mathrm{E}-01$ & -3.606 & -2.920 & -3.642 \\
\hline & 5.000 & $1.462 \mathrm{E}-01$ & -3.602 & -2.846 & -3.635 \\
\hline \multirow[t]{4}{*}{2.00} & 3.500 & $1.217 \mathrm{E}-01$ & -3.495 & -2.564 & -3.457 \\
\hline & 4.000 & $1.192 \mathrm{E}-01$ & -3.610 & -2.766 & -3.584 \\
\hline & 4.500 & $1.251 \mathrm{E}-01$ & -3.710 & -2.911 & -3.699 \\
\hline & 5.000 & $1.493 \mathrm{E}-01$ & -3.678 & -2.840 & -3.695 \\
\hline \multirow[t]{4}{*}{2.50} & 3.500 & $1.270 \mathrm{E}-01$ & -3.596 & -2.547 & -3.469 \\
\hline & 4.000 & $1.233 \mathrm{E}-01$ & -3.707 & -2.757 & -3.643 \\
\hline & 4.500 & $1.285 \mathrm{E}-01$ & -3.798 & -2.908 & -3.800 \\
\hline & 5.000 & $1.529 \mathrm{E}-01$ & -3.778 & -2.843 & -3.796 \\
\hline
\end{tabular}

